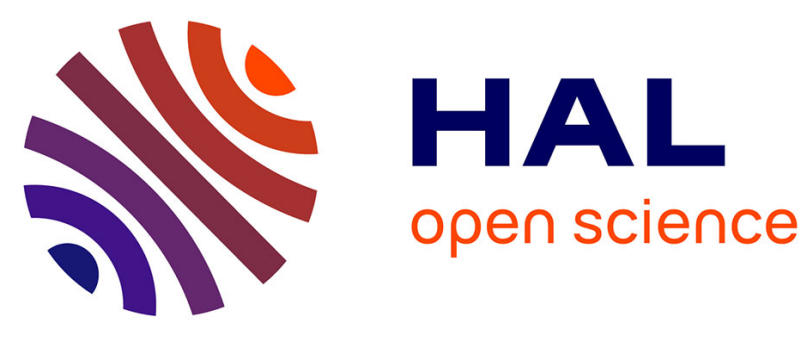

\title{
Iron Stearate Structures: An Original Tool for Nanoparticles Design
}

Francis Perton, Geoffrey Cotin, Céline Kiefer, Jean-Marc Strub, Sarah

Cianferani, Jean-Marc Greneche, Nathalie Parizel, Benoît Heinrich, Benoit

Pichon, Damien Mertz, et al.

\section{To cite this version:}

Francis Perton, Geoffrey Cotin, Céline Kiefer, Jean-Marc Strub, Sarah Cianferani, et al.. Iron Stearate Structures: An Original Tool for Nanoparticles Design. Inorganic Chemistry, 2021, 60 (16), pp.1244512456. 10.1021/acs.inorgchem.1c01689 . hal-03379902

\section{HAL Id: hal-03379902 https://hal.science/hal-03379902}

Submitted on 15 Oct 2021

HAL is a multi-disciplinary open access archive for the deposit and dissemination of scientific research documents, whether they are published or not. The documents may come from teaching and research institutions in France or abroad, or from public or private research centers.
L'archive ouverte pluridisciplinaire HAL, est destinée au dépôt et à la diffusion de documents scientifiques de niveau recherche, publiés ou non, émanant des établissements d'enseignement et de recherche français ou étrangers, des laboratoires publics ou privés. 


\title{
The iron stearate structures: an original tool for nanoparticles design
}

Francis Perton ${ }^{1,2, \Psi}$, Geoffrey Cotin ${ }^{1,2, \Psi}$, Céline Kiefer ${ }^{1,2}$, Jean-Marc Strub ${ }^{3}$, Sarah Cianferani ${ }^{3}$, Jean-Marc Greneche $^{4}$, Nathalie Parizel ${ }^{5,6,7}$, Benoît Heinrich ${ }^{1}$, Benoit Pichon ${ }^{1,2}$, Damien Mertz ${ }^{1,2}$, Sylvie BeginColin $^{1,2^{*}}$

${ }^{1}$ Université de Strasbourg, CNRS, Institut de Physique et Chimie des Matériaux de Strasbourg, UMR 7504, F-67034 Strasbourg, France. Em

${ }^{2}$ Labex CSC, Fondation IcFRC/Université de Strasbourg, 8 allée Gaspard Monge BP 70028 F - 67083 Strasbourg Cedex.

3 Laboratoire de Spectrométrie de Masse BioOrganique, Université Strasbourg, CNRS, IPHC UMR 7178, F-67000 Strasbourg, France

${ }^{4}$ Institut des Molécules et Matériaux du Mans IMMM UMR CNRS 6283, Université du Maine, Avenue Olivier Messiaen, 72085 Le Mans Cedex 9, France

5 Institut de Chimie de Strasbourg (UMR 7177, CNRS Unistra)

${ }^{6}$ Université de Strasbourg, 4 rue Blaise Pascal, CS 90032, F-67081 Strasbourg - France

${ }^{7}$ French EPR Federation of Research (Reseau National de Rpe Interdisciplinaire, RENARD), Fédération IR-RPE CNRS 3443, 67000 Strasbourg, France

${ }^{\Psi}$ have equally contributed.

* corresponding author: sylvie.begin@unistra.fr

Corresponding author email address : sylvie.begin@unistra.fr

\begin{abstract}
Iron carboxylates are widely used as iron precursors in the thermal decomposition process or considered as in situ formed intermediate precursors. Their molecular and 3D-structural nature has been shown to affect the shape, size and composition of the resulting iron oxide nanoparticles (NPs). Among carboxylate precursors, stearates are particularly attractive because of their higher stability to aging and hydration and they are used as additives in many applications. Despite the huge interest of iron stearates, very few studies aimed up to now at deciphering their full metal-ligand structures and the mechanisms allowing to form on a controlled fashion the bottom-up NPs formation. In this work, we have thus investigated the molecular structure and composition of two iron sterarate precursors, synthesized by introducing either two $\left(\mathrm{FeSt}_{2}\right)$ or three $\left(\mathrm{FeSt}_{3}\right)$ stearate $(\mathrm{St})$ chains. Interestingly both iron stearates consist of a lamellar structures with planes of iron polynuclear complexes (polycations) separated with stearate chains in all trans conformation. The iron content in polycations was found very different between both iron stearates. Their detailed characterizations indicate that $\mathrm{FeSt}_{2}$ is mainly composed of $\left[\mathrm{Fe}_{3}-\left(\mu_{3}-\mathrm{O}\right) \mathrm{St}_{6} \mathrm{xH}_{2} \mathrm{O}\right] \mathrm{Cl}$, with no (or few) free stearate whereas $\mathrm{FeSt}_{3}$ is a mixture of mainly $\left[\mathrm{Fe}_{7}\left(\mu_{3}-\mathrm{O}(\mathrm{H})\right)_{6}\left(\mu_{2}-\mathrm{OH}\right)_{x} \mathrm{St}_{12-2 x}\right] \mathrm{St}$ with some $\left[\mathrm{Fe}_{3}\left(\mu_{3}-\mathrm{O}\right) \mathrm{St}_{6} . \mathrm{xH}_{2} \mathrm{O}\right] \mathrm{St}$ and free stearic acid. The formation of bigger polynuclear complexes with $\mathrm{FeSt}_{3}$ was related to higher hydrolysis and condensation rates within the iron (III) chloride solution compared to the iron (II) chloride solution.
\end{abstract}


These data suggested a nucleation mechanism based on the condensation of polycation radicals generated by the catalytic departure of two stearate chains from iron polycation based molecule.

Keywords: iron oxide nanoparticles, iron stearate, iron stearate composition and structure, iron stearate synthesis mechanisms, nucleation mechanism

\section{Introduction}

Metal carboxylates, also known as metal soaps, are produced by the reaction between metals and organic fatty acids. They are used as catalysts for chemical reactions such as organic polymerization in the manufacturing of synthetic rubber and also as additives in the paints and inks industry and in lubricating oils and greases. The carboxylates of transition metals ( $\mathrm{Fe}, \mathrm{Mn}, \mathrm{Co}$ ), and in particular iron (III) stearate $^{1}$, are the most-used prodegradants of the Totally Degradable Plastic Additives type. In addition, they are also widely used as precurors for the synthesis of metal or oxide nanoparticles (NPs) by the thermal decomposition process.

Since the $2000 \mathrm{~s}^{2-4}$, this thermal decomposition method quickly developed for the synthesis of a large variety of NPs such as quantum dots, but also of iron oxide NPs (IONPs), which are used in a broad range of applications including the promising nanomedicine ${ }^{5-7}$. Its interest relies on the separation of nucleation and growth steps which is a key factor to obtain NPs with a narrow size distribution but also to tailor their size $\mathrm{e}^{2,3,8,9}$ and their shape $\mathrm{e}^{10-12}$. In order to achieve such control of nucleation and growth steps, the precursor must be stable at low temperature and decompose upon heating rapidly with a controlled rate to ensure NPs monodispersity ${ }^{13}$. The most common iron precursors are Fe $(\mathrm{acac})_{\mathrm{n}}$ (acac $=$ acetylacetonate) ) $^{3,4,14}$ and iron oleate ${ }^{2,8,11,15-18}$ (unsaturated $\mathrm{C} 18$ ) but other precursors are also used such as iron stearate ${ }^{9,19-21}$ (saturated $\mathrm{C} 18$ ) or carbonyls $\mathrm{Fe}(\mathrm{CO}) \mathrm{x}^{22,23}$. It has been reported that reaction mixture involving oleic acid with iron pentacarbonyl or Fe(acac)n would conduct to an intermediate iron oleate precursor during the synthesis process ${ }^{2,24}$. Despite numerous publication on the IONPs synthesis process involving iron carboxylate precursors, few studies have investigated the effect of the chemical nature of the precursor ${ }^{23,25-31}$ on NPs characteristics and synthesis mechanisms.

The washing and aging conditions of iron oleate ${ }^{27}$ and the alkyl chains' length of the iron carboxylate precursor ${ }^{31}$ have already been shown to affect the IONPs size and shape. The nature of precursors and the amount of surfactant have also an impact on the IONPs synthesis of specific size range. ${ }^{32}$. We reported recently a strong role of the precursor nature and of its pre-heat-treatment on the shape of $\mathrm{IONPs}^{30}$. We synthesized iron stearates, FeSt ${ }_{2}$ and $\mathrm{FeSt}_{3}\left(\mathrm{St}_{=} \mathrm{C}_{18} \mathrm{H}_{35} \mathrm{O}_{2}\right)$, through coprecipitation of the metallic salts and sodium stearate in water (ratio metallic salt:sodium stearate; 1:2 and 1:3 for $\mathrm{FeSt}_{2}$ and $\mathrm{FeSt}_{3}$ respectively). In the same synthesis conditions, FeSt ${ }_{3}$ led to a large range of NPs size ( 6 to $25 \mathrm{~nm}$ ) when FeSt ${ }_{2}$ allowed only a smaller range $(9-15 \mathrm{~nm})^{33}$. However, not only the size can be impacted but also the shape: by applying the same anistropic thermal decomposition parameters, $\mathrm{FeSt}_{3}$ led preferentially to nanocubes when $\mathrm{FeSt}_{2}$ favoured the formation of nanoplates ${ }^{29}$. Some hypotheses have been drawn to explain these differences between both precursors by investigating their thermal behaviour and modelling ${ }^{30}$. Indeed, $\mathrm{FeSt}_{3}$ would be composed of several precursors displaying a higher thermal stability by comparison with $\mathrm{FeSt}_{2}$. These different studies ${ }^{29,30,33}$ 
showed clearly an influence of the nature of precursors on the size and shape of IONPs. Therefore, it appears important to characterize the structure and composition of iron stearates to better understand their effect in the thermal decomposition process.

Several papers have dealt with the structure and composition of $\mathrm{Zn}$ or $\mathrm{Cr}$ stearates or acetates but very few papers dealt with pure iron precursors ${ }^{34}$. Indeed, the structure and composition of long chain carboxylates are not easy to determine and it is also more complex because iron can display different oxidation degree. The structure of iron oleate has been investigated only recently by Chang et $a l^{26}$. They studied the structure of iron oleate (synthesized by a ligand exchange and phase transfer process) and reported, from MALDI-TOF MS analysis, a structure based mainly on $\mu$-oxo $\mathrm{Fe}_{3} \mathrm{O}\left(\mathrm{O}_{2} \mathrm{CR}\right)_{6}\left(\mathrm{H}_{2} \mathrm{O}\right)_{3}$ with $\mathrm{R}=\mathrm{C}_{17} \mathrm{H}_{33} \mathrm{O}_{2}{ }^{26}$. They noticed that, after heating at $100^{\circ} \mathrm{C}$ in presence of 1-decanol added to enhance the precursor decomposition at low temperature (esterification reaction), bigger polycations would be formed composed of 4 to 6 iron ions. From the combination of different analyses, they also proposed a continuous growth mechanism without a clear nucleation step as synthesis mechanism of IONPs in this route. Similarly, Feld and al..$^{25}$ formed pure iron oleates by reaction at $60^{\circ} \mathrm{C}$ of iron (II) and iron(III) carbonates with oleic acid. They identified, using MALDI-TOF MS, multiple $\mu$-oxo complexes in the so formed iron oleates whose proportions depend on the iron (II) or (III) source. They followed then the evolution of these iron oleates during thermal decomposition and observed a reduction process and the formation of a polymeric iron oleate network prior to nucleation. Doyle et al. ${ }^{35-37}$ investigated the extraction of iron ions using decanoic acid. They reported the formation of $\mathrm{Fe}_{3}(\mathrm{OH})\left(\mathrm{O}_{2} \mathrm{CR}\right)_{6}$ and $\mathrm{Fe}_{3} \mathrm{O}\left(\mathrm{O}_{2} \mathrm{CR}\right)_{5}\left(\mathrm{R}=\mathrm{C}_{10} \mathrm{H}_{19}\right)$ complexes having a $\mu_{3}$-oxo core. They suggested that the formation of such structures was due to the polymerisation of intermediary species such as $\left[\mathrm{Fe}(\mathrm{OH})\left(\mathrm{O}_{2} \mathrm{CR}\right)_{2}\right]$ and $\left[\mathrm{Fe}_{2}(\mathrm{OH})_{2}\left(\mathrm{O}_{2} \mathrm{CR}\right)_{4}\right]$, which react together to give trimeric species: $\mathrm{Fe}_{3}(\mathrm{OH})$ with chelate or monodentate coordinated carboxylates. After ageing or dehydration, this species with monodentate and chelate carboxylates will convert into $\mathrm{Fe}_{3}(\mathrm{OH})$ bearing bridging carboxylates.

The structure of iron stearates has been firstly investigated earlier by Abrahamson et $a^{38}$ while Nakamoto et al. ${ }^{39}$ studied its interaction and solvation with pyridine. Some mixed-valence trinuclear $\mu$-oxo iron carboxylate complexes, $\left[\mathrm{Fe}^{\mathrm{II \prime}}{ }_{2} \mathrm{Fe}^{\mathrm{II}} \mathrm{O}\left(\mathrm{O}_{2} \mathrm{CR}\right)_{6} \mathrm{~L}_{3}\right]$ (with $\mathrm{R}$ alkyl chain and $\mathrm{L}$ solvent molecule or ligand) were proposed and the solvation to balance the charge would lead for acetate to $\left[\mathrm{Fe}_{3} \mathrm{O}\left(\mathrm{O}_{2} \mathrm{CCH}_{3}\right)_{6} \mathrm{~L}_{3}\right]\left(\mathrm{O}_{2} \mathrm{CCH}_{3}\right)^{39}$. Abrahamson et al. ${ }^{38}$ reported that commercial $\mathrm{FeSt}_{2}$ was a mixed valence compound ( $\mu$-oxo trimer) $\left[\mathrm{Fe}^{\prime \prime \prime}{ }_{2} \mathrm{Fe}^{\prime \prime} \mathrm{O}(\mathrm{St})_{6}\left(\mathrm{H}_{2} \mathrm{O}\right)_{3}\right]$ in agreement with Nakamoto et al. For $\mathrm{FeSt}_{3}$, Abrahamson et al. reported that the commercial product consisted of a mixture of stearic acid and a trinuclear $\mu$-oxo $\mathrm{Fe}(+\mathrm{III})$ cluster (trimer) and for the $\mathrm{FeSt}_{3}$ that they synthesized, they proposed the following $\mu$-oxo trimer: $\left[\mathrm{Fe}_{3} \mathrm{O}(\mathrm{St})_{6}\left(\mathrm{H}_{2} \mathrm{O}\right)_{3}\right][\mathrm{St}]$. Therefore, the determination of the structure and compositions of iron carboxylates and especially for iron stearate needs to be completed and remains a challenge due to the involvement of long carboxylate chains and to the several oxidation degree of iron.

By tuning the synthesis conditions of iron stearates and by determining their structure and composition, we aim at demonstrating that the design of iron precursor is an important step in the nanoparticle synthesis. We selected the coprecipitation method to elaborate iron stearates. Indeed, iron oleate is mainly synthesized using a ligand exchange and phase transfer process (iron chloride is 
solubilized in a mixture of water and ethanol and soduim stearate in the organic phase, the iron oleate phase formed in the organic phase $)^{11,26,40}$ and iron stearate was at first synthesized by Abrahamson et $\mathrm{al}^{38}$ by coprecipitation in water. We tested both methods but we faced solubility problems of soduim stearate with the biphasic method and observed the recurrent formation of a water/hexane emulsion. We noticed also a great impact of the soduim stearate purity on the iron stearate synthesis reproducibility. The coprecipitation method appeared simpler to process by comparison with the biphasic one, there are also very few papers on iron stearates and we wanted to be able to compare our results with those of Abrahamson et al. Therefore, we developped the iron stearate synthesis by the coprecipitation method. The characterization of iron stearates by combining different characterization techniques demonstrated that iron stearates consist of lamellar materials which present, depending on their synthesis conditions, polycations with different iron content. The identification of such structures allows thus to understand the decomposition behaviour of the different stearates' precursors and to propose an original nucleation mechanism.

\section{MATERIAL AND METHODS}

Synthesis of both iron stearate precursors. Iron stearate (II) and (III) were prepared by precipitation of sodium stearate and ferrous chloride or ferric chloride salts in an aqueous solution as previously reported ${ }^{29,30}$.

\section{Characterization techniques}

Electron paramagnetic resonance (EPR): X-band EPR spectra were recorded with a continuous-wave ESP-300-E spectrometer (Bruker Biospin GmbH, Germany). The resonator is a Bruker ER 4102ST standard rectangular cavity operating in the $\mathrm{TE}_{108}$ mode equipped with an ESR900 Oxford cryostat ( $v \sim 9.3 \mathrm{GHz}$ in $\mathrm{X}$-band). Temperature was measured with a Cernox sensor (accuracy: $\Delta T / T \sim 5 \%$ ).

The spectrometer was tuned so as the settings (modulation coils, incident microwave power) do not distort the EPR signal.

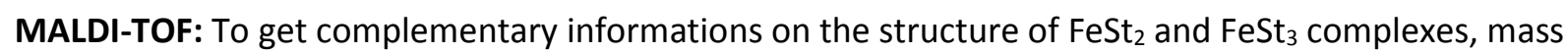
measurements were carried out on an Autoflex ${ }^{\mathrm{TM}}$ MALDI-TOF mass spectrometer (Bruker Daltonics $\mathrm{GmbH}$, Bremen, Germany). This instrument was used at a maximum accelerating potential of $20 \mathrm{kV}$ in positive mode and was operated in linear mode at $19 \mathrm{kV}$. The delay extraction was fixed at $80 \mathrm{~ns}$ and the frequency of the laser (nitrogen $337 \mathrm{~nm}$ ) was set at $5 \mathrm{~Hz}$. The acquisition mass range was set to $1000-6000 \mathrm{~m} / \mathrm{z}$ with a matrix suppression deflection (cut off) set to $500 \mathrm{~m} / \mathrm{z}$. The equipment was externally calibrated with a standard peptide calibration mixture that contained 7 peptides (Bruker Peptide Calibration Standard \#206196, Bruker Daltonics GmbH, Bremen, Germany) covering the 1000$3200 \mathrm{~m} / \mathrm{z}$ range. Each raw spectrum was treated with flexAnalysis 2.4 build 11 (Bruker Daltonics GmbH, Bremen, Germany) software.

Sample preparation was performed with the dried droplet method using a mixture of $0.5 \mu$ l of sample with $0.5 \mu \mathrm{l}$ of matrix solution dry at room temperature. The matrix solution was prepared at $10 \mathrm{mg} / \mathrm{ml}$ of 9-nitroantracene in dichloromethane in our case selected to be able to compare our results with those of Feld ${ }^{25}$ and Chang $^{25}$ ). In the case of iron cations, redox phenomena are not excluded as well. 
Finally, the presence of positive adducts such as $\mathrm{Na}^{+}$or $\mathrm{K}^{+}$is always possible. We expected the positive charge to originate from the loss of a stearate chain (St), redox process in the iron center (loss of an electron) or presence of a positive adduct $\left(\mathrm{H}^{+}, \mathrm{Na}^{+}\right.$or eventually $\left.\mathrm{K}^{+}\right)$.

Elemental analysis: Iron was quantified by ICP-AES of FeSt $t_{x}$ dissolved in nitric acid solution, while oxygen and carbon plus hydrogen were quantified by $\mathrm{O}$ and $\mathrm{CHN}$ microanalysers.

\section{STRUCTURAL AND CHARACTERIZATION RESULTS}

Fe oxidation degree by Mössbauer and electron paramagnetic resonance spectroscopies. Mössbauer and electron paramagnetic resonance (EPR) spectroscopies have been used to determine the oxidation degree of Fe in iron stearates. For each stearate, Fe(III) species with mainly two different environments are noticed. From Mössbauer spectrometry detailed in reference ${ }^{33}$, the first "environment" (IS = $0.5 \mathrm{~mm} \cdot \mathrm{s}^{-1}, \mathrm{QS}=0.7 \mathrm{~mm} \cdot \mathrm{s}^{-1}$ with IS: isomer shift; QS: quadrupole splitting) is present in both precursors, and with a proportion larger than $50 \%$. It is characteristic of HS (high spin) iron III in a distorted octahedral environment. For FeSt ${ }_{2}$, we observed a second quadrupolar doublet (IS $=0.5 \mathrm{~mm} \cdot \mathrm{s}^{-1}, \mathrm{QS}=1.15 \mathrm{~mm} \cdot \mathrm{s}^{-1}$ ), which was assigned to $\mathrm{Fe}_{3} \mathrm{O}$ in iron acetate $\mathrm{e}^{41-44}$. That is consistent with the increase of QS showing an increase of the electric field gradient around the nucleus, which may be related to the short Fe-O distance in $\mu$-oxo compounds ${ }^{45}$. For FeSt $\mathrm{Fe}_{3}$, the second doublet (IS $=$ $0.5 \mathrm{~mm} \cdot \mathrm{s}^{-1} ; \mathrm{QS}=0.5 \mathrm{~mm} \cdot \mathrm{s}^{-1}$ ) with a lower QS would be related to HS Fe (III) in a less distorted octahedric environment. A first difference between FeSt ${ }_{2}$ and $\mathrm{FeSt}_{3}$ is visible from Mössbauer spectra.

Continuous-Wave EPR spectroscopy performed at X-band (ca. 9.3 GHz), detailed in SI part, revealed at least two species for each stearate derivative (Figures S1 and S2). Both compounds display a strong signal around $\mathrm{g}=2$ associated with a high-spin state $(\mathrm{S}=5 / 2)$ of $\mathrm{Fe}^{\mathrm{III}}$ complex in the axial symmetry and corresponding to the lowest Kramers' doublets energy. The small hump observed at low field for FeSt $\mathrm{F}_{2}$ most likely originates from a high-spin $(\mathrm{S}=2) \mathrm{Fe}^{\text {"l }}$ species. For $\mathrm{FeSt}_{3}$, the peak at $\mathrm{g}=$ 4.3 implies the presence of a high-spin $(S=5 / 2) \mathrm{Fe}^{\text {III }}$ species in the rhombic symmetry and is associated with the intermediate Kramers' doublet ${ }^{46}$.

RPE and Mössbauer spectroscopies evidenced the presence of small amount of Fe ${ }^{2+}$ in "fresh" FeSt 2 but otherwise all stearates would exhibit $\mathrm{Fe}^{3+}$ with two different environments.

Lamellar structure by X-ray diffraction, IR spectroscopy and SAXS. Powder X-Ray diffraction (XRD) patterns of $\mathrm{FeSt}_{2}$ and $\mathrm{FeSt}_{3}$ exhibit peaks characteristic of the Bragg reflection of (00/) plans (Figure S3A). These XRD patterns are characteristic of a lamellar structure, which was also confirmed by SEM and TEM images of $\mathrm{FeSt}_{2}$ and $\mathrm{FeSt}_{3}$ (Figure S3B\&D). In FeSt ${ }_{2}$ XRD pattern, only one serie of harmonic is observed, with an unusual asymmetric behaviour (the even reflections are less intense than the odd reflections), while two "populations" are observed for FeSt ${ }_{3}$. The $d(001)$ distance, which corresponds to the distance between two iron layers, gives information about the packing of the alkyl chains. For FeSt $2, d(001)=49.5 \AA \approx 2 \mathrm{~L}$ ( $\mathrm{L}=$ length of a stearate chain) would be characteristic of alkyl chains in all-trans conformation perpendicular to an iron layer. The analysis of $\mathrm{FeSt}_{3}$ is more complex with $d(001)=39.1 \AA$ and $24.0 \AA$. The last value corresponds quite to the length of one stearate chain, while the first one is lower than two stearate chains in all-trans configuration as observed with FeSt ${ }_{2}$. 
Such values could be explained either by chain intercalation/interdigitation or by the presence of an angle between the iron layer and the alkyl chains (Figure S3D). The FeSt 3 structure is quite different and more complexe than that of $\mathrm{FeSt}_{2}$.

A SAXS analysis (Figure S4) has also confirmed the lamellar structure of these iron stearates. $\mathrm{FeSt}_{2}$ is organized in a lamellar crystal phase "Lam0" (reflections (001), periodicity $d=50.7 \AA$ in agreement with XRD), with a lateral arrangement of the aliphatic chains in a two-dimensional hexagonal subarray of rotator type $\left(h_{c h, c r}=4.12 \AA\right.$; section of the chains: $\left.S_{c h, ~ c r}=19.6 \AA^{2}\right)$. FeSt $t_{3}$ formed a classical threedimensional lamellar crystal phase "Lam0" (reflections (001), periodicity $d=50.1 \AA$ ), in which the signals of the crystalline phase and of the excess stearic acid are superimposed.

FTIR spectra are given in reference ${ }^{33}$ but they are more in depth analysed here. Both $\mathrm{FeSt}_{2}$ and $\mathrm{FeSt}_{3}$ IR spectra exhibit main bands which can be attributed to alkyl chains $\left(\mathrm{V}_{\mathrm{s}}\left(\mathrm{CH}_{2}\right)=2847 \mathrm{~cm}^{-1} ; \mathrm{vas}_{\text {as }}\left(\mathrm{CH}_{2}\right)\right.$ $=2915 \mathrm{~cm}^{-1}$ ) (Figure S5) and carboxylate bands (peaks between 1700 and $1300 \mathrm{~cm}^{-1}$ ) (Figure S6B, Table S1). From the alkyl band analysis (Figure S5B\&S6A), both compounds adopted a hexagonal packing with an all trans-conformation of the chains. Both IR spectroscopy and SAXS confirmed the lamellar structure of iron stearates. FeSt 3 is shown to contain free stearic acid, the peak at $1700 \mathrm{~cm}^{-1}$ in IR spectra (Figure S6B) is ascribed to free stearic acid and not to monodentate coordination.

From the carboxyl band intensities and position (Figures S6B\&S7 and Tables S1\&S2), which have been carefully compared to those of soduim stearate and stearic acid and which attributions are detailed in SI part, FeSt ${ }_{3}$ displays mainly a COO bridging coordination $\left(\Delta v=1577-1418=159 \mathrm{~cm}^{-1}\right)$ when FeSt 2 displays mainly a chelate coordination $\left(\Delta v=1525-1445=80 \mathrm{~cm}^{-1}\right)$. To investigate a possible interaction of carboxylate groups with water molecules, the synthesis of FeSt $\mathrm{F}_{3}$ and $\mathrm{FeSt}_{2}$ has been conducted in $\mathrm{D}_{2} \mathrm{O}$, which has a higher capacity to solvate polar species compared to $\mathrm{H}_{2} \mathrm{O}$ (Figure S8). Their analysis in $\mathrm{Sl}$ led to conclude that $\mathrm{FeSt}_{3}$ consists mainly of bridging carboxylates, with one oxygen involved in $\mathrm{H}$-bonding with water molecules, and chelating carboxylates. For FeSt ${ }_{2}$, the carboxylate coordination is mainly chelating with some bridging coordination without water interaction. We observed further that a heat treatment at low temperature of $\mathrm{FeSt}_{3}$ leads to the chelating coordination as shown in IR spectra in Figure S9. The observation of a more predominant chelating coordination is quite surprising as most published structures reported mainly a bridging coordination of carboxylates.

The possible presence of $\mathrm{Fe}-\mathrm{O}-\mathrm{Fe}$ bonds (such as in a $\mathrm{Fe}_{3} \mathrm{O}$ polycation) has been investigated by considering bands in the range $700-400 \mathrm{~cm}^{-1}$ (Figure $\mathrm{S} 10$ and detailed analysis in $\mathrm{SI}$ ). They are generally scarcely assigned in litterature due to their low intensity. We do observe two bands at around 600 and $580 \mathrm{~cm}^{-1}$ for both precursors, which are more intense for $\mathrm{FeSt}_{3}$ than for FeSt $\mathrm{F}_{2}$ and could be an indication of the presence of more Fe-O features in $\mathrm{FeSt}_{3}$.

Polycations identification. The MALDI-TOF analysis has been performed to determine the composition of iron polycations and spectra are given in Figure 1. There is a strong difference between $\mathrm{FeSt}_{2}$ and FeSt ${ }_{3}$ spectra in the region 3000-4500 Da, where intense peaks are detected for FeSt but $_{3}$ not for FeSt ${ }_{2}$. On the other hand, peaks between 1200 and $2100 \mathrm{Da}$ look very similar at first sight. Focus in this region is shown in Figure 1 . Three peaks at $\mathrm{m} / \mathrm{z}=1316,1599$ \& $1883 \mathrm{Da}$ are identified, which differ by $283 \mathrm{Da}$, the mass of one stearate chain. It matches quite well with the theoretical mass of complexes $\left[\mathrm{Fe}_{3} \mathrm{OSt}_{n}\right]^{+}$, with $\mathrm{n}=4,5 \& 6$ (theoretical mass of 1317.4, 1600.9 and 1884.4)(Figure 2). The 
lowest peak at $\mathrm{m} / \mathrm{z}=1282 \mathrm{Da}$ cannot be linked to $\left[\mathrm{Fe}_{3} \mathrm{OSt}_{n}\right]^{+}$since it does not differ from $283 \mathrm{Da}$. The mass difference with $\left[\mathrm{Fe}_{3} \mathrm{OSt}_{4}\right]^{+}$is $34 \mathrm{Da}$ which is too low to correspond to an iron but too high to be only one oxygen. We found a good correspondence with a complex having a dimeric structure close to that reported earlier by Doyle ${ }^{37}$ and also by Feld et $a l^{25}$ with iron oleate, i.e $\left[\mathrm{Fe}_{2}(\mathrm{OH})\left(\mathrm{OH}_{2}\right) \mathrm{St}_{4}\right]^{+}$. We also found evidence of tetramers species such as $\mathrm{Fe}_{4} \mathrm{O}_{2} \mathrm{St}_{6}$ especially in FeSt ${ }_{2}$.
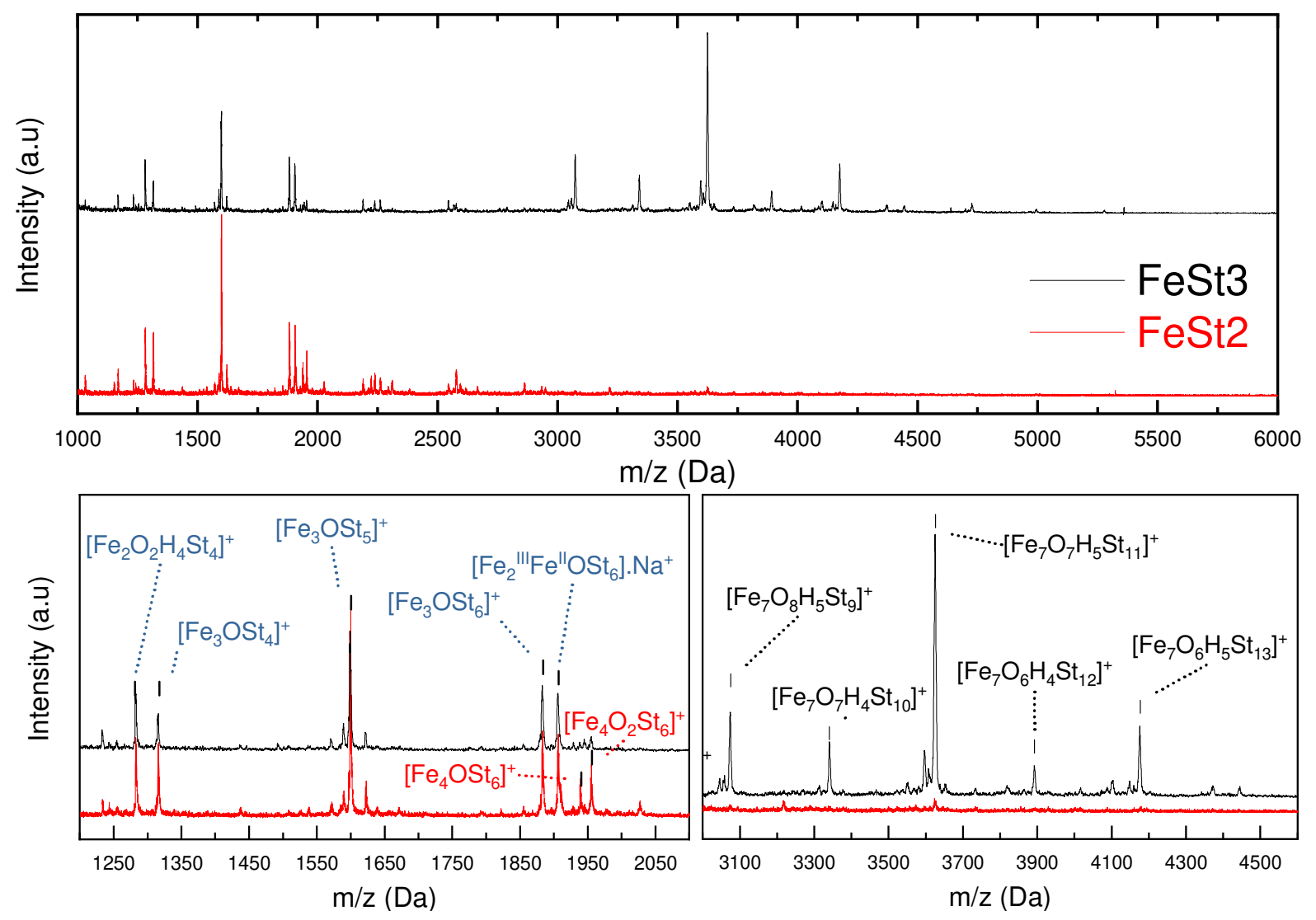

Figure 1. (Top) MALDI-TOF spectra of FeSt $\mathrm{F}_{2}$ (red line) and FeSt ${ }_{3}$ (black line) positive mode. (Bottom) Focus on the area 1200-2100 Da and 3000-4600 Da. Peaks assigned to $\mathrm{FeSt}_{2}$ and $\mathrm{FeSt}_{3}$ are written in red and black respectively. Shared peaks are written in blue.

For FeSt ${ }_{3}$, five strong peaks are also detected at $\mathrm{m} / \mathrm{z}=3073,3340,3624,3891$ and $4174 \mathrm{Da}$. They are separated in pairs by a mass of $283 \mathrm{Da}$ (4174 - 3891 and 3624 - 3340) or $267 \mathrm{Da}$ (3891-3624 and 3340-3073). The first one corresponds to the molecular weight of one stearate chain while the second corresponds to the loss of one stearate chain and the addition of one oxygen atom. All these peaks are at first attributed to the complex $\left[\mathrm{Fe}_{7} \mathrm{O}_{6} \mathrm{H}_{4} \mathrm{St}_{13}\right]^{+}$, where the loss of stearate chains would lead to the different peaks. However, this would imply that, at each time, two stearate chains leave and one oxygen atom is added. However, it would be very unlikely that the addition of oxygen comes from the ionisation process. Therefore, instead of one complex, we propose, as detailed below, three different complexes, each of them displays two peaks in spectra deduced by removing one stearate chain or by absorption/addition of a proton:

$$
\left[\mathrm{Fe}_{7}^{I I I} \mathrm{O}_{8} \mathrm{H}_{5} S t_{9}\right]^{+}\left(\frac{m}{z}=3075.2\right) \stackrel{+H^{+}}{\longleftarrow} \mathrm{Fe}_{7}^{I I I} \mathrm{O}_{8} H_{4} S t_{9} \stackrel{-S t^{-}}{\longrightarrow}\left[\mathrm{Fe}_{7}^{I I I} \mathrm{O}_{8} H_{4} S t_{8}\right]^{+}\left(\frac{m}{z}=2790.7\right)
$$




$$
\begin{aligned}
& {\left[\mathrm{Fe}_{7}^{I I I} \mathrm{O}_{7} \mathrm{H}_{5} S t_{11}\right]^{+}\left(\frac{m}{z}=3626.1\right) \stackrel{+H^{+}}{\longleftarrow} F e_{7}^{I I I} O_{7} H_{4} S t_{11} \stackrel{-S t^{-}}{\longrightarrow}\left[F e_{7}^{I I I} O_{7} H_{4} S t_{10}\right]^{+}\left(\frac{m}{z}=3341.6\right)} \\
& {\left[\mathrm{Fe}_{7}^{I I I} O_{6} H_{5} S t_{13}\right]^{+}\left(\frac{m}{z}=4177.1\right) \stackrel{+H^{+}}{\longleftarrow} F e_{7}^{I I I} O_{6} H_{4} S t_{13} \stackrel{-S t^{-}}{\longrightarrow}\left[F e_{7}^{I I I} O_{6} H_{4} S t_{12}\right]^{+}\left(\frac{m}{z}=3892.6\right)}
\end{aligned}
$$

Some of the identified complexes for $\mathrm{FeSt}_{2}$ and $\mathrm{FeSt}_{3}$ were previously reported for iron stearate or iron oleate ${ }^{25,26,38,47}$, especially $\left[\mathrm{Fe}^{\mathrm{II \prime}}{ }_{3} \mathrm{OSt}_{6}\right]^{+}$(Figure 2 ), $\left[\mathrm{Fe}^{\mathrm{II}}{ }_{2} \mathrm{Fe}^{\mathrm{II}} \mathrm{OSt}_{5}\right]^{+}$, and also complexes very similar to $\left[\mathrm{Fe}^{\mathrm{II \prime}}{ }_{2} \mathrm{Fe}_{2}{ }_{2}(\mathrm{OH})_{2} \mathrm{St}_{7}\right]^{+},\left[\mathrm{Fe}^{\mathrm{II \prime}}{ }_{3} \mathrm{Fe}_{2}{ }_{2} \mathrm{O}_{2} \mathrm{St}_{8}\right]^{+}$and $\left[\mathrm{Fe}^{\mathrm{II \prime}}{ }_{3} \mathrm{Fe}_{2}{ }_{2} \mathrm{O}(\mathrm{OH}) \mathrm{St}_{9}\right]^{+}$reported by Feld et al ${ }^{25}$. For FeSt ${ }_{3}$, the main complex would be based on a $\mathrm{Fe}_{7} \mathrm{O}(\mathrm{H})_{7 \pm 1}$ unit as suggested by this analysis (Figure 3). Such structures are poorly reported in the literature, but few authors mention the formation of $\mathrm{Fe}_{n} \mathrm{O}_{n \pm 1}$ very stable rings for $n<5$ and towers for $n>5^{48,49}$. Considering the Fe/O ratio in these complexes close to or higher than 1, they would explain the formation of wüstite FeO nuclei proved recently in our experimental conditions $\mathrm{s}^{33}$. It has also been demonstrated that strongly chelating and long alkyl chain ligands are able to stabilize large polycations ${ }^{50,51}$. Structures such as $\left[\mathrm{Fe}_{17}\left(\mu_{3}-\mathrm{O}\right)_{4}\left(\mu_{3}-\mathrm{OH}\right)_{6}\left(\mu_{2^{-}}\right.\right.$ $\mathrm{OH})_{10}(\mathrm{~L})_{8}\left(\mathrm{H}_{2} \mathrm{O}\right)_{12}$ ] were thus synthesized by adding a solution of $\mathrm{N}\left(\mathrm{CH}_{2} \mathrm{COOH}\right)_{2}\left(\mathrm{CH}_{2} \mathrm{CH}_{2} \mathrm{OH}\right)$ in an aqueous solution of ferric nitrate ${ }^{52}(\mathrm{pH}$ not given). Very interestingly, this structure derived from a $\left[\mathrm{Fe}_{7}\left(\mu_{3}-\mathrm{OH}\right)_{6}\left(\mu_{2}-\mathrm{OH}\right)_{6}\right]^{9+}$ core (Figure 3).

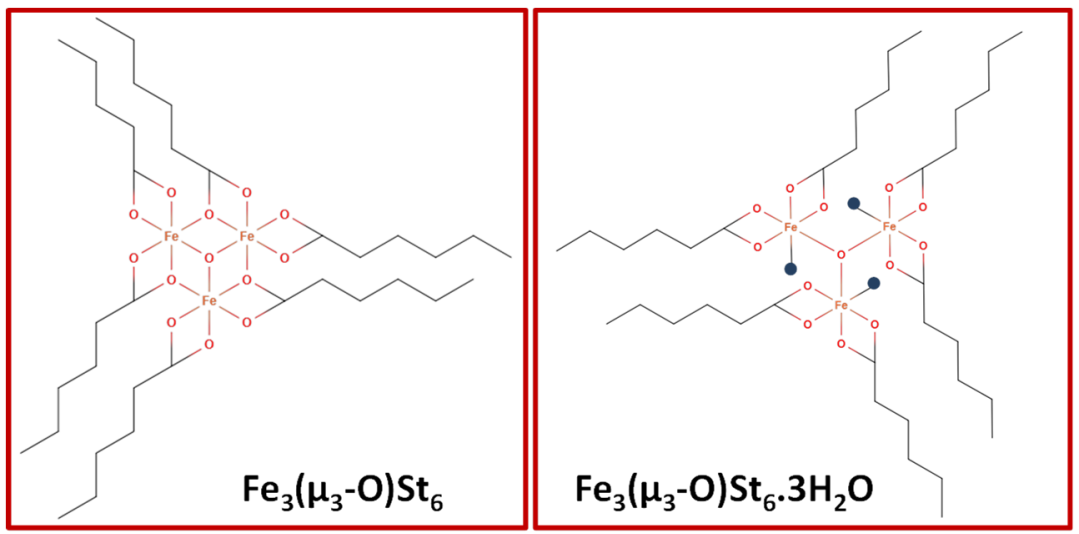

Figure 2. Proposal of structure for $\mathrm{FeSt}_{2}$ based on $\mathrm{Fe}_{3} \mathrm{O}$ core (left) without water and tridentate coordinated carboxylate (right) with water and bidentate chelate carboxylate. Water is represented by blue dots.
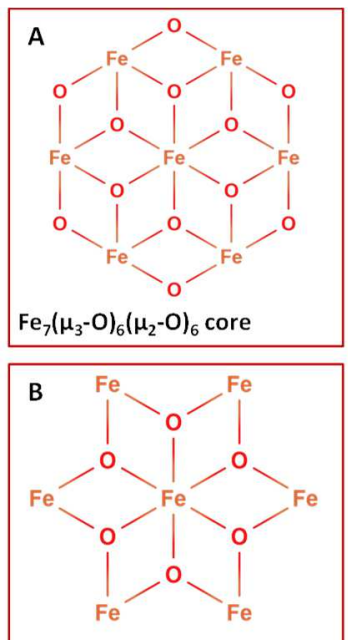

$\mathrm{Fe}_{7}\left(\mu_{3}-\mathrm{O}\right)_{6}$ core

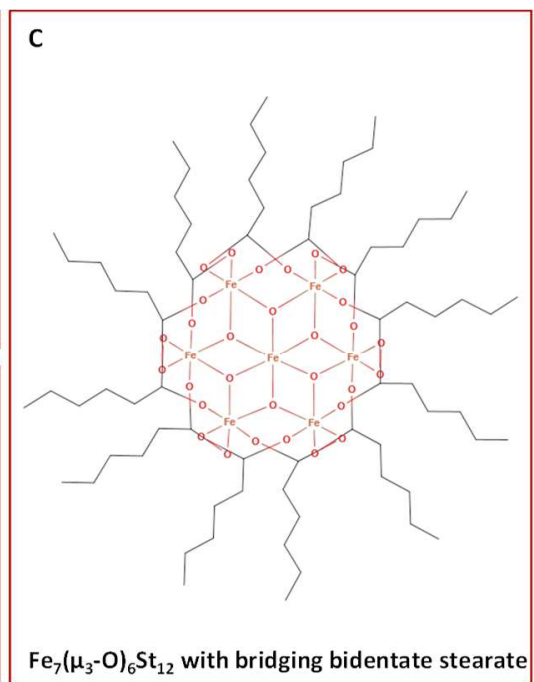

D

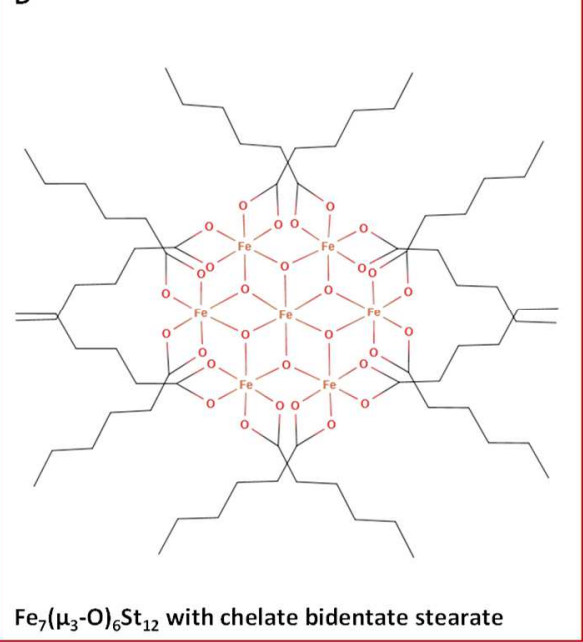


Figure 3. Structure of the $\mathrm{Fe}_{7}$ core $(\mathrm{A})$ with or $(\mathrm{B})$ without $\left(\mu_{2}-\mathrm{O}\right)$ bridge. Proposition of structure for the complex $\left.\mathrm{Fe}_{7}\left(\mu_{3}-\mathrm{O}(\mathrm{H})\right)_{6} \mathrm{St}_{12}\right] \mathrm{St}$ with $(\mathrm{C})$ bridging or $(\mathrm{D})$ chelate stearate. For clarity, hydrogen atoms were omitted.

Determination of the composition of both stearates. Elemental analysis results were compared with the published and theoretical ones of other reported iron stearates (Table 1). Due to measurements incertitude and separated measurement techniques, the total weight analysis of both iron stearates might not be $100 \%$. Also, impurities such as sodium or chloride ions are not considered by these analyses.

Table 1. Comparison between experimental results of elemental analysis and theoretical prediction with the proposed structure

\begin{tabular}{|c|c|c|c|c|c|c|}
\hline \multicolumn{7}{|c|}{$\mathrm{FeSt}_{2}$} \\
\hline & $\mathrm{Fe}(\%)$ & $\mathrm{C}(\%)$ & $\mathrm{H}(\%)$ & $0(\%)$ & $\mathrm{Cl}(\%)$ & Total \\
\hline \multicolumn{7}{|c|}{ Experimental composition } \\
\hline FeSt2 & 9 & 67.6 & 11 & 9.7 & ND & 97.3 \\
\hline \multicolumn{7}{|c|}{ Theoretical composition } \\
\hline$\left[\mathrm{Fe}_{3} \mathrm{OSt}_{6}\right] \mathrm{St}$ & 7.7 & 69.8 & 11.4 & 11.1 & 0.0 & 100.0 \\
\hline$\left[\mathrm{Fe}_{3} \mathrm{OSt}_{6}\right] \mathrm{Cl}$ & 8.7 & 67.6 & 11.0 & 10.8 & 1.8 & 100.0 \\
\hline$\left[\mathrm{Fe}_{3} \mathrm{OSt}_{6 .} 3 \mathrm{H}_{2} \mathrm{O}\right] \mathrm{Cl}$ & 8.5 & 65.7 & 11.0 & 13.0 & 1.8 & 100.0 \\
\hline$\left[\mathrm{Fe}_{3} \mathrm{OSt}_{6 .} 2 \mathrm{H}_{2} \mathrm{O}\right] \mathrm{Cl}$ & 8.6 & 66.3 & 11.0 & 12.3 & 1.8 & 100.0 \\
\hline \multicolumn{7}{|c|}{ FeSt3 } \\
\hline \multicolumn{7}{|c|}{ Experimental composition } \\
\hline FeSt3 & 6.4 & $69.6 \pm 1.8$ & $11.5 \pm 0.3$ & $11.1 \pm 0.6$ & & 98.6 \\
\hline \multicolumn{7}{|c|}{ Theoretical composition } \\
\hline$\left[\mathrm{Fe}_{3} \mathrm{OSt}_{6}\right] \mathrm{St}$ & 7.7 & 69.8 & 11.4 & 11.1 & 0.0 & 100 \\
\hline$\left[\mathrm{Fe}_{3} \mathrm{OSt}_{6}\right] \mathrm{St}+2 \mathrm{St}$ & 6.1 & 71.1 & 11.6 & 11.1 & 0.0 & 100.0 \\
\hline$\left[\mathrm{Fe}_{3} \mathrm{OSt}_{6}\right] \mathrm{St}+\mathrm{St}$ & 6.8 & 70.6 & 11.5 & 11.1 & 0.0 & 100.0 \\
\hline$\left[\mathrm{Fe}_{7} \mathrm{O}_{6} \mathrm{H}_{4} \mathrm{St}_{12}\right] \mathrm{St}$ & 9.3 & 66.7 & 11.1 & 12.9 & 0.0 & 100.0 \\
\hline$\left[\mathrm{Fe}_{7} \mathrm{O}_{6} \mathrm{H}_{4} \mathrm{St}_{12}\right] \mathrm{St}+7 \mathrm{St}$ & 6.3 & 69.7 & 11.6 & 12.4 & 0.0 & 100.0 \\
\hline$\left[\mathrm{Fe}_{7} \mathrm{O}_{6} \mathrm{H}_{4} \mathrm{St}_{12}\right] \mathrm{St}+8 \mathrm{St}$ & 6.0 & 70.0 & 11.7 & 12.3 & 0.0 & 100.0 \\
\hline
\end{tabular}

In FeSt ${ }_{2}$, the starting ratio of stearate to iron is 2 and matches with [ $\left.\mathrm{Fe}_{3}\left(\mu_{3}-\mathrm{O}\right) \mathrm{St}_{6}\right]$. Normally from experimental conditions using also a ratio equal to 2, no stearate should be available to act as counter ion. Therefore, we suggest that $\mathrm{Cl}^{-}$acts as counter ion. The formula $\left[\mathrm{Fe}_{3}\left(\mu_{3}-\mathrm{O}\right) \mathrm{St}_{6}\right] \mathrm{Cl}$ matches also quite well with the results of the elemental analysis (Table 1) of FeSt $t_{2}$, while the formula $\left[\mathrm{Fe}_{3}\left(\mu_{3}-\mathrm{O}\right) \mathrm{St}_{6}\right] \mathrm{St}$ displays not enough iron atoms and too much carbon ones. In addition, Mössbauer spectrometry showed that iron is in octahedral environment and IR spectroscopy that the carboxylates are bound to iron atoms by chelating bidentate coordination. Thus, 6 oxygens should be bound to iron. However, in $\mathrm{Fe}_{3} \mathrm{OSt}_{6}$, considering carboxylates with a bidentate coordination, only 5 oxygens per iron are present ( 6 chelating stearates each bringing 2 oxygens, plus one ligand ( $\mu_{3}-0 x 0$ ) bringing 3 oxygens, so 15 oxygens for 3 irons). The missing oxygen to ensure an octahedral environment can come from aquo ligand, as proposed by Abrahmson ${ }^{38}$ and Chang $^{26}$ (Figure 2), or from carboxylate acting as tridentate ligand (by being both bridging and chelate) as reported for $\mathrm{Cu}^{53}, \mathrm{Cd}^{54,55}$ or $\mathrm{Tb}^{56}$ carboxylates (Figure 2). The elemental analysis is more in favour of the second hypothesis, especially because of the low 
oxygen amount, but the imprecision in these measurements makes it difficult to conclude unambiguously. An important parameter also difficult to extract from these analyses is the water content but TGA experiments (Figure S11) show a small weight loss below $100^{\circ} \mathrm{C}$. At this stage, the proposed structure for $\mathrm{FeSt}_{2}$ is $\left[\mathrm{Fe}_{3}\left(\mu_{3}-\mathrm{O}\right) \mathrm{St}_{6} \cdot \mathrm{xH}_{2} \mathrm{O}\right] \mathrm{Cl}$. The weight loss of one water molecule for $\mathrm{x}=1-$ 3 is about $0.9 \%$ in agreement with the observed weight loss, suggesting the presence of water molecules in FeSt ${ }_{2}$. However, one may notice that by comparison with reported structures based on $\left[\mathrm{Fe}_{3}\left(\mu_{3}-\mathrm{O}\right) \mathrm{St}_{6}\right]$ unit, the carboxylates here are coordinated by chelating bidentate coordination while the most reported coordination is the bridging bidentate one.

The MALDI spectra have also shown the presence of iron polycations with higher iron content especially in $\mathrm{FeSt}_{3}$. The composition of such polycation may be discussed by considering the $\mathrm{FeSt}_{3}$ structure. In FeSt ${ }_{3}$ MALDI spectra, the iron complex with a $\mu_{3}$-oxo iron core, similar to $\mathrm{FeSt}_{2}$, is also identified. However, because of the excess of stearate in $\mathrm{FeSt}_{3}$ (stearate/iron ratio of 3 ) by comparison with $\mathrm{FeSt}_{2}$, we suggest that the counter anion is more likely to be stearate than chloride one, leading thus to the complex $\left[\mathrm{Fe}_{3} \mathrm{OSt}_{6}\right] \mathrm{St}$, as also reported by Abramhson ${ }^{38}$. Other complexes with formulas [ $\left.\mathrm{Fe}_{7} \mathrm{O}_{6} \mathrm{H}_{4} \mathrm{St}_{12}\right],\left[\mathrm{Fe}_{7} \mathrm{O}_{7} \mathrm{H}_{4} \mathrm{St}_{10}\right]$ and $\left[\mathrm{Fe}_{7} \mathrm{O}_{8} \mathrm{H}_{4} \mathrm{St}_{8}\right]$ are also identified. All of them probably derived from $\left.\left[\mathrm{Fe}_{7}\left(\mu_{3}-\mathrm{OH}\right)_{6}\right)\left(\mu_{2}-\mathrm{OH}\right)_{6}\right]^{9+}$ core ${ }^{52}$ (Figure $\left.3 \mathrm{~A}\right)$, which is formed by successive condensation of $\left[\mathrm{Fe}(\mathrm{OH})_{3}\left(\mathrm{H}_{2} \mathrm{O}\right)_{3}\right]$ and $\left[\mathrm{Fe}(\mathrm{OH})_{2}\left(\mathrm{OH}_{2}\right)_{4}\right]^{+}$species in water. The full substitution of $\left(\mu_{2}-\mathrm{OH}\right)$ bridges by carboxylate would lead to the formation of $\left[\mathrm{Fe}_{7}\left(\mu_{3}-\mathrm{O}(\mathrm{H})\right)_{6} \mathrm{St}_{12}\right] \mathrm{St}$ (Figure $3 \mathrm{C} \& \mathrm{D}$ ) , but given the species observed in MALDI-TOF, a better description of our complexes would be $\left[\mathrm{Fe}_{7}\left(\mu_{3}-\mathrm{O}(\mathrm{H})\right)_{6}\left(\mu_{2}-\mathrm{O}(\mathrm{H})\right)_{x} \mathrm{St}_{12}\right.$ 2x]St.

However, firstly, the elemental analysis, especially the iron content, does not match with a $\left[\mathrm{Fe}_{7}\left(\mu_{3^{-}}\right.\right.$ $\left.\mathrm{O}(\mathrm{H}))_{6} \mathrm{St}_{12}\right] \mathrm{St}$ complex. As the stearate/Fe ratio (13/7 at maximum) in this complex is lower than 3 (and even 2 ) and since the starting stearate to iron ratio is 3 , an excess in stearate should be present in the reacting medium. This assessment is also true for all complexes $\left[\mathrm{Fe}_{7}\left(\mu_{3}-\mathrm{O}(\mathrm{H})\right)_{6}\left(\mu_{2}-\mathrm{O}(\mathrm{H})\right)_{x} \mathrm{St}_{12-2 x}\right] \mathrm{St}$. Even if $\left[\mathrm{Fe}_{3}\left(\mu_{3}-\mathrm{O}\right) \mathrm{St}_{6}\right] \mathrm{St}(\mathrm{St} / \mathrm{Fe}=2.3)$ is also present in $\mathrm{FeSt}_{3}$, some free stearates/stearic acid molecules have to be considered in $\mathrm{FeSt}_{3}$ to understand the excess of carbon. The presence of free stearic acid was clearly deduced from SAXS analysis of $\mathrm{FeSt}_{3}$, when it was not observed with $\mathrm{FeSt}_{2}{ }^{57}$. By considering the elemental analysis with an iron content around $6.4 \%$, the presence of free stearate chains and also of some $\left[\mathrm{Fe}_{3} \mathrm{OSt}_{6}\right] \mathrm{St}$ based complex, we may conclude that this complex is $\left.\mathrm{Fe}_{7}\left(\mu_{3}-\mathrm{O}(\mathrm{H})\right)_{6}\left(\mu_{2}-\mathrm{O}(\mathrm{H})\right)_{x} \mathrm{St}_{12-2 x}\right] \mathrm{St}$ and that free stearate/stearic acid are present in the mixture. The structure for the $\mathrm{Fe}_{7}$ complex may correspond to that based on the work of Heath et $a^{52}$ which is given in Figure 3C\&D with a bridging or chelating coordination respectively. Concerning the water content, as for FeSt ${ }_{2}$, we cannot exclude the presence of water in $\left[\mathrm{Fe}_{3} \mathrm{OSt}_{6}\right] \mathrm{St}$ structure and we know also that some water is involved in the bridging coordination.

To confirm the composition of the two stearates, the TGA curves and especially the total weight losses (Figure S11 and Table S3) of iron stearates have been considered (details in SI part). For both iron II and iron III stearates, the final product after TGA should be the oxydized iron (III) oxide, $\mathrm{Fe}_{2} \mathrm{O}_{3}(\mathrm{Mw}=159.69 \mathrm{~g} / \mathrm{mol})$, considering that decomposition products such as hydrocarbons, cetone compounds, water and carbon dioxide are evaporated. From different TGA experiments (cf. SI part), the final mean weight losses are $86.3 \pm 1.4 \%$ and $92.8 \pm 2.3 \%$ for $\mathrm{FeSt}_{2}$ and $\mathrm{FeSt}_{3}$ respectively. The 
experimental weight loss of $\mathrm{FeSt}_{2}$ and $\mathrm{FeSt}_{3}$ has been compared with the ones of the previous proposed polynuclear structures. Once again, the complex $\left[\mathrm{Fe}_{3} \mathrm{OSt}_{6}\right] \mathrm{Cl}$ gives results in accordance with the experimental weight loss for $\mathrm{FeSt}_{2}$, while for $\mathrm{FeSt}_{3}$, the total weight loss is too high for a complex with a polynuclear composition of $\mathrm{Fe}_{7} \mathrm{O}_{6}$. Even if some $\left[\mathrm{Fe}_{3} \mathrm{OSt}_{6}\right] \mathrm{St}$ complex is present in $\mathrm{FeSt}_{3}$, it cannot explain the observed weight loss. Free stearic acid needs again to be considered to find a theoretical weight loss close to the experimental one. That is again in agreement with previous hypothesis on the presence of free stearic acid in FeSt 3 . In addition, the presence of free stearic acid is confirmed by the presence of an endothermic peak at $68.6^{\circ} \mathrm{C}$ related to free stearic acid in FeSt ${ }_{3}$ DTA curve $^{33}$.

\section{Investigation of the synthesis mechanism of iron stearates. Why different polycations?}

Previous experiments evidenced that $\mathrm{FeSt}_{2}$ would mainly consist of $\left[\mathrm{Fe}_{3}\left(\mu_{3}-\mathrm{O}\right) \mathrm{St}_{6} \cdot \mathrm{xH}_{2} \mathrm{O}\right] \mathrm{Cl}$ and $\mathrm{FeSt}_{3}$ would be a mixture of $\left[\mathrm{Fe}_{3}\left(\mu_{3}-\mathrm{O}\right) \mathrm{St}_{6} \cdot \mathrm{xH}_{2} \mathrm{O}\right] \mathrm{St}$, $\left[\mathrm{Fe}_{7}\left(\mu_{3}-\mathrm{O}(\mathrm{H})\right)_{6}\left(\mu_{2}-\mathrm{O}(\mathrm{H})\right)_{\times} \mathrm{St}_{12-2 x}\right] \mathrm{St}$ and free stearic acid. Reported results suggested that polycations would be formed by successive condensation of $\left[\mathrm{Fe}(\mathrm{OH})_{3}\left(\mathrm{H}_{2} \mathrm{O}\right)_{3}\right]$ and $\left[\mathrm{Fe}(\mathrm{OH})_{2}\left(\mathrm{OH}_{2}\right)_{4}\right]^{+}$species in water during the coprecipitation steps. The hydrolysis pathway of iron chlorides was thus investigated as well as their possible condensation and reactions when sodium stearate is added. Indeed, the structural differences of $\mathrm{FeSt}_{2}$ and $\mathrm{FeSt}_{3}$ may originate from different reactions occurring during iron II \& III chloride hydrolysis when dissolved in water ${ }^{50}$, and then during the complexation reaction with stearates. Such investigation is detailled in $\mathrm{SI}$ and the main results are given below.

Table 2. Calculated hydrolysis of iron II and III in our experimental conditions (hydrated iron chlorides solubilized in deionized water)

\begin{tabular}{|l|l|l|l|c|}
\hline & \multicolumn{1}{|c|}{$[\mathrm{Fe}] \mathrm{M}$} & \multicolumn{1}{c|}{ pH measured } & \multicolumn{1}{c|}{ h calculated } & \multicolumn{1}{c|}{ Main species } \\
\hline Fe II & 0.1 & 3.10 & 1.6 & {$\left[\mathrm{Fe}(\mathrm{OH})_{1.6}\left(\mathrm{H}_{2} \mathrm{O}\right)_{4.4}\right]^{0.4}$} \\
\hline Fe III & 0.067 & 1.88 & 2.6 & {$\left[\mathrm{Fe}(\mathrm{OH})_{2.6}\left(\mathrm{H}_{2} \mathrm{O}\right)_{3.4}\right]^{0.4}$} \\
\hline
\end{tabular}

The analyses of the hydrolysis of $\mathrm{FeCl}_{2}$ and $\mathrm{FeCl}_{3}$ let us to conclude that both iron chlorides are hydrolyzed with a higher hydrolysis degree for $\mathrm{FeCl}_{3}$ than $\mathrm{FeCl}_{2}$ (Table 2). After this hydrolysis step, some condensation can occur either by olation $\mathrm{M}-\mathrm{OH}+\mathrm{M}-\mathrm{H}_{2} \mathrm{O} \rightarrow \mathrm{M}-(\mathrm{OH})-\mathrm{M}+\mathrm{H}_{2} \mathrm{O}$, or by oxolation $\mathrm{M}-$ $\mathrm{OH}+\mathrm{M}-\mathrm{OH} \rightarrow \mathrm{M}-\mathrm{O}-\mathrm{M}+\mathrm{H}_{2} \mathrm{O}$. It has been reported that condensation would occur for ferric cations at a $\mathrm{pH}>1$, while a $\mathrm{pH}>6$ is proposed for ferrous cations $\mathrm{s}^{50,58}$. However, the case of ferrous species is particular due to the fast oxidation of iron (II) in oxidizing environment like in our synthesis conditions at $80^{\circ} \mathrm{C}$ in water and under air. For ferric ions, many oxo-hydroxide based species have been reported in the literature (goethite $\alpha-\mathrm{FeOOH}$, alkagenide $\beta-\mathrm{FeOOH} .$. ) and are very dependent on the $\mathrm{pH}$. Rose et al. ${ }^{59}$ investigated the early stage formation of iron oxyhydroxide from iron(III) nitrate at $\mathrm{pH} 3$, and observed by SAXS the formation of iron clusters within the first seconds of mixing. It was reported that the size of these polycations increases with the increase in $\mathrm{pH}^{60}$. As a result, species such as $\left[\mathrm{Fe}_{a} \mathrm{O}_{b}(\mathrm{OH})_{c}\left(\mathrm{H}_{2} \mathrm{O}\right)_{d}\right]$ are formed in the water solutions of iron chlorides. As in our experimental conditions, the $\mathrm{pH}$ of the ferrous and ferric solutions is 3.1 and 1.9 respectively, we can argue that some condensation may occur especially with $\mathrm{Fe}$ (III) solution as the $\mathrm{pH}$ of the ferric solution is higher 
than 1 . The condensation should be rather limited within the ferrous solution whose $\mathrm{pH}$ is lower than 6.

Upon the mixing step between the iron chloride and sodium stearate solutions, several reactions should occur simultaneously. Firstly, stearate ligands will complex iron cations, probably by substitution of aquo ligands. They can also coordinate to iron cations, which are already involved in polycations formed during the hydrolysis step. Secondly, since the temperature and pH are higher than those of the pre-formed iron chloride solutions, condensation should also be favoured. The competition between those two main reactions may drive the final structure of $\mathrm{FeSt}_{2}$ and $\mathrm{FeSt}_{3}$. Oxidation of ferrous species is also expected due to the oxidizing environment. This will eventually favor condensation, as we have shown that the condensation of ferric ions is easier. Nevertheless, the $\mathrm{pH}$ stabilization of the mixture, below 6 for the FeSt $\mathrm{F}_{2}$ mixture and 3 for the $\mathrm{FeSt}_{3}$ one, occurs quickly within 30s (Figure S12) and it has already been reported that the presence of complexing agent such as carboxylates could stop the condensation of iron by stabilizing polycations ${ }^{58,61}$.

For $\mathrm{FeSt}_{2}$, according to $\mathrm{pH}$, an important condensation reaction in the iron chloride solution is not expected as pH stays always below 6 . Therefore, species such as $\left[\mathrm{Fe}(\mathrm{OH})\left(\mathrm{H}_{2} \mathrm{O}\right)_{5}\right]^{+}$, $\left[\mathrm{Fe}(\mathrm{OH})_{2}\left(\mathrm{H}_{2} \mathrm{O}\right)_{4}\right]$ or $\left[\mathrm{Fe}_{2}(\mathrm{OH})_{2}\left(\mathrm{H}_{2} \mathrm{O}\right)_{8}\right]^{2+}$ are probably present before mixing with the stearate solution. Once in contact with stearate, the complexation should start quickly on those species, to form the species predicted by Doyle: $\left[\mathrm{Fe}(\mathrm{OH})_{2} \mathrm{St}_{2}\right],\left[\mathrm{Fe}_{2}(\mathrm{OH})_{2} \mathrm{St}_{4}\right]$ (Figure 4$)^{35,36}$. Yet, oxidation will occur, favoring hydroxylation and condensation. We followed the evolution of $\mathrm{pH}$ with time in the reaction mixture as shown in Figure S12. As the chloride solution is "introduced" into the stearate solution, the initial pH of 9.5 is the pH of the stearate solution. For FeSt ${ }_{2}$, following the mixing step, the $\mathrm{pH}$ drops to 5.8 and stays constant for $60 \mathrm{~s}$, before dropping again at 5.35. It was reported that condensation of ferrous species happens at $\mathrm{pH}$ 5-6 which remains constant during condensation ${ }^{62}$. This would suggest that condensation occurs during this mixing step with $\mathrm{FeSt}_{2}$.

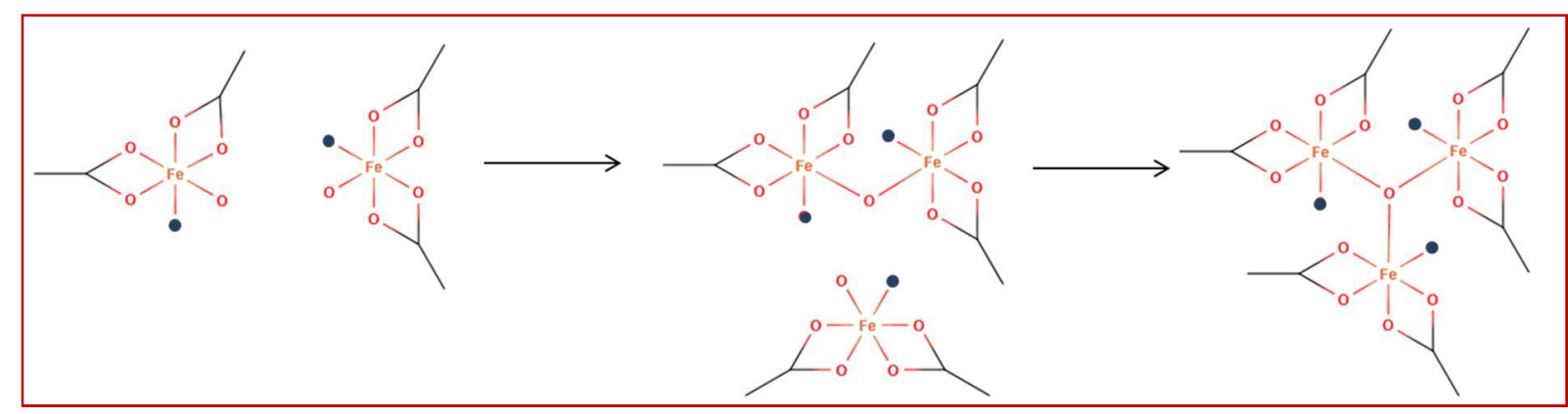

Figure 4. Proposition of mechanism for the synthesis of $\mathrm{Fe}_{3} \mathrm{O}$ core in water by condensation of monomeric $\left[\mathrm{Fe}(\mathrm{OH})_{2} \mathrm{St}_{2}\right]$ and dimeric $\left[\mathrm{Fe}_{2}(\mathrm{OH})_{2} \mathrm{St}_{4}\right]$ species. Hydrogen atoms were omitted for clarity and $\mathrm{OH}$ is represented by blue dots.

Regarding $\mathrm{FeSt}_{3}$, some polycations are already present in the chloride solution. Therefore, stearate chain should substitute water on these polycations, which stabilize them and prevent them from their growth. We can also expect to form, as with $\mathrm{FeSt}_{2}$, monomeric like $\left[\mathrm{Fe}(\mathrm{OH})_{2} \mathrm{St}_{2}\right]$ or dimeric $\left[\mathrm{Fe}_{2}(\mathrm{OH})_{2} \mathrm{St}_{4}\right]$ structures, which would eventually form $\left[\mathrm{Fe}_{3} \mathrm{OSt}_{6}\right]^{+}$by condensation (Figure 4). $\mathrm{pH}$ monitoring with 
$\mathrm{FeSt}_{3}$ (Figure S12) shows a quick drop to $\mathrm{pH} 2.9$, which is high enough to promote condensation of monomeric species. In addition, it has been reported that heating at $80-100^{\circ} \mathrm{C}$ of an acidic solution of iron (III) leads to the formation of $\mu_{3}$-oxo or $\mu_{3}$-hydroxo units. Finally, we should keep in mind that in the case of $\mathrm{FeSt}_{3}$, we have three stearate chains for one iron. However, in all the reported structures, the ratio $\mathrm{St} / \mathrm{Fe}$ is often close to 2 . Therefore, it would make sense to consider the presence of more free stearates with $\mathrm{FeSt}_{3}$ than with $\mathrm{FeSt}_{2}$.

To conclude, this analysis suggests that polycations would be formed during the preparation of iron chloride solutions with iron (III) chlorides, but not likely with iron (II) chlorides. Therefore, after mixing with the stearate solution, stearate would form complexes such as monomeric or dimeric species with ferric and ferrous iron, but also bigger polycationic structures with ferric ions. This analysis confirms thus MALDI-TOF investigations that the precursors are rather a mixture of several complexes with different iron atom contents.

Specific case of polycations in FeSt t $_{3}$. Polycations would be present in the iron (III) chloride solution even before the reaction with sodium stearate, but not in the ferrous chloride solution. Thus, the complexation of sodium stearate on these polycations would lead to the formation of polynuclear species for $\mathrm{FeSt}_{3}$. The identification of $\left[\mathrm{Fe}_{7}\left(\mu_{3}-\mathrm{O}(\mathrm{H})\right)_{6}\left(\mu_{2}-\mathrm{O}(\mathrm{H})\right)_{x} \mathrm{St}_{12-x}\right] \mathrm{St}$ complex with $\mathrm{FeSt}_{3}$ and not with $\mathrm{FeSt}_{2}$ supports this conclusion. In order to check further this hypothesis, $\mathrm{FeSt}_{3}$ was synthesized by using a ferric chloride solution at $\mathrm{pH} 1$ by addition of $\mathrm{HCl}$. At this $\mathrm{pH}$, only $\left[\mathrm{Fe}\left(\mathrm{H}_{2} \mathrm{O}\right)_{6}\right]^{3+}$ is expected to be the main hydrolysis specie and the solution is below the $\mathrm{pH}$ reported to favor condensation reactions. $\mathrm{Fe}_{7}$ based species were not identified in MALDI-TOF spectra (Figure S13), only species below 3000 Da were identified as $\mathrm{Fe}_{3} \mathrm{O}$ based species (Figure 4). This supplementary experiment confirmed our hypothesis that the condensation in iron chloride solutions leads to the presence of polynuclear complexes in the as-synthesized iron stearates. One may further notice that no condensation would favor the formation of $\mathrm{Fe}_{3} \mathrm{O}$ based complexes.

Secondly, the effect of the reaction time (15 $\mathrm{min}$ as usually and $60 \mathrm{~min}$ ) on the formation of polynuclear complexes has been investigated (after mixing of iron (III) chloride at $\mathrm{pH} 1$ and sodium stearate solutions). No difference between the MALDI-TOF spectra was noticed, confirming again that the polycations $\mathrm{Fe}_{7}$ were formed in the chloride solution, and not during the complexation with sodium stearate. However, a change in the IR spectra of complexes was observed when the reaction time was $1 \mathrm{~h}$ instead of 15 minutes (Figure S13). Indeed, the carboxylate coordination became bidentate chelate instead of bridging after 15 minutes. Moreover, this reaction time effect on the carboxylate coordination was also observed in the standard conditions (without setting the iron chloride solution $\mathrm{pH}$ at 1). These results suggest that the "stable" carboxylate coordination would be the chelating bidentate one but also that the carboxylate coordination does not depend on the type of polynuclear iron complexes. The formation of the bridging coordination with $\mathrm{FeSt}_{3}$ may be explained by the following observations: i) water molecules are involved in the bridging coordination (experiments with

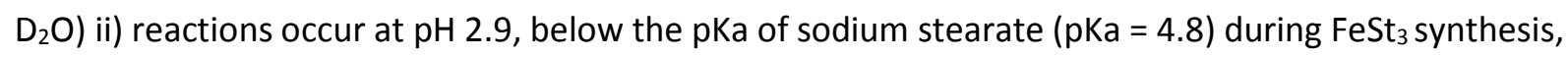
while the $\mathrm{pH}$ is at 5.8 for $\mathrm{FeSt}_{2}$ (Figure S13). There would be a competition between the coordination of stearate on iron and the acidification of stearate to form stearic acid, which could form hydrogen 
bonds with water coordinated to iron. That may explain the presence of water in the bridging coordination seen with $\mathrm{FeSt}_{3}$, even if it is not the more stable coordination.

Therefore, without the preformed large polycations (but only monomeric or dimeric species as in Figure 4) during the iron chloride solution formation, the main species are $\mathrm{Fe}_{3}\left(\mu_{3}-\mathrm{O}(\mathrm{H})\right)$-based species with a bidentate chelate coordination, while the presence of preformed larger polycations leads to the formation of $\mathrm{Fe}_{7}$ based clusters. The presence also of $\mathrm{Fe}_{3} \mathrm{O}$ based complex in $\mathrm{FeSt}_{3}$ would be explained by an uncompleted/heterogeneous condensation.

\section{DISCUSSION}

IR spectroscopy evidenced that FeSt ${ }_{2}$ displays carboxylates that are mainly coordinated by chelating bidentate bonds while for $\mathrm{FeSt}_{3}$, the main mode for carboxylate coordination is bridging bidentate. However, some bridging and chelating bidentates are also respectively observed in $\mathrm{FeSt}_{2}$ and $\mathrm{FeSt}_{3}$. Mössbauer spectrometry and EPR showed that the iron oxidation degree is mainly Fe(III) even if some Fe(II) may be observed in very freshly synthesized FeSt ${ }_{2}$. Further, these both caracterisation techniques supported the idea of $\mathrm{Fe}(\mathrm{III})$ with two different environnements. The MALDI-TOF analysis evidenced the presence of iron oxo polycations in both iron stearates. FeSt $_{2}$ would mainly consist of $\left[\mathrm{Fe}_{3}\left(\mu_{3}-\mathrm{O}\right) \mathrm{St}_{6} . \mathrm{xH}_{2} \mathrm{O}\right] \mathrm{Cl}$ while $\mathrm{FeSt}_{3}$ would be a mixture of $\left[\mathrm{Fe}_{3}\left(\mu_{3}-\mathrm{O}\right) \mathrm{St}_{6} . \mathrm{XH}_{2} \mathrm{O}\right] \mathrm{St}$, $\left[\mathrm{Fe}_{7}\left(\mu_{3^{-}}\right.\right.$ $\mathrm{O}(\mathrm{H}))_{6}\left(\mu_{2}-\mathrm{O}(\mathrm{H})\right)_{\times} \mathrm{St}_{12-2 \mathrm{x}} \mathrm{St}$ and free stearic acid. A lamellar structure for both stearates has been evidenced by SAXS, XRD and IR spectroscopy and one may suppose that the structure of iron stearates consists of planes of polycations separated by alkyl chains in different conformations. The presence of lamellar structures considering these complexes is not surprinsing since it has been reported for other metal alkanaote ${ }^{34,63,64}$. Yet, it is important to point out that the lamellar structure should be formed during the complexation of sodium stearate to iron. We have checked that stearates were not involved in micelles. Indeed, our working conditions ( $[\mathrm{NaSt}]=0.1 \mathrm{M}=30 \mathrm{~g} \cdot \mathrm{L}^{-1}$ ) are below the reported value for the Critical Micellar Concentration $(\mathrm{cmc})$ of sodium stearate ${ }^{65}\left(\mathrm{cmc}=200 \mathrm{~g} \cdot \mathrm{L}^{-1}\right)$. The observed different interlamellar distances for $\mathrm{FeSt}_{2}$ and $\mathrm{FeSt}_{3}$ could be due to their different carboxylate coordination and to the supplementary presence of $\mathrm{Fe}_{7}$ based clusters in $\mathrm{FeSt}_{3}$ by comparison with $\mathrm{FeSt}_{2}$. Moreover, the second series of peaks in the XRD pattern of FeSt ${ }_{3}$ could be attributed to free stearate/stearic acid, in accordance with the SAXS study in $\mathrm{SI}^{57}$, which showed that $\mathrm{FeSt}_{3}$ formed a three dimensional lamellar crystal, in which the signal of free stearic acid was superimposed. From all these investigations, it was concluded that $\mathrm{FeSt}_{2}$ is composed mainly of $\left[\mathrm{Fe}_{3}-\left(\mu_{3}-\mathrm{O}\right) \mathrm{St}_{6} \cdot \mathrm{xH}_{2} \mathrm{O}\right] \mathrm{Cl}$, with no (or few) free stearate (Figure 2) whereas $\mathrm{FeSt}_{3}$ is a mixture composed mainly of $\left[\mathrm{Fe}_{7}\left(\mu_{3}-\mathrm{O}(\mathrm{H})\right)_{6}\left(\mu_{2}-\mathrm{OH}\right)_{x} \mathrm{St}_{12-2 x}\right] \mathrm{St}$ (Figure 3), some $\left[\mathrm{Fe}_{3}\left(\mu_{3}-\mathrm{O}\right) \mathrm{St}_{6} . \mathrm{xH}_{2} \mathrm{O}\right] \mathrm{St}$ and free stearic acid.

Synthesis mechanism. Standard synthesis of $10 \mathrm{~nm}$ NPs by thermal decomposition of iron stearate in presence of oleic acid at $291^{\circ} \mathrm{C}$ in octylether led to NPs with a mean size of 10 and $9 \mathrm{~nm}$ with FeSt 2 and $\mathrm{FeSt}_{3}$ respectively. It was hypothetized that all complexes in $\mathrm{FeSt}_{3}$ were not decomposed at $291^{\circ} \mathrm{C}$ limitating their growth whereas quite full decomposition was observed for FeSt $2 .{ }^{66}$ The hypothesis was that as compared to $\mathrm{FeSt}_{2}$, $\mathrm{FeSt}_{3}$ displays a larger distribution of complexes with the presence of complexes with higher thermal stability. That was confirmed also during the synthesis optimisation of $20 \mathrm{~nm}$ NPs which was performed by using solvents with higher boiling point $\mathrm{t}^{33}$. Indeed, obtaining NPs 
with sizes higher than 14-15 nm was hardly achievable with $\mathrm{FeSt}_{2}$ when larger mean sizes were obtained with FeSt 3 . By considering these results and the main complexes identified in both stearates, with FeSt ${ }_{2}$ mainly constituted of $\left[\mathrm{Fe}_{3}-\left(\mu_{3}-\mathrm{O}\right) \mathrm{St}_{6}\right] \mathrm{Cl}$ and $\mathrm{FeSt}_{3}$ mainly constituted of $\left[\mathrm{Fe}_{3}\left(\mu_{3}-\mathrm{O}\right) \mathrm{St}_{6} . \mathrm{xH}_{2} \mathrm{O}\right] \mathrm{St}$ and $\left[\mathrm{Fe}_{7}\left(\mu_{3}-\mathrm{O}(\mathrm{H})\right)_{6}\left(\mu_{2}-\mathrm{O}(\mathrm{H})\right)_{x} \mathrm{St}_{12-\mathrm{x}}\right] \mathrm{St}$, one may advance that $\left[\mathrm{Fe}_{3}-\left(\mu_{3}-\mathrm{O}\right) \mathrm{St}_{6}\right]$ based complexes decomposed at lower temperature than those based on $\left[\mathrm{Fe}_{7}\left(\mu_{3}-\mathrm{O}(\mathrm{H})\right)_{6}\left(\mu_{2}-\mathrm{O}(\mathrm{H})\right)_{\times} \mathrm{St}_{12-\mathrm{x}}\right] \mathrm{St}$. Indeed, larger polynuclear Fe complexes or clusters would be more thermally stable, and so decompose at higher temperature. These observations are in accordance with DFT calculations showing a higher binding energy of the carboxylate ligand to iron clusters bonds for larger clusters ${ }^{26}$.

Furthermore, recent studies showed that the composition of the nuclei is wüstite ${ }^{25,33}$. Indeed, Fe (III) in iron stearates are reduced in the nucleation temperature range and this reduction was demonstrated to occur simultaneously with the departure of two precursor carboxylate chains. That mechanism is supported by reported works on decarboxylation catalyzed by iron (III) cations leading to a reduction in iron(+II) ${ }^{67-69}$. A Mössbauer spectrometry study in temperature of both iron stearates (detailed in ref. ${ }^{33}$ ) evidenced complexes with $\mathrm{Fe}(\mathrm{III})$ in two different environments with a proportion close to 50:50 for starting stearates. When the temperature increases, the proportion of the doublet, very similar for both stearates, with $\mathrm{IS}^{\sim} 0.5 \mathrm{~mm} . \mathrm{s}^{-1}$ and $Q \mathrm{~S}^{\sim} 0.7 \mathrm{~mm} . \mathrm{s}^{-1}$, increases with temperature at the beginning and then fluctuates depending on the iron stearate. At the end of the whole heat treatment, its proportion is 56 and $75 \%$ for $\mathrm{FeSt}_{3}$ and $\mathrm{FeSt}_{2}$ respectively. As this doublet proportion increases with the heat treatment, particularly for $\mathrm{FeSt}_{2}$ and knowing that a great part of $\mathrm{FeSt}_{2}$ is "decomposed" during the germination step, one may attribute this doublet to iron atoms surrounded by oxygen atoms, which are not provided by coordinated carboxylates. It would correspond to $\mu_{3}$-oxo bonds, which would originate from a polymerization of $\mathrm{Fe}_{3} \mathrm{OSt}_{6}$ building block to form larger polynuclear complexes (Figure 5) similarly to what was proposed above for the elaboration of polycations. Such a process would be in agreement with recent results reported by the Heyon's group ${ }^{26}$. They identified iron oleate (synthesized by phase transfer) as a $\mathrm{Fe}_{3} \mathrm{O}$ based cluster: $\left[\mathrm{Fe}_{3} \mathrm{O}\left(\mathrm{C}_{18} \mathrm{H}_{33} \mathrm{O}_{2}\right)_{6}\right]^{+}\left(\mathrm{C}_{18} \mathrm{H}_{33} \mathrm{O}_{2}\right)^{-}\left(\mathrm{C}_{18} \mathrm{H}_{33} \mathrm{O}_{2}\right)_{2}\left(\mathrm{H}_{2} \mathrm{O}\right)_{3}$. They used different conditions than ours: 1-decanol as a solvent and a reaction promotor to slow down and favour the reaction below $200^{\circ} \mathrm{C}$. They showed thus that the thermal decomposition process would not consist of a germination step followed by a growth step but it will be continuous with a growth from tri-iron oxo clusters to larger sized iron oxo clusters followed by the formation of iron oxide NPs. Their DFT calculations and experiments showed a high thermodynamic stability of large clusters. They hypothesized also that the growth of clusters is driven by esterification of ligand moities (1-decanol and oleate) strongly bounded to the tri iron $\mu_{3} 0 x 0$ core. It would lead to a hydroxyl group on iron and then complexes growth by condensation between hydroxyls group of clusters. The growth rate would be controlled by the esterification rate between oleate from iron oleate and 1-decanol, which is controlled by the temperature. Our results would support such a mechanism but we have no alcohol in our experiments, which concern only iron stearates. Therefore, considering the structure of $\mathrm{Fe}_{3} \mathrm{OSt}_{6}$ complex in Figure 5 and our results, we propose that around the germination temperature, there is a catalyzed loss of 2 stearate chains per $\mathrm{Fe}_{3} \mathrm{OSt}_{6}$ base unit (decarboxylation catalyzed by iron III) together with reduction of $\mathrm{Fe}(\mathrm{III})$ in $\mathrm{Fe}(\mathrm{II})$. Then, 
a condensation reaction between complexes occurs, providing thus a quite "coherent" nucleation mechanism as proposed in Figure 5.

1. Reduction of $\mathrm{Fe}_{3} \mathrm{O}$ based unit following the equation:
\[ \mathrm{Fe}_{3}^{I I I} \mathrm{O}(\mathrm{RCOO})_{6} \stackrel{\Delta}{\rightarrow} \mathrm{Fe}_{2}^{I I I} \mathrm{OFe} e^{I I} \mathrm{O}(\mathrm{RCOO})_{4}+R C O R+\mathrm{CO}_{2} \]

2. Condensation of two $\mathrm{Fe}_{3} \mathrm{O}$ complexes together:

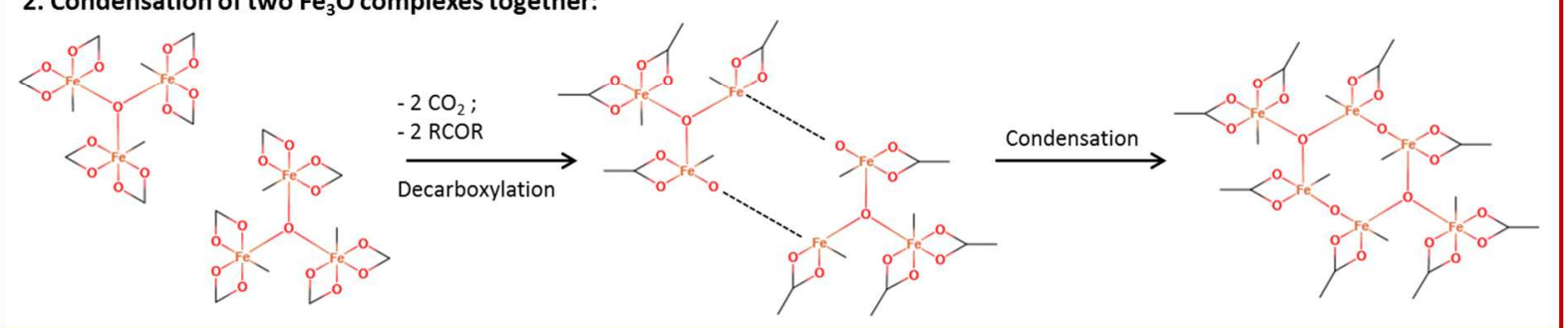

Figure 5. Proposed mechanism for the thermal decomposition of iron stearate. First, the loss of two stearate chains due to temperature is catalyzed by the reduction of iron. One oxygen of the carboxylate stays bounded to iron, which is reduced. Secondly, because of the reduction of coordination to the "surface iron", condensation of $\mathrm{Fe}_{3} \mathrm{O}_{2}$ units is possible.

As $\mathrm{FeSt}_{3}$ is composed of a mixture of large and small polynuclear complexes, the kinetics of condensation/reduction should be different allowing observing intermediate state/complexes in this process. The presence of large polynuclear complexes (by comparison with $\mathrm{FeSt}_{2}$ ) should lead to the formation of mixed valence complexes, which should be deformed complexes due to the presence of iron mixed valences. The redox character of these iron complexes should induce the whole reduction process. All these "reactions" should occur simultaneously leading thus to a continuous reduction of iron (III) complexes in iron (II) complexes.

\section{CONCLUSION}

The determination of the structure and composition of $\mathrm{FeSt}_{2}$ and $\mathrm{FeSt}_{3}$ precursors used in the thermal decomposition process has shown that iron stearates are constituted of iron based polynuclear complexes. $\mathrm{FeSt}_{2}$ consists mainly of $\left[\mathrm{Fe}_{3}\left(\mu_{3}-\mathrm{O}\right) \mathrm{St}_{6} . \mathrm{xH}_{2} \mathrm{O}\right] \mathrm{Cl}$, when $\mathrm{FeSt}_{3}$ is composed of $\left[\mathrm{Fe}_{3}\left(\mu_{3}-\mathrm{O}\right) \mathrm{St}_{6} \cdot \mathrm{xH}_{2} \mathrm{O}\right] \mathrm{St}$ but also of larger polynuclear iron complexes: $\left[\mathrm{Fe}_{7}\left(\mu_{3}-\mathrm{O}(\mathrm{H})\right)_{6}\left(\mu_{2}-\mathrm{O}(\mathrm{H})\right)_{x} \mathrm{St}_{12-2 x}\right]$ and of free stearic acid. The formation of bigger polynuclear complexes with $\mathrm{FeSt}_{3}$ was related to higher hydrolysis and condensation rates within the iron (III) chloride solution compared to the iron (II) chloride solution. The polynuclear complexes with high iron content would decompose at higher temperature. Thanks to these different experiments, the presence of iron-based complexes with different thermal stabilities was thus confirmed. The investigation of the nucleation mechanism showed, that the formation of nuclei would result from a continous growth of polynuclear complexes resulting from two reactions; a first reaction consisting in a decarboxylation reaction catalyzed by iron (III) cations leading also to a reduction in iron(II) and then, a condensation reaction between such activated polynuclear complexes leading thus to $\mathrm{FeO}$ nuclei. With $\mathrm{FeSt}_{3}$, the bigger polynuclear complexes thermallly more stable should contribute to the further grain growth. Such studies pave the 
way towards a better control of the NPs design (in particular, their shape and size) by tuning of the polynuclear complex composition.

Acknowledgments. The authors thank for financial and personal supports the "NANOTRANSMED» project which is co-funded by the European Regional Development Fund (ERDF) in the framework of the INTERREG V Upper Rhine program «Transcending borders with every project». The " NANOTRANSMED » project is co-funded by the Swiss Confederation and the Swiss cantons of Aargau, Basel-Landschaft andBasel-Stadt.

Supporting information. EPR spectroscopy study; XRD patterns, SEM and TEM images, SAX patterns and IR spectra of FeSt ${ }_{2}$ and $\mathrm{FeSt}_{3}$; study on the attribution of IR carboxylate bands; MALDI-TOF study and TGA curves analysis of FeSt ${ }_{2}$ and $\mathrm{FeSt}_{3}$; Investigation of the hydrolysis pathway of iron chlorides; study on the Influence of the synthesis conditions on $\mathrm{FeSt}_{3}$ structure. 


\section{References}

(1) Cichy, B.; Kwiecień, J.; Piątkowska, M.; Kużdżał, E.; Gibas, E.; Rymarz, G. Polyolefin OxoDegradation Accelerators - a New Trend to Promote Environmental Protection. Polish Journal of Chemical Technology 2010, 12 (4). https://doi.org/10.2478/v10026-0100049-3.

(2) Park, J.; An, K.; Hwang, Y.; Park, J.-G.; Noh, H.-J.; Kim, J.-Y.; Park, J.-H.; Hwang, N.-M.; Hyeon, T. Ultra-Large-Scale Syntheses of Monodisperse Nanocrystals. Nat Mater 2004, 3 (12), 891-895. https://doi.org/10.1038/nmat1251.

(3) Sun, S.; Zeng, H.; Robinson, D. B.; Raoux, S.; Rice, P. M.; Wang, S. X.; Li, G. Monodisperse MFe2O4 (M = Fe, Co, Mn) Nanoparticles. J. Am. Chem. Soc. 2004, 126 (1), 273-279. https://doi.org/10.1021/ja0380852.

(4) Sun, S.; Zeng, H. Size-Controlled Synthesis of Magnetite Nanoparticles. J. Am. Chem. Soc. 2002, 124 (28), 8204-8205.

(5) Laurent, S.; Forge, D.; Port, M.; Roch, A.; Robic, C.; Vander Elst, L.; Muller, R. N. Magnetic Iron Oxide Nanoparticles: Synthesis, Stabilization, Vectorization, Physicochemical Characterizations, and Biological Applications. Chemical Reviews 2008, 108 (6), 20642110. https://doi.org/10.1021/cr068445e.

(6) Na, H. B.; Song, I. C.; Hyeon, T. Inorganic Nanoparticles for MRI Contrast Agents. Advanced Materials 2009, 21 (21), 2133-2148. https://doi.org/10.1002/adma.200802366.

(7) Kim, D.; Kim, J.; Park, Y. I.; Lee, N.; Hyeon, T. Recent Development of Inorganic Nanoparticles for Biomedical Imaging. ACS Cent. Sci. 2018, 4(3), 324-336. https://doi.org/10.1021/acscentsci.7b00574.

(8) Demortière, A.; Panissod, P.; Pichon, B. P.; Pourroy, G.; Guillon, D.; Donnio, B.; Bégin-Colin, S. Size-Dependent Properties of Magnetic Iron Oxide Nanocrystals. Nanoscale 2011, 3 (1), 225-232. https://doi.org/10.1039/C0NR00521E.

(9) Baaziz, W.; Pichon, B. P.; Fleutot, S.; Liu, Y.; Lefevre, C.; Greneche, J.-M.; Toumi, M.; Mhiri, T.; Begin-Colin, S. Magnetic Iron Oxide Nanoparticles: Reproducible Tuning of the Size and Nanosized-Dependent Composition, Defects, and Spin Canting. J. Phys. Chem. C 2014, 118 (7), 3795-3810. https://doi.org/10.1021/jp411481p.

(10) Kovalenko, M. V.; Bodnarchuk, M. I.; Lechner, R. T.; Hesser, G.; Schäffler, F.; Heiss, W. Fatty Acid Salts as Stabilizers in Size- and Shape-Controlled Nanocrystal Synthesis: The Case of Inverse Spinel Iron Oxide. J. Am. Chem. Soc. 2007, 129 (20), 6352-6353. https://doi.org/10.1021/ja0692478.

(11) Pichon, B. P.; Gerber, O.; Lefevre, C.; Florea, I.; Fleutot, S.; Baaziz, W.; Pauly, M.; Ohlmann, M.; Ulhaq, C.; Ersen, O.; Pierron-Bohnes, V.; Panissod, P.; Drillon, M.; Begin-Colin, S. Microstructural and Magnetic Investigations of Wüstite-Spinel Core-Shell Cubic-Shaped Nanoparticles. Chem. Mater. 2011, 23(11), 2886-2900. https://doi.org/10.1021/cm2003319.

(12) Kim, D.; Lee, N.; Park, M.; Kim, B. H.; An, K.; Hyeon, T. Synthesis of Uniform Ferrimagnetic Magnetite Nanocubes. Journal of the American Chemical Society 2009, 131 (2), 454-455. https://doi.org/10.1021/ja8086906.

(13) van Embden, J.; Chesman, A. S. R.; Jasieniak, J. J. The Heat-Up Synthesis of Colloidal Nanocrystals. Chemistry of Materials 2015, 27 (7), 2246-2285. https://doi.org/10.1021/cm5028964.

(14) Redl, F. X.; Black, C. T.; Papaefthymiou, G. C.; Sandstrom, R. L.; Yin, M.; Zeng, H.; Murray, C. B.; O'Brien, S. P. Magnetic, Electronic, and Structural Characterization of Nonstoichiometric Iron Oxides at the Nanoscale. J. Am. Chem. Soc. 2004, 126(44), 1458314599. https://doi.org/10.1021/ja046808r.

(15) Wetterskog, E.; Tai, C.-W.; Grins, J.; Bergström, L.; Salazar-Alvarez, G. Anomalous Magnetic Properties of Nanoparticles Arising from Defect Structures: Topotaxial Oxidation of Fe ${ }_{1-x}$ O|Fe ${ }_{3-\delta} \mathrm{O}_{4}$ Core|Shell Nanocubes to Single-Phase Particles. ACS Nano 2013, 7(8), 71327144. https://doi.org/10.1021/nn402487q. 
(16) Lak, A.; Kraken, M.; Ludwig, F.; Kornowski, A.; Eberbeck, D.; Sievers, S.; Litterst, F. J.; Weller, H.; Schilling, M. Size Dependent Structural and Magnetic Properties of FeO-Fe304 Nanoparticles. Nanoscale 2013, 5(24), 12286. https://doi.org/10.1039/c3nr04562e.

(17) Hai, H. T.; Yang, H. T.; Kura, H.; Hasegawa, D.; Ogata, Y.; Takahashi, M.; Ogawa, T. Size Control and Characterization of Wustite (Core)/Spinel (Shell) Nanocubes Obtained by Decomposition of Iron Oleate Complex. Journal of Colloid and Interface Science 2010, 346 (1), 37-42. https://doi.org/10.1016/j.jcis.2010.02.025.

(18) Sun, X.; Frey Huls, N.; Sigdel, A.; Sun, S. Tuning Exchange Bias in Core/Shell FeO/Fe ${ }_{3} \mathrm{O}_{4}$ Nanoparticles. Nano Letters 2012, 12 (1), 246-251. https://doi.org/10.1021/nl2034514.

(19) Walter, A.; Billotey, C.; Garofalo, A.; Ulhaq-Bouillet, C.; Lefèvre, C.; Taleb, J.; Laurent, S.; Vander Elst, L.; Muller, R. N.; Lartigue, L.; Gazeau, F.; Felder-Flesch, D.; Begin-Colin, S. Mastering the Shape and Composition of Dendronized Iron Oxide Nanoparticles To Tailor Magnetic Resonance Imaging and Hyperthermia. Chem. Mater. 2014, 26 (18), 5252-5264. https://doi.org/10.1021/cm5019025.

(20) Baaziz, W.; Pichon, B. P.; Liu, Y.; Grenèche, J.-M.; Ulhaq-Bouillet, C.; Terrier, E.; Bergeard, N.; Halté, V.; Boeglin, C.; Choueikani, F.; Toumi, M.; Mhiri, T.; Begin-Colin, S. Tuning of Synthesis Conditions by Thermal Decomposition toward Core-Shell Co ${ }_{x} \mathrm{Fe}_{1-x}$ O@Co ${ }_{y}$ $\mathrm{Fe}_{3-y} \mathrm{O}_{4}$ and $\mathrm{CoFe}_{2} \mathrm{O}_{4}$ Nanoparticles with Spherical and Cubic Shapes. Chemistry of Materials 2014, 26(17), 5063-5073. https://doi.org/10.1021/cm502269s.

(21) Baaziz, W.; Pichon, B. P.; Lefevre, C.; Ulhaq-Bouillet, C.; Greneche, J.-M.; Toumi, M.; Mhiri, T.; Bégin-Colin, S. High Exchange Bias in Fe3-804@CoO Core Shell Nanoparticles Synthesized by a One-Pot Seed-Mediated Growth Method. J. Phys. Chem. C2013, 117 (21), 11436-11443. https://doi.org/10.1021/jp402823h.

(22) Shipway, A. N.; Katz, E.; Willner, I. Nanoparticle Arrays on Surfaces for Electronic, Optical, and Sensor Applications. Chemphyschem 2000, 1 (1), 18-52. https://doi.org/10.1002/1439-7641(20000804)1:1<18::AID-CPHC18>3.0.CO;2-L.

(23) Herman, D. A. J.; Cheong-Tilley, S.; McGrath, A. J.; McVey, B. F. P.; Lein, M.; Tilley, R. D. How to Choose a Precursor for Decomposition Solution-Phase Synthesis: The Case of Iron Nanoparticles. Nanoscale 2015, 7(14), 5951-5954. https://doi.org/10.1039/C5NR00718F.

(24) Lassenberger, A.; Grünewald, T. A.; van Oostrum, P. D. J.; Rennhofer, H.; Amenitsch, H.; Zirbs, R.; Lichtenegger, H. C.; Reimhult, E. Monodisperse Iron Oxide Nanoparticles by Thermal Decomposition: Elucidating Particle Formation by Second-Resolved in Situ Small-Angle X-Ray Scattering. Chem. Mater. 2017, 29 (10), 4511-4522. https://doi.org/10.1021/acs.chemmater.7b01207.

(25) Feld, A.; Weimer, A.; Kornowski, A.; Winckelmans, N.; Merkl, J.-P.; Kloust, H.; Zierold, R.; Schmidtke, C.; Schotten, T.; Riedner, M.; Bals, S.; Weller, H. Chemistry of Shape-Controlled Iron Oxide Nanocrystal Formation. ACS Nano 2019, 13 (1), 152-162. https://doi.org/10.1021/acsnano.8b05032.

(26) Chang, H.; Kim, B. H.; Jeong, H. Y.; Moon, J. H.; Park, M.; Shin, K.; Chae, S. I.; Lee, J.; Kang, T.; Choi, B. K.; Yang, J.; Bootharaju, M. S.; Song, H.; An, S. H.; Park, K. M.; Oh, J. Y.; Lee, H.; Kim, M. S.; Park, J.; Hyeon, T. Molecular-Level Understanding of Continuous Growth from IronOxo Clusters to Iron Oxide Nanoparticles. J. Am. Chem. Soc. 2019, 141 (17), 7037-7045. https://doi.org/10.1021/jacs.9b01670.

(27) Bronstein, L. M.; Huang, X.; Retrum, J.; Schmucker, A.; Pink, M.; Stein, B. D.; Dragnea, B. Influence of Iron Oleate Complex Structure on Iron Oxide Nanoparticle Formation. Chem. Mater. 2007, 19(15), 3624-3632. https://doi.org/10.1021/cm062948j.

(28) Sharifi Dehsari, H.; Heidari, M.; Halda Ribeiro, A.; Tremel, W.; Jakob, G.; Donadio, D.; Potestio, R.; Asadi, K. Combined Experimental and Theoretical Investigation of Heating Rate on Growth of Iron Oxide Nanoparticles. Chem. Mater. 2017, 29 (22), 9648-9656. https://doi.org/10.1021/acs.chemmater.7b02872.

(29) Cotin, G.; Kiefer, C.; Perton, F.; Ihiawakrim, D.; Blanco-Andujar, C.; Moldovan, S.; Lefevre, C.; Ersen, O.; Pichon, B.; Mertz, D.; Bégin-Colin, S. Unravelling the Thermal Decomposition 
Parameters for The Synthesis of Anisotropic Iron Oxide Nanoparticles. Nanomaterials 2018, 8 (11), 881. https://doi.org/10.3390/nano8110881.

(30) Cotin, G.; Kiefer, C.; Perton, F.; Boero, M.; Özdamar, B.; Bouzid, A.; Ori, G.; Massobrio, C.; Begin, D.; Pichon, B.; Mertz, D.; Begin-Colin, S. Evaluating the Critical Roles of Precursor Nature and Water Content When Tailoring Magnetic Nanoparticles for Specific Applications. ACS Applied Nano Materials 2018, 1 (8), 4306-4316. https://doi.org/10.1021/acsanm.8b01123.

(31) Bronstein, L. M.; Atkinson, J. E.; Malyutin, A. G.; Kidwai, F.; Stein, B. D.; Morgan, D. G.; Perry, J. M.; Karty, J. A. Nanoparticles by Decomposition of Long Chain Iron Carboxylates: From Spheres to Stars and Cubes. Langmuir 2011, 27(6), 3044-3050. https://doi.org/10.1021/la104686d.

(32) Hufschmid, R.; Arami, H.; Ferguson, R. M.; Gonzales, M.; Teeman, E.; Brush, L. N.; Browning, N. D.; Krishnan, K. M. Synthesis of Phase-Pure and Monodisperse Iron Oxide Nanoparticles by Thermal Decomposition. Nanoscale 2015, 7(25), 11142-11154. https://doi.org/10.1039/c5nr01651g.

(33) Cotin, G.; Perton, F.; Petit, C.; Sall, S.; Kiefer, C.; Begin, V.; Pichon, B.; Lefevre, C.; Mertz, D.; Greneche, J.-M.; Begin-Colin, S. Harnessing Composition of Iron Oxide Nanoparticle: Impact of Solvent-Mediated Ligand-Ligand Interaction and Competition between Oxidation and Growth Kinetics. Chemistry of Materials 2020, 32 (21), 9245-9259. https://doi.org/10.1021/acs.chemmater.0c03041.

(34) Nelson, P. N.; Taylor, R. A. Theories and Experimental Investigations of the Structural and Thermotropic Mesomorphic Phase Behaviors of Metal Carboxylates. Applied

Petrochemical Research 2014, 4 (3), 253-285. https://doi.org/10.1007/s13203-0140044-3.

(35) Doyle, F. M. The Physical Chemistry of the Precipitation Stripping Process for Removing Iron (III) from Carboxylate Solutions with Dilute Sulphuric Acid. Hydrometallurgy 1988, 20(1), 65-85. https://doi.org/10.1016/0304-386X(88)90027-8.

(36) Doyle, F. M.; Pouillon, D.; Villegas, E. A. Solvent Extraction of Metals with Carboxylic Acids - Coextraction of Base Metals with Fe(III) and Characterization of Selected Carboxylate Complexes. Hydrometallurgy 1988, 19(3), 289-308. https://doi.org/10.1016/0304386X(88)90036-9.

(37) Doyle, F. M.; Monhemius, A. J. Kinetics and Mechanisms of Precipitation of Nickel Ferrite by Hydrolytic Stripping of Iron (III)-Nickel Carboxylate Solutions. Hydrometallurgy 1994, 35(2), 251-265. https://doi.org/10.1016/0304-386X(94)90054-X.

(38) Abrahamson, H. B.; Lukaski, H. C. Synthesis and Characterization of Iron Stearate Compounds. Journal of Inorganic Biochemistry 1994, 54 (2), 115-130. https://doi.org/10.1016/0162-0134(94)80025-1.

(39) Nakamoto, T.; Katada, M.; Sano, H. Mixed-Valence States of Iron Long-Chain Carboxylate Complexes. Inorganica Chimica Acta 1999, 291 (1-2), 127-135. https://doi.org/10.1016/S0020-1693(99)00124-3.

(40) Park, J.; An, K.; Hwang, Y.; Park, J.-G.; Noh, H.-J.; Kim, J.-Y.; Park, J.-H.; Hwang, N.-M.; Hyeon, T. Ultra-Large-Scale Syntheses of Monodisperse Nanocrystals. Nature Materials 2004, 3 (12), 891-895. https://doi.org/10.1038/nmat1251.

(41) Shweky, I.; Pence, L. E.; Papaefthymiou, G. C.; Sessoli, R.; Yun, J. W.; Bino, A.; Lippard, S. J. A Hexairon(III) Complex with Three Nonplanar $\eta^{2}-\mu^{4}$-Peroxo Ligands Bridging Two Basic Iron Acetate Units. Journal of the American Chemical Society 1997, 119 (5), 1037-1042. https://doi.org/10.1021/ja963062r.

(42) Baranwal, B. P.; Gupta, T. Synthesis and Spectral Characterization of Some Oxo-Centered, Trinuclear Mixed-Valence Iron Thiocarboxylates. Spectrochimica Acta Part A: Molecular and Biomolecular Spectroscopy 2003, 59(4), 859-865. https://doi.org/10.1016/S13861425(02)00232-9.

(43) Nakamoto, T.; Katada, M.; Sano, H. Synthesis and Mössbauer Spectroscopic Studies of OxoCentered Mixed-Valence Trinuclear Iron Carboxylates with Long Chain Fatty Acid Anions. Chem. Lett. 1990, 19(2), 225-228. https://doi.org/10.1246/cl.1990.225. 
(44) Yoshida, M.; Nakamoto, T.; Kawata, S.; Katada, M.; Sano, H. Dependence of Intramolecular Valence Delocalization on Crystal Form in Mixed-Valence Trinuclear Iron Phenylacetate [Fe2IIIFeIIO(PhCH2CO2)6(Py)3]. Hyperfine Interact 1994, 84 (1), 583-588. https://doi.org/10.1007/BF02060713.

(45) Gütlich, P.; Bill, E.; Trautwein, A. Mössbauer Spectroscopy and Transition Metal Chemistry: Fundamentals and Application; Springer: Berlin ; Heidelberg, 2011.

(46) Walker, F. A. Models of the Bis-Histidine-Ligated Electron-Transferring Cytochromes. Comparative Geometric and Electronic Structure of Low-Spin Ferro- and Ferrihemes. Chemical Reviews 2004, 104 (2), 589-615. https://doi.org/10.1021/cr020634j.

(47) Rardin, R. L.; Poganiuch, P.; Bino, A.; Goldberg, D. P.; Tolman, W. B.; Liu, S.; Lippard, S. J. Synthesis and Characterization of Novel Trinuclear Iron(II) and Manganese(II) Carboxylate Complexes: Structural Trends in Low Valent Iron and Manganese Carboxylates. Journal of the American Chemical Society 1992, 114 (13), 5240-5249. https://doi.org/10.1021/ja00039a041.

(48) Jones, N. O.; Reddy, B. V.; Rasouli, F.; Khanna, S. N. Structural Growth in Iron Oxide Clusters: Rings, Towers, and Hollow Drums. Phys. Rev. B 2005, 72 (16), 165411. https://doi.org/10.1103/PhysRevB.72.165411.

(49) Ohshimo, K.; Komukai, T.; Moriyama, R.; Misaizu, F. Isomer Separation of Iron Oxide Cluster Cations by Ion Mobility Mass Spectrometry. J. Phys. Chem. A 2014, 118(22), 3899-3905. https://doi.org/10.1021/jp5015687.

(50) Jolivet, J.-P.; Henry, M.; Livage, J. De la Solution à I'oxyde: condensation des cations en solution aqueuse, chimie de surface des oxydes; InterEditions : CNRS Editions: Paris, 1994.

(51) Lippard, S. J. Oxo-Bridged Polyiron Centers in Biology and Chemistry. Angewandte Chemie International Edition in English 1988, $27(3)$, 344-361. https://doi.org/10.1002/anie.198803441.

(52) Heath, S. L.; Powell, A. K. The Trapping of Iron Hydroxide Units by the Ligand "Heidi": Two New Hydroxo(Oxo)Iron Clusters Containing 19 and 17 Iron Atoms. Angewandte Chemie International Edition in English 1992, 31 (2), 191-193. https://doi.org/10.1002/anie.199201911.

(53) Deacon, G. B.; Phillips, R. J. Relationships between the Carbon-Oxygen Stretching Frequencies of Carboxylato Complexes and the Type of Carboxylate Coordination. Coordination Chemistry Reviews 1980, 33 (3), 227-250. https://doi.org/10.1016/S00108545(00)80455-5.

(54) Ruíz, M.; Perelló, L.; Server-Carrió, J.; Ortiz, R.; García-Granda, S.; Díaz, M. R.; Cantón, E. Cinoxacin Complexes with Divalent Metal Ions. Spectroscopic Characterization. Crystal Structure of a New Dinuclear Cd(II) Complex Having Two Chelate-Bridging Carboxylate Groups. Antibacterial Studies. Journal of Inorganic Biochemistry 1998, 69 (4), 231-239. https://doi.org/10.1016/S0162-0134(97)10028-9.

(55) Sen, S.; Kumar Saha, M.; Kundu, P.; Mitra, S.; Kruger, C.; Bruckmann, J. Synthesis and Structure of a Heptacoordinated Cadmium(II) Complex. Inorganica Chimica Acta 1999, 288(1), 118-121. https://doi.org/10.1016/S0020-1693(99)00048-1.

(56) Barja, B.; Baggio, R.; Garland, M. T.; Aramendia, P. F.; Peña, O.; Perec, M. Crystal Structures and Luminescent Properties of Terbium(III) Carboxylates. Inorganica Chimica Acta 2003, 346, 187-196. https://doi.org/10.1016/S0020-1693(02)01429-9.

(57) Cotin, G. Nouvelles stratégies vers la synthèse de nanoparticules magnétiques multifonctionnelles innovantes combinant imagerie par IRM et/ou thérapie par hyperthermie magnétique. 344.

(58) Jolivet, J.-P.; Chanéac, C.; Tronc, E. Iron Oxide Chemistry. From Molecular Clusters to Extended Solid Networks. Chem. Commun. 2004, No. 5, 477-483. https://doi.org/10.1039/B304532N.

(59) Rose, A. L.; Bligh, M. W.; Collins, R. N.; Waite, T. D. Resolving Early Stages of Homogeneous Iron(III) Oxyhydroxide Formation from Iron(III) Nitrate Solutions at PH 3 Using Time- 
Resolved SAXS. Langmuir 2014, 30 (12), 3548-3556.

https://doi.org/10.1021/la404712r.

(60) Bottero, J. Yves.; Tchoubar, D.; Arnaud, M.; Quienne, P. Partial Hydrolysis of Ferric Nitrate Salt. Structural Investigation by Dynamic Light Scattering and Small-Angle $\mathrm{x}$-Ray Scattering. Langmuir 1991, 7 (7), 1365-1369. https://doi.org/10.1021/la00055a013.

(61) Jolivet, J.-P.; Tronc, E.; Chanéac, C. Iron Oxides: From Molecular Clusters to Solid. A Nice Example of Chemical Versatility. Comptes Rendus Geoscience 2006, 338(6), 488-497. https://doi.org/10.1016/j.crte.2006.04.014.

(62) Santoyo Salazar, J.; Perez, L.; de Abril, O.; Truong Phuoc, L.; Ihiawakrim, D.; Vazquez, M.; Greneche, J.-M.; Begin-Colin, S.; Pourroy, G. Magnetic Iron Oxide Nanoparticles in 10-40 Nm Range: Composition in Terms of Magnetite/Maghemite Ratio and Effect on the Magnetic Properties. Chem. Mater. 2011, 23 (6), 1379-1386. https://doi.org/10.1021/cm103188a.

(63) Marques, E. F.; Burrows, H. D.; Miguel, M. da G. The Structure and Thermal Behaviour of Some Long Chain Cerium(III) Carboxylates. Journal of the Chemical Society, Faraday Transactions 1998, 94 (12), 1729-1736. https://doi.org/10.1039/A800326B.

(64) Ishioka, T.; Maeda, K.; Watanabe, I.; Kawauchi, S.; Harada, M. Infrared and XAFS Study on Structure and Transition Behavior of Zinc Stearate. Spectrochimica Acta Part A: Molecular and Biomolecular Spectroscopy 2000, 56(9), 1731-1737. https://doi.org/10.1016/S1386-1425(00)00225-0.

(65) McBain, J. W.; Vold, R. D.; Frick, M. A Phase Rule Study of the System Sodium StearateWater. J. Phys. Chem. 1940, 44 (9), 1013-1024. https://doi.org/10.1021/j150405a001.

(66) Cotin, G.; Kiefer, C.; Perton, F.; Boero, M.; Özdamar, B.; Bouzid, A.; Ori, G.; Massobrio, C.; Begin, D.; Pichon, B.; Mertz, D.; Begin-Colin, S. Evaluating the Critical Roles of Precursor Nature and Water Content When Tailoring Magnetic Nanoparticles for Specific Applications. ACS Appl. Nano Mater. 2018, 1 (8), 4306-4316. https://doi.org/10.1021/acsanm.8b01123.

(67) Davis, R.; Schultz, H. P. Studies of Thermal Decarboxylation of Iron Carboxylates. I. Preparation of Symmetrical Aliphatic Ketones 1,2. The Journal of Organic Chemistry 1962, 27(3), 854-857. https://doi.org/10.1021/jo01050a039.

(68) Gooßen, L. J.; Mamone, P.; Oppel, C. Catalytic Decarboxylative Cross-Ketonisation of Aryland Alkylcarboxylic Acids Using Magnetite Nanoparticles. Advanced Synthesis \& Catalysis 2011, 353(1), 57-63. https://doi.org/10.1002/adsc.201000429.

(69) Pérez, N.; López-Calahorra, F.; Labarta, A.; Batlle, X. Reduction of Iron by Decarboxylation in the Formation of Magnetite Nanoparticles. Physical Chemistry Chemical Physics 2011, 13(43), 19485. https://doi.org/10.1039/c1cp20457b. 


\section{For Table of Contents Only}

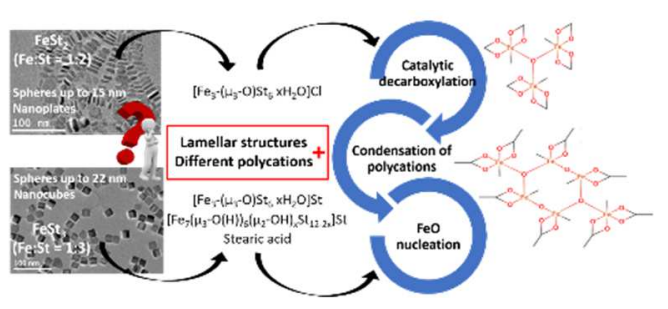

The studies of the structure and composition of iron stearate precursors and of the nucleation step allow explaining the different characteristics of nanoparticles synthesized using these precursors. Such control of precursor design paves the way towards a better control of the nanoparticles design. 


\section{SUPPLEMENTARY INFORMATION}

The iron stearate structures: an original tool for nanoparticles design

Francis Perton ${ }^{1,2, \Psi}$, Geoffrey Cotin ${ }^{1,2, \Psi}$, , Céline Kiefer ${ }^{1,2}$, Jean-Marc Strub ${ }^{3}$, Sarah Cianferani ${ }^{3}$, JeanMarc Greneche ${ }^{4}$, Nathalie Parizel ${ }^{5,6,7}$, Benoît Heinrich ${ }^{1}$, Benoit Pichon ${ }^{1,2}$, Damien Mertz ${ }^{1,2}$, Sylvie Begin-Colin ${ }^{1,2^{*}}$

${ }^{1}$ Université de Strasbourg, CNRS, Institut de Physique et Chimie des Matériaux de Strasbourg, UMR 7504, F-67034 Strasbourg, France

${ }^{2}$ Labex CSC, Fondation IcFRC/Université de Strasbourg, 8 allée Gaspard Monge BP 70028 F - 67083 Strasbourg Cedex.

${ }^{3}$ Laboratoire de Spectrométrie de Masse BioOrganique, Université Strasbourg, CNRS, IPHC UMR 7178, F-67000 Strasbourg, France

${ }^{4}$ Institut des Molécules et Matériaux du Mans IMMM UMR CNRS 6283, Université du Maine, Avenue Olivier Messiaen, 72085 Le Mans Cedex 9, France

${ }^{5}$ Institut de Chimie de Strasbourg (UMR 7177, CNRS Unistra)

${ }^{6}$ Université de Strasbourg, 4 rue Blaise Pascal, CS 90032, F-67081 Strasbourg - France

${ }^{7}$ French EPR Federation of Research (Reseau National de Rpe Interdisciplinaire, RENARD), Fédération IR-RPE CNRS 3443, 67000 Strasbourg, France

Corresponding author email address : sylvie.begin@unistra.fr

\section{EPR spectroscopy}

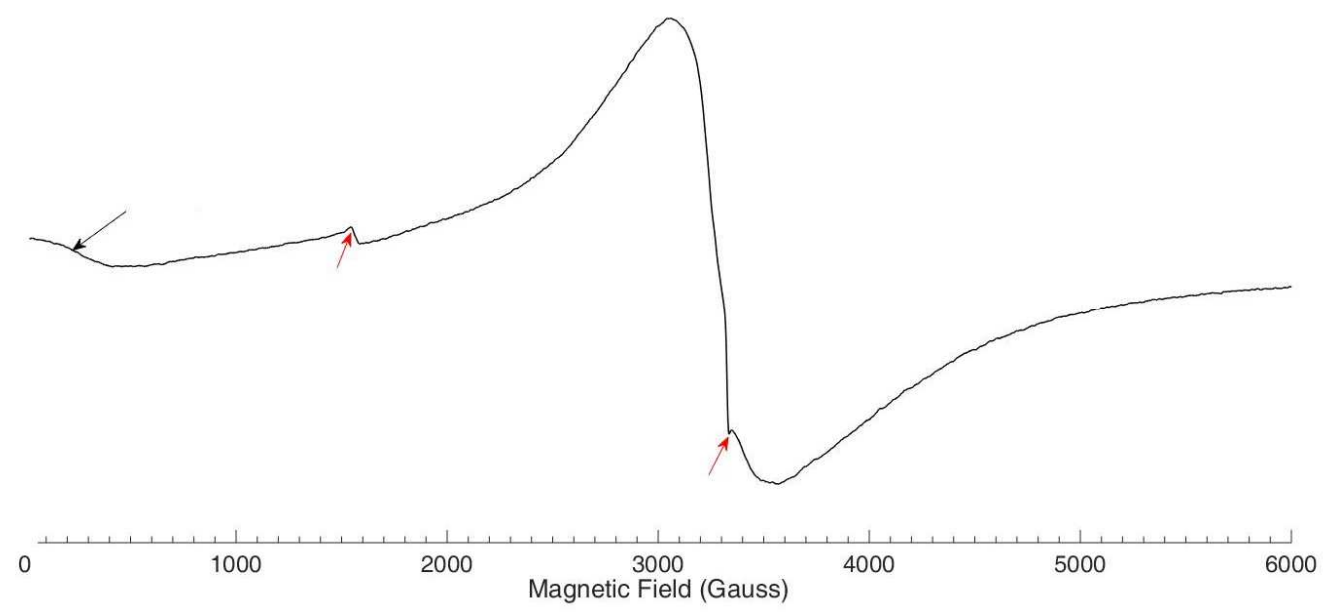

Figure S1. X-band EPR spectrum of powder sample of FeSt 2 recorded at $6 \mathrm{~K}$ 

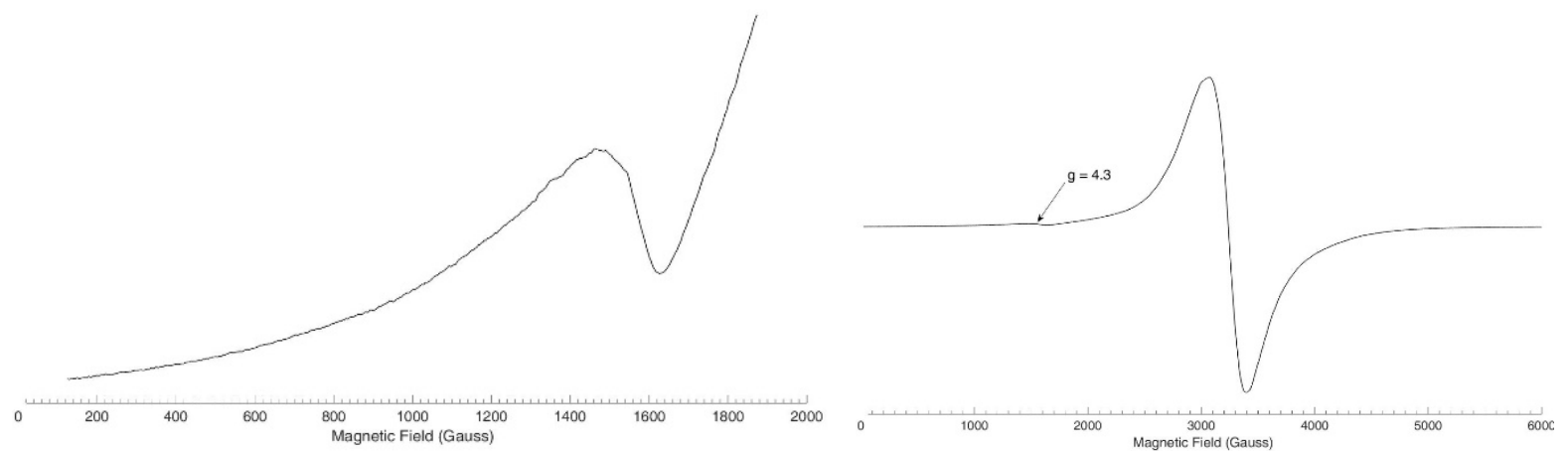

Figure S2. Right: X-band EPR spectrum of the powder sample of FeSt $\mathrm{F}_{3}$ recorded at $6 \mathrm{~K}$ - left: enlargement around $\mathrm{g}=4.3$

We have recorded continuous wave X-band EPR spectra at $6 \mathrm{~K}$ of Fe stearate powder samples to identify their spin state.

The spectra of the two samples show an intense line around $g=2$ and weaker signals at lower fields. In particular, the signal at $g=4.3$ observed for FeSt3 directs us towards the high spin state of Fe ${ }^{\text {III }}(S=5 / 2)$ and its three Kramers doublets $( \pm 1 / 2 ; \pm 3 / 2 ; \pm 5 / 2)$. In this system, the ground state splits into three doublets due to spin-orbit coupling with the excited states.

The representative Hamiltonian of the system is:

$$
H=\left[S_{Z}^{2}-\frac{1}{3} S(S+1)\right]+\frac{E}{D}\left(S_{X}^{2}-S_{Y}^{2}\right)+\frac{1}{D} \beta \boldsymbol{H} \cdot \boldsymbol{g} \cdot \boldsymbol{S}
$$

where $S^{2}=S_{X}^{2}+S_{Y}^{2}+S_{Z}^{2}$ and $E$ and $D$ are zero-field splitting $(Z F S)$ parameters.

This interaction scheme predicts a signal at $\mathrm{g}=4.3$ corresponding to the intermediate Kramers doublet $( \pm 3 / 2)$ having a maximum rhombicity characterized by the ratio $E / D=1 / 3$. It represents a distorted octahedral site of Fe'll. The $g=2$ line should then be attributed to the axial $( \pm 1 / 2)$ doublet. Another component (resonant field perpendicular to the D component of the ZFS) could be observed at $g=6$ for this $( \pm 1 / 2)$ doublet. Whereas it obviously does not occur for FeSt3, it cannot be discarded for FeSt2 where it could be obscured by the strong underlying component. As already mentionned, FeSt2 EPR spectra exhibit broader lines than FeSt3. We suggest for FeSt2 some disorder which is responsible for the coexistence of several species that we cannot separate. The very low-field hump (black arrow) could reveal a high-spin ( $S=2) \mathrm{Fe}^{\prime \prime}$ species. Although such integer spin species is expected to be EPR silent at conventional fields and frequencies (X-band, $9.31 \mathrm{GHz}$ ), disorder may induce a distribution of ZFS components, which in turn may allow the observation of such so-called "forbidden" transitions. Note that the small peaks observed on the FeSt2 spectrum at 1546 and $3334 \mathrm{G}$ (red arrows) are due to impurities coming from the cryostat. They appear due to the required strong amplification to observe the sample signal.

As a summary, we have identified for FeSt2 one $\mathrm{Fe}^{\prime \prime \prime}(\mathrm{S}=5 / 2)$ and one $\mathrm{Fe}^{\prime \prime}(\mathrm{S}=2)$ with certainly one or more unidentified species, and for FeSt3, two Fe"'( $(\mathrm{S}=5 / 2)$ corresponding to octahedral sites with more or less distorted axial symmetry. 

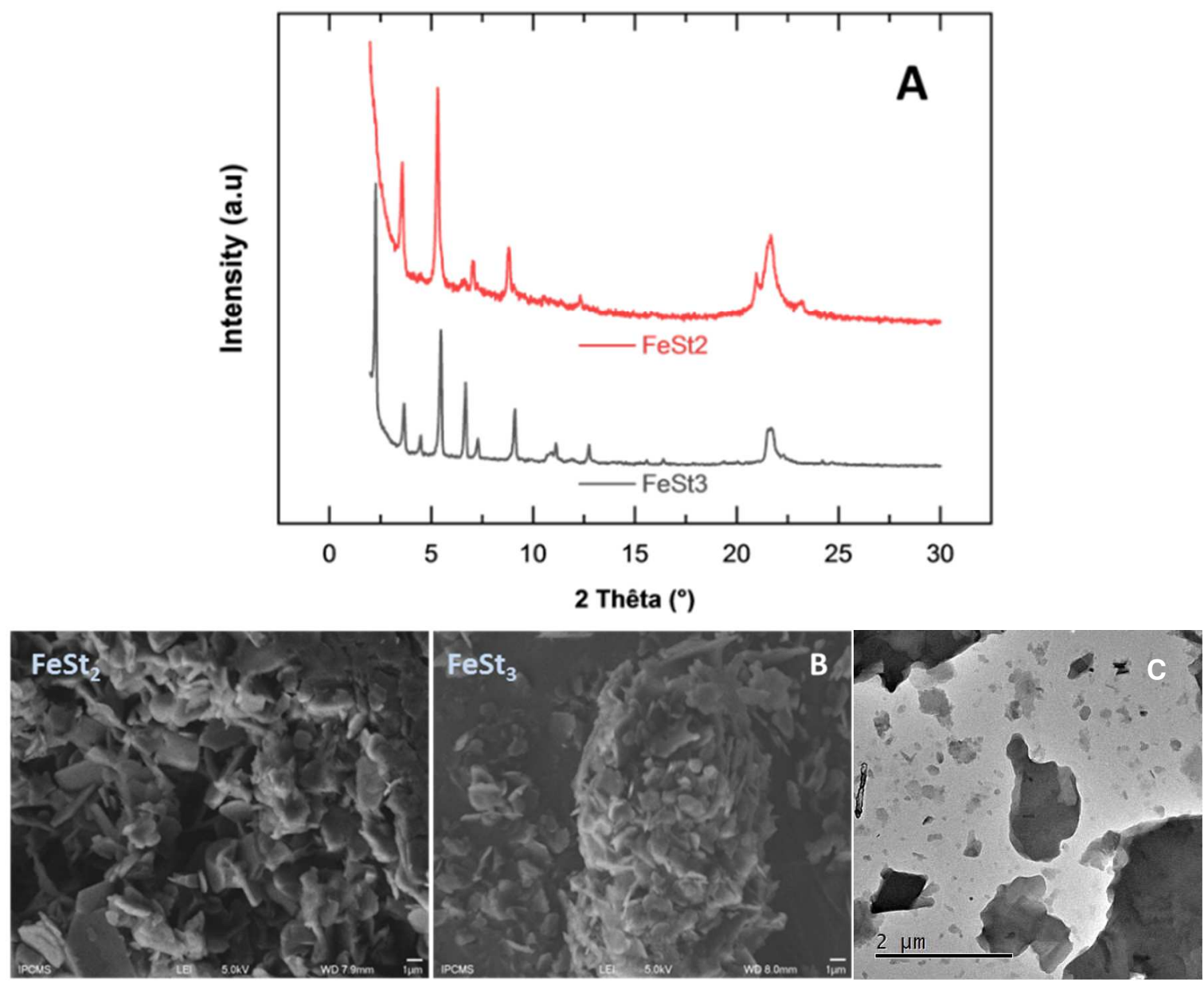

(D)
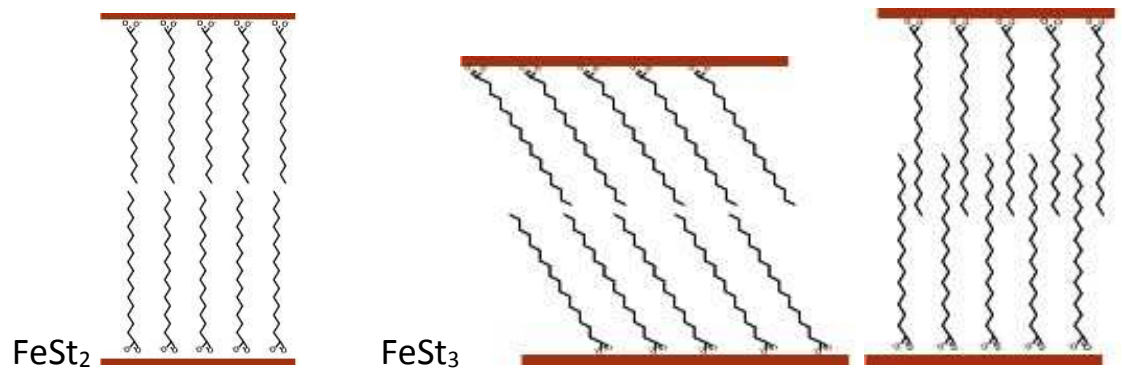

Figure S3. (A) XRD of the precursors at low $\theta-2 \theta$ values. FeSt $_{2}$ (red) and $\mathrm{FeSt}_{3}$ (black) XRD patterns display peaks characteristic of a lamellar structure. (B) SEM of FeSt 2 and FeSt , $_{3}$ (C) TEM image of FeSt 3 and (D) possible chain conformations. 

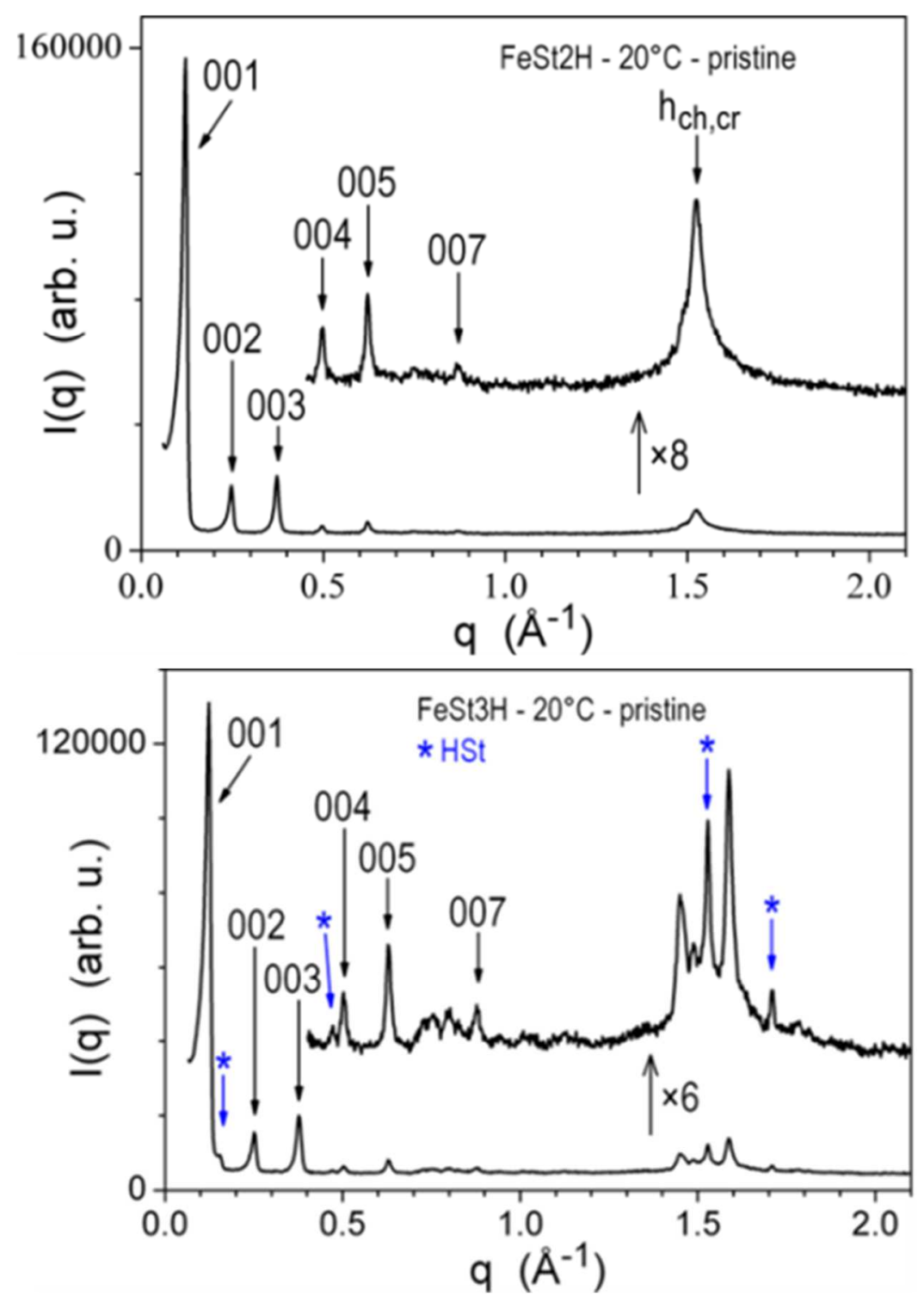

Figure S4. SAXS patterns of FeSt 2 (top) and $\mathrm{FeSt}_{3}$ (down)

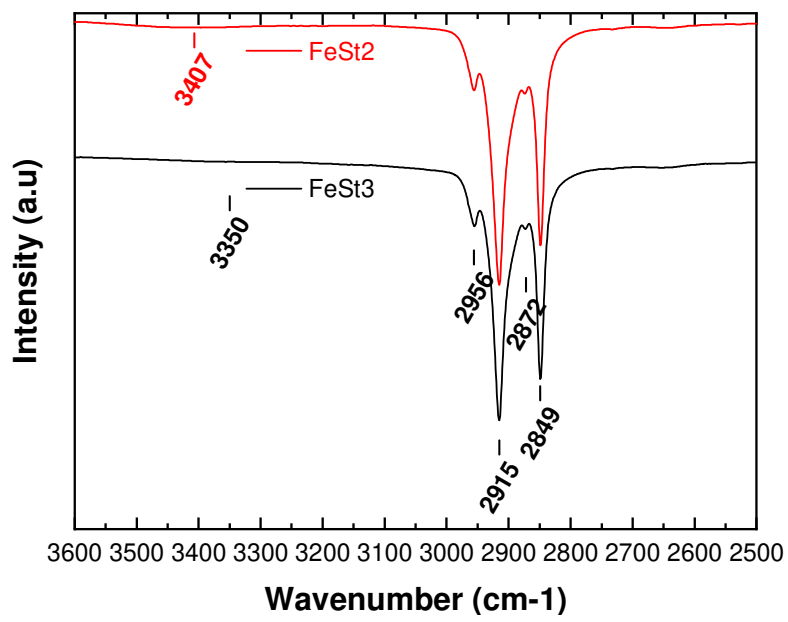

Figure S5. IR spectra of FeSt 2 (red) and FeSt 3 (black) in the $3600-2500 \mathrm{~cm}^{-1}$ area showing the stretching of CH3 (2956 and $\left.2972 \mathrm{~cm}^{-1}\right)$ and $\mathrm{CH} 2\left(2915\right.$ and $\left.2849 \mathrm{~cm}^{-1}\right)$ 

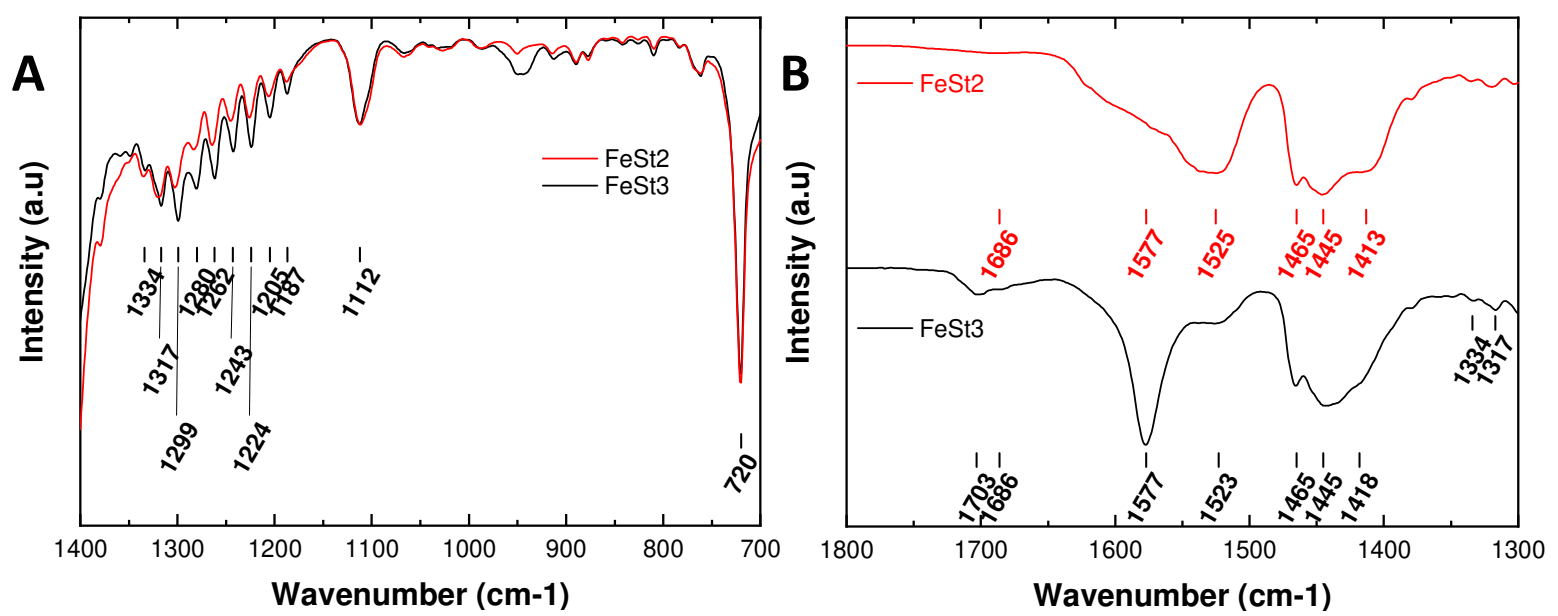

Figure S6. IR spectra of FeSt 2 (red) and FeSt 3 (black). (A) Zoom on the $1400-700 \mathrm{~cm}^{-1}$ area showing the wagging progression of the alkyl chain as well as the rocking band (proving the lamellar structure). (B) Zoom on the carboxylate bands exhibiting the difference of coordination for the two precursors (the band at $1465 \mathrm{~cm}^{-1}$ is attributed to $\delta \mathrm{CH}_{2}$ ).

\section{Attribution of carboxylate bands}

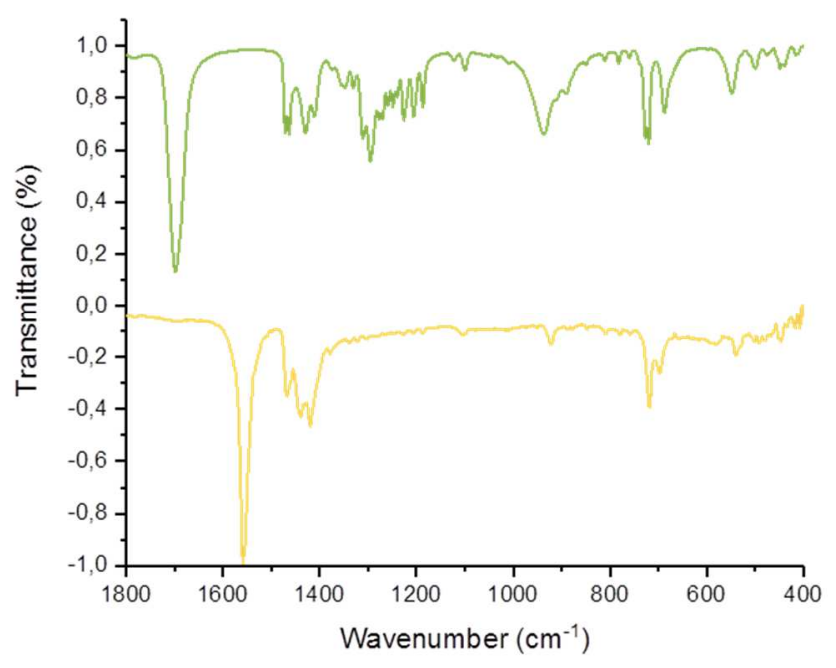

Figure S7. IR spectra of stearic acid (green) and sodium stearate (yellow)

Table S1. IR attribution for the $1800-1300 \mathrm{~cm}^{-1}$ area for stearic acid (HSt), sodium stearate (NaSt), $\mathrm{FeSt}_{2}$ and $\mathrm{FeSt}_{3}$. Red line is for bridging coordination, green line for chelating (vw = very weak, $\mathrm{w}=$ weak, $\mathrm{m}=$ medium, $\mathrm{s}=$ strong)

\begin{tabular}{|l|l|l|l|l|}
\hline HSt & NaSt & FeSt $_{2}$ & FeSt $_{3}$ & Attribution \\
\hline $1700 \mathrm{vs}$ & & $1703 \mathrm{vw}$ & $1703 \mathrm{w}$ & $\mathrm{v}(\mathrm{C}=0)$ \\
\hline & & $1686 \mathrm{w}$ & $1686 \mathrm{w}$ & $\mathrm{v}(\mathrm{C}=0)$ (dimer) \\
\hline & $1558 \mathrm{vs}$ & $1577 \mathrm{~m}$ & $1577 \mathrm{~s}$ & $\mathrm{v}_{\text {as }}\left(\mathrm{COO}^{-}\right)$ \\
\hline
\end{tabular}




\begin{tabular}{|l|l|l|l|l|}
\hline & & $1525 \mathrm{~s}$ & $1523 \mathrm{~m}$ & \\
\hline $1470-1462 \mathrm{~m}$ & 1467 & $1465 \mathrm{~s}$ & $1465 \mathrm{~s}$ & $\delta\left(\mathrm{CH}_{2}\right)$ \\
\hline $1429 \mathrm{~s}$ & $1441 \mathrm{~s}$ & $1445 \mathrm{~s}$ & $1445 \mathrm{~s}$ & \multirow{2}{*}{$\mathrm{v}_{\mathrm{s}}\left(\mathrm{COO}^{-}\right)$} \\
\hline 1410 & $1419 \mathrm{~s}$ & $1413 \mathrm{~s}$ & $1418 \mathrm{~s}$ & \\
\hline
\end{tabular}

Table S2.- $\Delta v$ calculated for HSt, NaSt, $\mathrm{FeSt}_{2}$ and $\mathrm{FeSt}_{3}$.

\begin{tabular}{|c|c|c|c|c|}
\hline & monodentate & bridging & mixed & Chelating \\
\hline NaSt & & & 117,139 & \\
\hline HSt & 271,290 & & & \\
\hline FeSt $_{2}$ & & $164 \mathrm{~m}$ & & $80 \mathrm{~s}$ \\
\hline FeSt $_{3}$ & & $159 \mathrm{~s}$ & & $78 \mathrm{~s}$ \\
\hline
\end{tabular}

IR spectra of all stearates displayed similar carboxyl bands : two $\mathrm{V}_{\text {as }} \mathrm{COO}$ bands and two $\mathrm{v}_{s} \mathrm{COO}$ with different intensities as a function of the nature of stearates (Table S1). The presence of weak band at $1700 \mathrm{~cm}^{-1}$, in particular for FeSt ${ }_{3}$, suggested the presence of very small amount of free stearic acid. Similarly, the weak band at $1620 \mathrm{~cm}^{-1}$ is only more or less clearly observed when the broad band between $3500-3000 \mathrm{~cm}^{-1}$ is visible. Otherwise, the foot of the peak, where carboxyl bands are present, is quite large at this position and may include this small contribution. As in IR spectra of naked oxides, a broad vibration band between 3600 and $3200 \mathrm{~cm}^{-1}$ and the band at $1621 \mathrm{~cm}^{-1}$ are assigned to the $\mathrm{OH}$ stretching vibrations of water molecules (physisorbed molecular water) and to with their bending mode respectively, this band has been attributed to the bending mode of water molecules.

Our main difficulty is the assignment of the carboxylate bands as for all iron stearates, several $\mathrm{v}_{\text {as }} \mathrm{COO}$ and $\mathrm{v}_{\mathrm{s}} \mathrm{COO}$ are observed (Figure S6B and Table S1). At first, we decided to consider the IR spectra of stearic acid (HSt) and sodium stearate (NaSt) and to compare them to those of iron stearates (Figure $\mathrm{S} 7$ and Table S1).

The IR spectra of HSt displayed carboxyl bands $\left(1700,1429,1410 \mathrm{~cm}^{-1}\right)$ similar to those reported by Abrahamson et Lukaski ${ }^{1}$. The intense peak at $1700 \mathrm{~cm}^{-1}$ is assigned to $v_{\mathrm{c}=0}$ and peaks at 1429 and 1410 $\mathrm{cm}^{-1}$ are assigned to group C-O-H stretches. The IR spectra of the commercial sodium stearate (NaSt) is given in Figure $\mathrm{S} 7$. One may notice that this compound displayed a lamellar structure (wagging bands in the range $1350-1200 \mathrm{~cm}^{-1}$ ). The absence of the hydroxyl vibration in the region of $3300-3500 \mathrm{~cm}^{-1}$ and the replacement of the carbonyl $(\mathrm{C}=\mathrm{O})$ stretching band, at ca. $1700 \mathrm{~cm}^{-1}$, by carboxyl asymmetric (vas $\mathrm{COO}$ ) and symmetric ( $\mathrm{VSCOO}$ ) stretching vibrations indicated that $\mathrm{NaSt}$ is anhydrous and free of an excess of carboxylic acid. The presence of the carboxyl bands confirmed a complete resonance in the $\mathrm{COO}$ moieties as a result of coordination with the metal. The position of the carboxylate bands are given in Table S1 and three carboxyl bands are indexed. There is a strong band $\mathrm{v}_{\mathrm{as}} \mathrm{COO}$ band at 1558 $\mathrm{cm}^{-1}$ as expected and already identified in soduim alkanoates with different length of alkyl chains ${ }^{2}$. The presence of two symmetric stretching frequencies meant that the $\mathrm{v}_{\mathrm{s}} \mathrm{COO}$ band was split and indicated extensive head group intermolecular interactions. Both $v_{s} \mathrm{COO}$ bands led to $\Delta v$ values (Table S2) corresponding to a mix of bridging and chelating coordination which may be related to the observed lamellar structure.

Considering iron stearates IR spectra, the carboxyl bands positions are compared to those of $\mathrm{NaSt}$, which is considered often as the ionic carboxylate; a larger splitting of the stretching frequencies is often an indication of monodentate coordination: the $\mathrm{v}_{\mathrm{as}} \mathrm{COO}$ increased when the $\mathrm{v}_{\mathrm{s}} \mathrm{COO}$ decreased 
due to the breakdown in equality of the carbonyl group. The asymmetric and symmetric vibrational frequencies in the monodentate carboxylate are closer to the vibrations of $C=0\left(\sim 1700 \mathrm{~cm}^{-1}\right)$ and $C-O$ $\left(\sim 1400 \mathrm{~cm}^{-1}\right)$ in the carboxylic acid form. In our case, a weak asymmetric band at $1700 \mathrm{~cm}^{-1}$ is observed and could be attributed either to monodentate or free stearic acid.

For the chelating configuration, the carboxylate group has the same group symmetry as in the free ionic state. Therefore, a decrease in $\mathrm{v}_{\mathrm{as}} \mathrm{COO}$ and an increase in $\mathrm{v}_{\mathrm{s}} \mathrm{COO}$ frequencies are generally expected (relative to those of carboxylate in the monodentate coordination state). Thus the bands at 1525 and $1445 \mathrm{~cm}^{-1}$ are attributed to the presence of a chelating coordination in agreement with the calculated $\Delta v$ value. An asymmetrical vibration of $1550 \mathrm{~cm}^{-1}$ and symmetrical vibration at $1456 \mathrm{~cm}^{-1}$ $\left(\Delta v=94 \mathrm{~cm}^{-1}\right)$ has been reported for the bidentate carboxylate, $\mathrm{Zn}\left(\mathrm{O}_{2} \mathrm{CCH}_{3}\right)_{2} \cdot 2 \mathrm{H}_{2} \mathrm{O}^{3,4}$.

The bridging coordination of carboxylate has similarity to the unidentate coordination because in the bridging coordination only one oxygen coordinated with one particular cation. But the group symmetry in the bridging coordination state is similar to that in the chelate coordination. However the chelate coordination of carboxylate caused the OCO angle to decrease in comparison to those of the free ionic form and the bridging coordination. Therefore, relatively higher band positions (in wavenumbers) may be expected for the carboxylate vibration in the bridging coordination mode.

In another paper, it is reported that, to differentiate between monodentate and bridging cooordination, the $\mathrm{v}_{\text {as }} \mathrm{COO}$ is generally smaller in the bridging configuration. Therefore, the $\mathrm{v}_{\mathrm{as}} \mathrm{COO}$ band at $1577 \mathrm{~cm}^{-1}$ is attributed to the $\mathrm{V}_{\mathrm{as}} \mathrm{COO}$ band of the bridging configuration. The strong band at $1445 \mathrm{~cm}^{-1}$ being attributed to the chelating coordination, the band at 1413 or $1418 \mathrm{~cm}^{-1}$ is considered as the symmetric stretching frequency of the bridging configuration. Such $v_{a s}$ and $v_{s}$ values are in agreement with reported values for other carbylated compounds $s^{5}$ and the so calculated $\Delta v(\sim 160)$ is in agreement with the $\Delta v$ range reported for a bridging configuration: 140-170.

One may observe that in our case, $\Delta v_{\text {ionic }}$ values are intermediate between those of the bridging and chelating ones and the $v_{\text {as }}$ evolved similarly, which is completely different from previous reported results. This may be related to the fact that these rules have been established with complexes with short alkyl chains (mainly formate and acetate). Furthermore Deacon et al. ${ }^{6}$ by comparing their ranking with those of Manhas and Trikhas" established that "some complexes with symmetrically bridged carboxylates have both $\mathrm{v}_{\text {as }} \mathrm{COO}$ and $\mathrm{v}_{\mathrm{s}} \mathrm{COO}$ at higher frequencies than the corresponding ionic values". Thus all stearates have a structure with carboxylates in bridging and chelate coordinations. From the carboxyl band intensities, one may advance that $\mathrm{FeSt}_{3}$ displayed mainly a $\mathrm{COO}$ bridging coordination when FeSt ${ }_{2}$ displayed mainly a chelate coordination.

Figure S8 showed that water has a role in the bridging structure. Indeed, the stearates synthesized in $\mathrm{D}_{2} \mathrm{O}$ all have a predominantly chelating structure. That led to conclude that the bridging coordination in $\mathrm{FeSt}_{3}$ involved water molecules. 


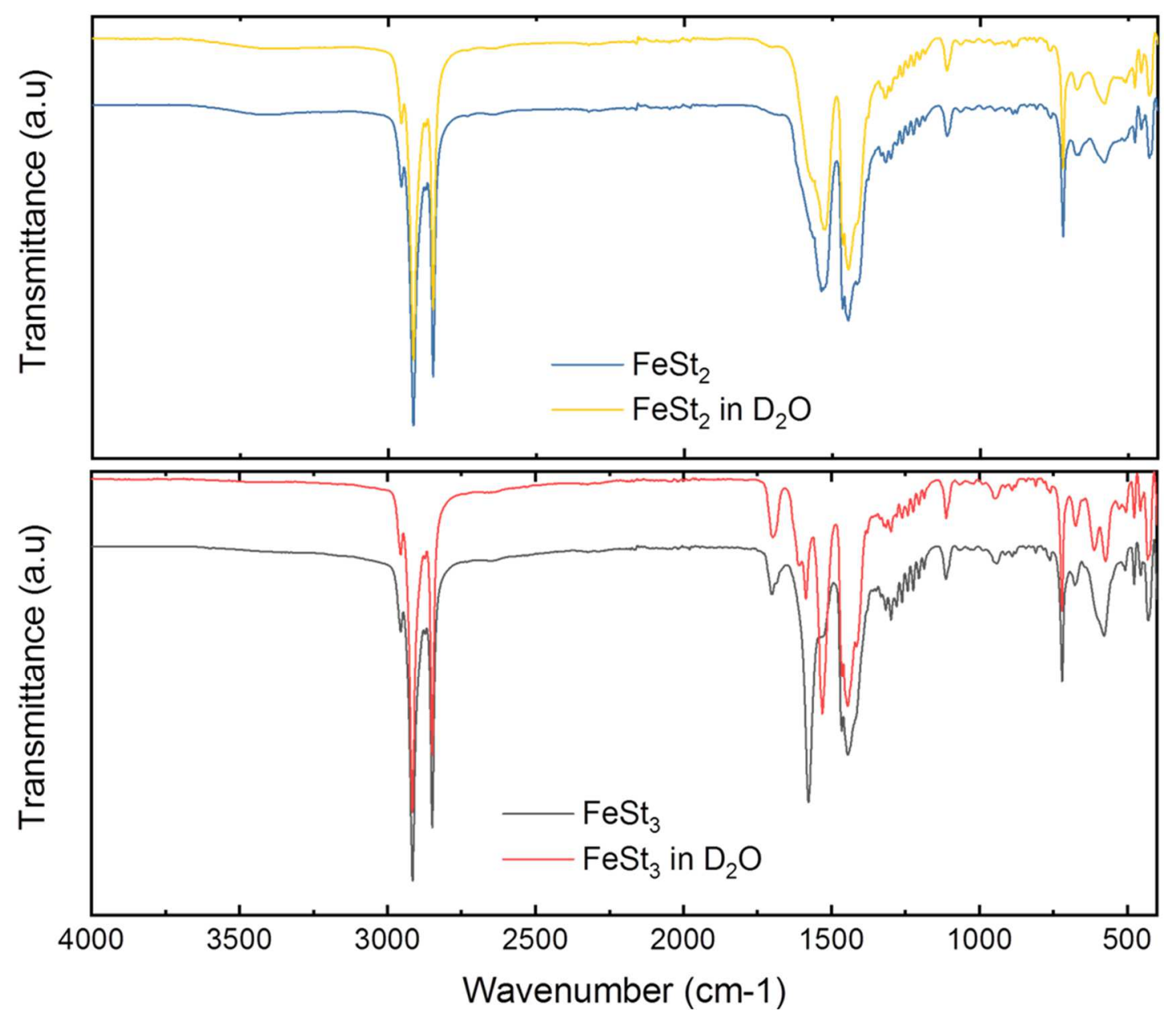

FigureS8. IR spectra of FeSt 2 (top) and $\mathrm{FeSt}_{3}$ (bottom) synthesized in $\mathrm{D}_{2} \mathrm{O}$.

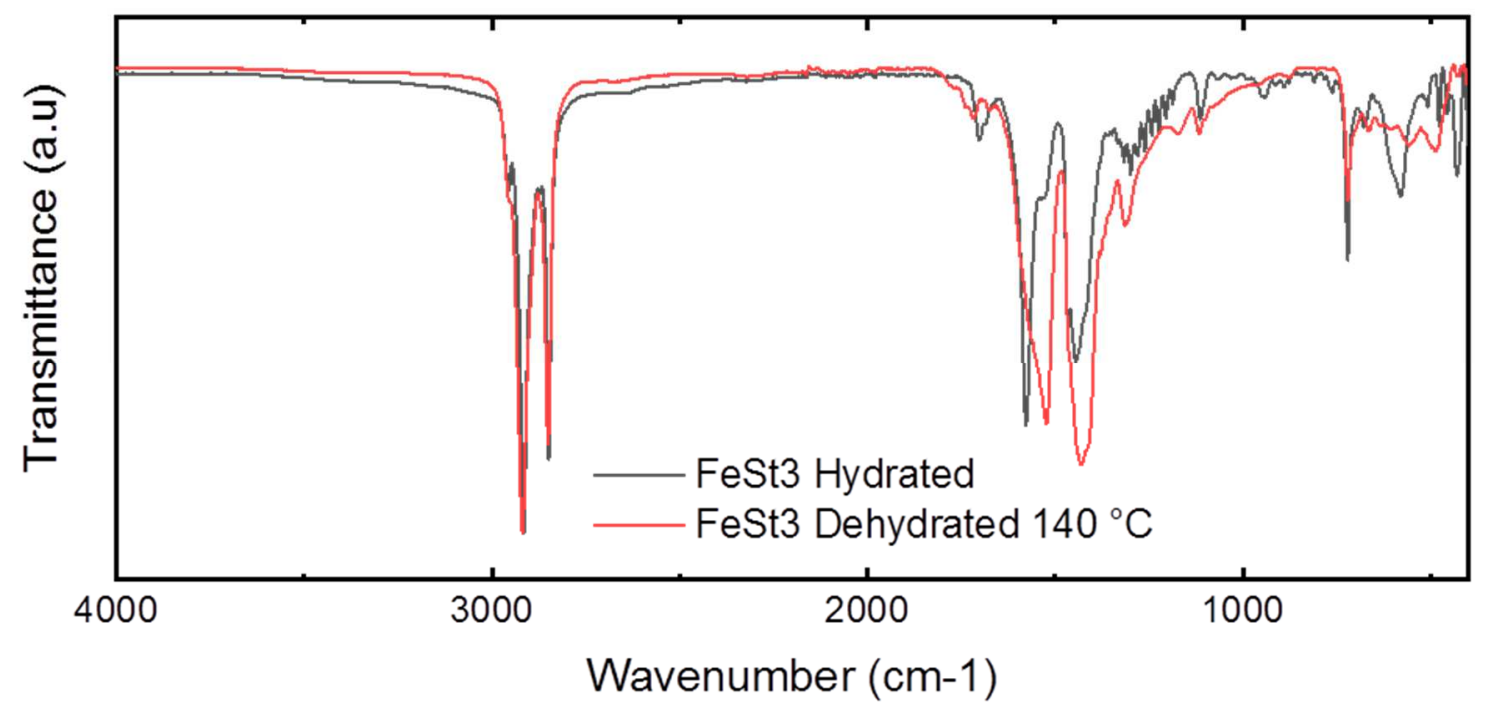

Figure S9. IR spectra of FeSt 3 (black line) before and (red line) after heat treatment at $140^{\circ} \mathrm{C}$ for $48 \mathrm{~h}$.

Possible presence of $\mathrm{Fe}_{3} \mathrm{O}$ or $\mathrm{FeO}$ bonds: Analysis of IR spectra below $700 \mathrm{~cm}^{-1}$

The possible presence of $\mathrm{Fe}-\mathrm{O}-\mathrm{Fe}$ bonds has been investigated by considering bands in the range $700-400 \mathrm{~cm}^{-1}$. One may notice that the bands in this wavenumber range are generally scarcely assigned in literature due to their low intensity. Moreover, the presence of vibration due to the coordination of 
carboxylate to iron leads to the appearance of bands in this area. Indeed, in addition to the presence of $v_{\text {as }}$ and $v_{s}$ as discussed previously, bands at 950 and $580 \mathrm{~cm}^{-1}$, due to out of plan twisting, are also reported in the literature ${ }^{2}$. The carboxylate scissoring ${ }^{1,8} \delta_{\mathrm{coo}}$ is also often described at $670 \mathrm{~cm}^{-1}$, while the rocking $\rho_{\text {coo }}$ is expected around $540 \mathrm{~cm}^{-1}$. For iron oxides, the IR spectra of stoichiometric magnetite displayed one Fe-O-Fe peak at around $570 \mathrm{~cm}^{-1}$ and maghemite with vacancy disordering exhibited IR spectrum with two broad features at around 600 and $450 \mathrm{~cm}^{-1}$, assigned respectively to $\mathrm{Fe}-\mathrm{O}$ deformation in $\mathrm{Oh}$ and $\mathrm{Td}$ sites and Fe-O deformation in $\mathrm{Oh}$ sites. According to Abrahamson et al. ${ }^{1}$ and Nakamoto et al. ${ }^{9}$, iron stearate with iron bridged by $\mu$-oxo trimer would display bands in the $100-400 \mathrm{~cm}^{-1}$ range and around $600 \mathrm{~cm}^{-1}$. They reported the $\mathrm{Fe}_{3} \mathrm{O}$ band position for different type of complexes: $\left[\mathrm{Fe}_{3} \mathrm{O}(\mathrm{St})_{6}\left(\mathrm{H}_{2} \mathrm{O}\right)_{3}\right][\mathrm{St}]$ at $582 \mathrm{~cm}^{-1},\left[\mathrm{Fe}_{3} \mathrm{O}(\mathrm{St})_{6}\left(\mathrm{H}_{2} \mathrm{O}\right)_{3}\right][\mathrm{St}] .8 \mathrm{H}_{2} \mathrm{O}$ at $585 \mathrm{~cm}^{-1}$, commercial FeSt 2 at 661 and $570 \mathrm{~cm}^{-1},\left[\mathrm{Fe}_{3} \mathrm{O}(\mathrm{St})_{6}\left(\mathrm{H}_{2} \mathrm{O}\right)_{3}\right]^{+}$at $635 \mathrm{~cm}^{-1},\left[\mathrm{Fe}_{3} \mathrm{O}(\mathrm{Ac})_{6}\left(\mathrm{H}_{2} \mathrm{O}\right)_{3}\right]^{+}$at $609 \mathrm{~cm}^{-1}$. Oh et al. ${ }^{10}$ also attributed the vibration around $600 \mathrm{~cm}^{-1}$ to the asymmetric stretching of $\mathrm{Fe}_{3} \mathrm{O}$. In his paper reporting the synthesis of $\mathrm{Fe}_{4} \mathrm{O}_{4}$ clusters, Baran ${ }^{11}$ assigned the vibration at $475 \mathrm{~cm}^{-1}$ to the $\mathrm{Fe}-\mathrm{O}$ stretching. Therefore, in many published data, the presence of $\mathrm{Fe}_{3} \mathrm{O}$ would be assigned to a band at around 600 $\mathrm{cm}^{-1}$. The band positions of our complexes are given in Figure S9. We do observe two bands at around 600 and $580 \mathrm{~cm}^{-1}$ for both precursors, which are more intense for FeSt ${ }_{3}$ than for FeSt ${ }_{2}$. Even if it is not clear whether these two bands are due to carboxylate or Fe- $\mu$-oxo bridges, it could be an indication of the presence of more Fe-O features in FeSt . The $_{3} 67 \mathrm{~cm}^{-1}$ peak of FeSt 2 and $675 \mathrm{~cm}^{-1}$ of FeSt $_{3}$ are attributed to scissoring of carboxylate.

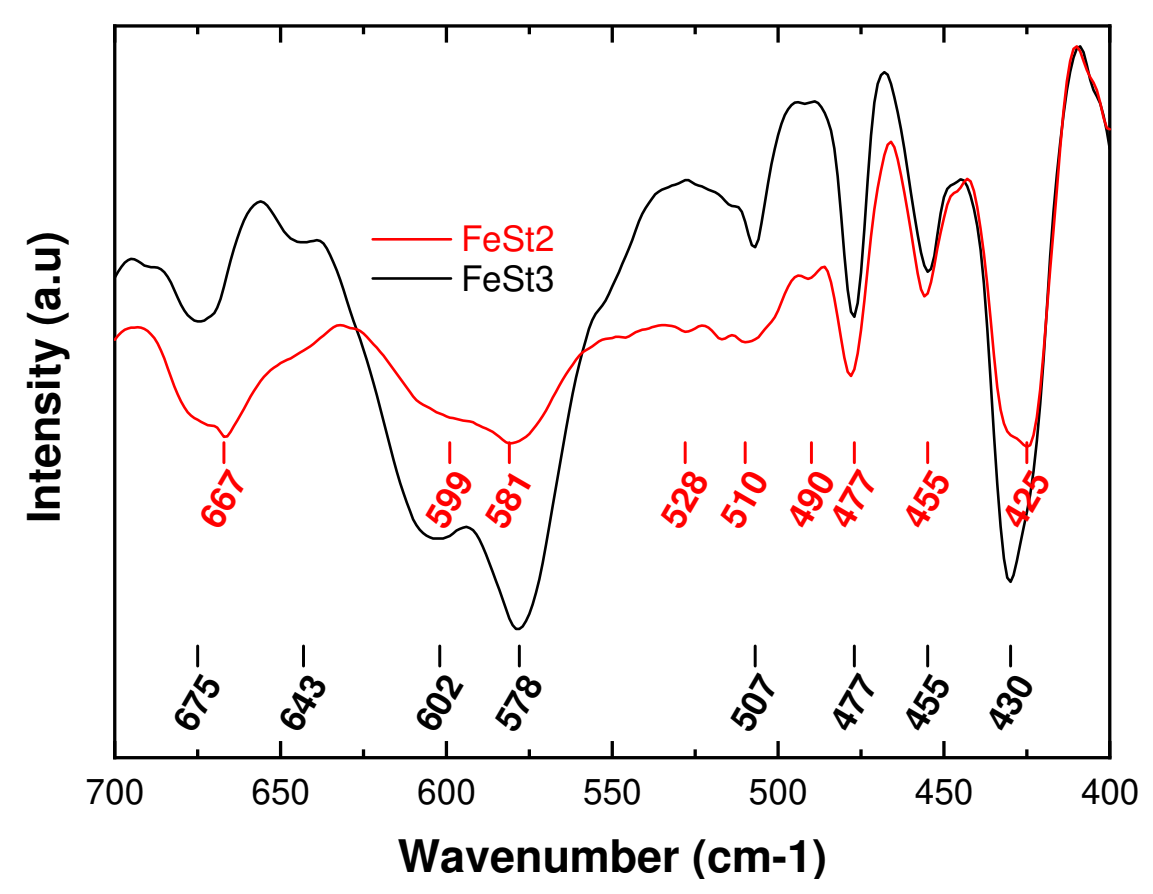

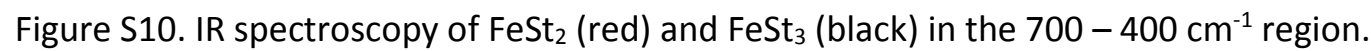

MALDI-TOF Very recently, Chang et $a l^{12}$ used MALDI-TOF to investigate the structure of iron oleate synthesized by the phase transfer process. They obtained a spectrum with several peaks and assigned these peaks by considering the molecular weight of possible ionized entities in iron oleate. They 
assigned their main peak at $\mathrm{m} / \mathrm{z}=1872$ Da to $\left[\mathrm{Fe}_{3} \mathrm{O}\left(\mathrm{C}_{18} \mathrm{H}_{33} \mathrm{COO}\right)_{6}\right]^{+}$. Other main peaks displaying a lower intensity in the spectrum were attributed to $\left[\mathrm{Fe}_{3} \mathrm{O}\left(\mathrm{C}_{18} \mathrm{H}_{33} \mathrm{COO}\right)_{n}\right]^{+}$, with $3 \leq n \leq 6$ and are considered as being "derived" from the main entity $\left[\mathrm{Fe}_{3} \mathrm{O}\left(\mathrm{C}_{18} \mathrm{H}_{33} \mathrm{COO}\right)_{6}\right]^{+}$by removing $\mathrm{C}_{18} \mathrm{H}_{33} \mathrm{COO}$ unit. In Feld et al. ${ }^{13}$ work, iron oleate was synthesized by inducing a reaction between iron II or III carbonate and oleic acid at $60^{\circ} \mathrm{C}$. They have then investigated the influence of the iron source $\left(\mathrm{FeCO}_{3}\right.$ or $\left.\mathrm{Fe}_{2} \mathrm{CO}_{3}\right)$ on the resulting formed species and the evolution with temperature of the different identified species. They detected from MALDI-TOF spectra a total of eight complexes in both iron II and III oleates only differing in intensities. Such complexes were positively charged by loss of an oleate ligand or by iron oxidation. With iron II, the main identified species were $\left[\left(\mathrm{Fe}^{\prime \prime}\right)_{2}(\mathrm{OA})_{3}\right]^{+}(\mathrm{m} / \mathrm{z}=955.6),\left[\left(\mathrm{Fe}^{\prime \prime \prime}\right)_{3}\left(\mathrm{Fe}^{\prime \prime}\right)_{2} \mathrm{O}_{2}(\mathrm{OA})_{8}\right]^{+}(\mathrm{m} / \mathrm{z}=$ 2661.6) and [( $\left.\left.\mathrm{Fe}^{\mathrm{III}}\right)\left(\mathrm{Fe}^{\prime \prime}\right)_{3} \mathrm{O}_{2}(\mathrm{OA})_{6}\right]^{+}(\mathrm{m} / \mathrm{z}=1927.2)$ with $\mathrm{OA}=\mathrm{C}_{17} \mathrm{H}_{33} \mathrm{COO}^{-}(\mathrm{m} / \mathrm{z}=281.4)$, while for iron III, they were $\left[\left(\mathrm{Fe}^{\prime \prime \prime \prime}\right)_{3}\left(\mathrm{Fe}^{\prime \prime}\right)_{2} \mathrm{O}_{2}(\mathrm{OA})_{8}\right]^{+}(\mathrm{m} / \mathrm{z}=2661.6),\left[\left(\mathrm{Fe}^{\prime \prime \prime \prime}\right)_{4}\left(\mathrm{Fe}^{\prime \prime \prime}\right) \mathrm{O}_{2}(\mathrm{OA})_{9}\right]^{+}(\mathrm{m} / \mathrm{z}=2942.6),\left[\left(\mathrm{Fe}^{\prime \prime \prime \prime}\right)_{2}\left(\mathrm{Fe}^{\prime \prime}\right)\right.$ $\left.\mathrm{O}(\mathrm{OA})_{5}\right]^{+}(\mathrm{m} / \mathrm{z}=1590.0)$, and $\left[\left(\mathrm{Fe}^{\mathrm{III}}\right)_{3} \mathrm{O}(\mathrm{OA})_{6}\right]^{+}(\mathrm{m} / \mathrm{z}=1871.2)$. One can see that there is a relation between the last different complexes, since we have two pairs which have a difference of one oleate (the charge being compensated by oxidation/reduction of iron).

\section{TGA curves analysis}

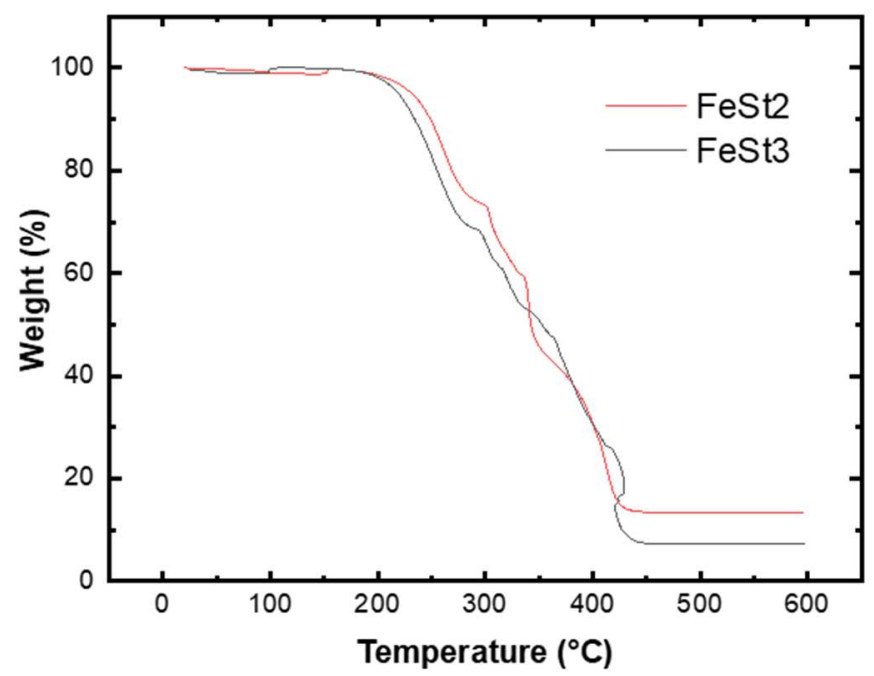

Figure S11. TGA curves of FeSt 2 and FeSt $3 .{ }^{14}$

At first, we considered the total weight losses of iron stearates. For both iron II and iron III stearates, the final product after TGA should be iron III oxide $\mathrm{Fe}_{2} \mathrm{O}_{3}(\mathrm{Mw}=159.69 \mathrm{~g} / \mathrm{mol})$, considering that decomposition products such as hydrocarbons, cetone compounds, water and carbon dioxide are evaporated. From different TGA experiments (Table S3), the final mean weight losses are $86.3 \pm 1.4 \%$ and $92.8 \pm 2.3 \%$ for $\mathrm{FeSt}_{2}$ and $\mathrm{FeSt}_{3}$ respectively.

We compared the experimental weight loss of $\mathrm{FeSt}_{2}$ and $\mathrm{FeSt}_{3}$ with the ones we would obtain with the previous proposed polynuclear structures. Once again, the complex $\left[\mathrm{Fe}_{3} \mathrm{OSt}_{6}\right] \mathrm{Cl}$ gives results in accordance with the experimental weight loss for $\mathrm{FeSt}_{2}$, while for $\mathrm{FeSt}_{3}$, the total weight loss is too high for a complex with a polynuclear composition of $\mathrm{Fe}_{7} \mathrm{O}_{6}$. Even if some $\left[\mathrm{Fe}_{3} \mathrm{OSt}_{6}\right] \mathrm{St}$ complex is present in $\mathrm{FeSt}_{3}$, it cannot explain the observed weight loss. Free stearic acid needs to be considered to find a theoretical weight loss close to the experimental one. That is in agreement with previous hypothesis on the presence of free stearic acid in FeSt 3 . 
In addition, the presence of free stearic acid is confirmed by the presence of an endothermic peak at $68.6^{\circ} \mathrm{C}$ related to free stearic acid in $\mathrm{FeSt}_{3}$ DTA curve in reference ${ }^{15}$. Indeed, two peaks at $68.6^{\circ} \mathrm{C}$ and $98.6^{\circ} \mathrm{C}$ are observed for $\mathrm{FeSt}_{3}$ while a single peak at $96.5^{\circ} \mathrm{C}$ was detected for $\mathrm{FeSt}_{2}$. The first peak for $\mathrm{FeSt}_{3}$ is assigned to the melting of HSt, reported around $67^{\circ} \mathrm{C}$ in other publications ${ }^{16}$. It confirms unambiguously the presence of $\mathrm{HSt}_{\text {in }} \mathrm{FeSt}_{3}$.

Table S3. Comparison between theoretical and experimental total weight losses of FeSt ${ }_{2}$ and $\mathrm{FeSt}_{3}$

\begin{tabular}{|c|c|c|c|c|}
\hline \multicolumn{5}{|c|}{ Experimental Weight Loss } \\
\hline & & & & Average \\
\hline $\mathrm{FeSt}_{2}$ & $86.6 \%$ & $87.6 \%$ & - & $86.3 \pm 1.4 \%$ \\
\hline $\mathrm{FeSt}_{3}$ & $92.7 \%$ & $88.2 \%$ & $92.7 \%$ & $91.7 \pm 2.3 \%$ \\
\hline \multicolumn{5}{|c|}{ Theoretical weight loss } \\
\hline$\left[\mathrm{Fe}_{3} \mathrm{OSt}_{6}\right] \mathrm{Cl}$ & \multicolumn{4}{|c|}{$87.3 \%$} \\
\hline$\left[\mathrm{Fe}_{3} \mathrm{OSt}_{6} .3 \mathrm{H}_{2} \mathrm{O}\right] \mathrm{Cl}$ & \multicolumn{4}{|c|}{$89.2 \%$} \\
\hline$\left[\mathrm{Fe}_{3} \mathrm{OSt}_{6}\right] \mathrm{St}$ & \multicolumn{4}{|c|}{$89.0 \%$} \\
\hline$\left[\mathrm{Fe}_{7} \mathrm{O}_{6} \mathrm{H}_{4} \mathrm{St}_{12}\right] \mathrm{St}$ & \multicolumn{4}{|c|}{$86.6 \%$} \\
\hline$\left[\mathrm{Fe}_{7} \mathrm{O}_{6} \mathrm{H}_{4} \mathrm{St}_{12}\right] \mathrm{St}+7 \mathrm{St}$ & \multicolumn{4}{|c|}{$90.9 \%$} \\
\hline$\left[\mathrm{Fe}_{7} \mathrm{O}_{6} \mathrm{H}_{4} \mathrm{St}_{12}\right] \mathrm{St}+8 \mathrm{St}$ & \multicolumn{4}{|c|}{$91.3 \%$} \\
\hline$\left[\mathrm{Fe}_{7} \mathrm{O}_{7} \mathrm{H}_{4} \mathrm{St}_{10}\right] \mathrm{St}$ & \multicolumn{4}{|c|}{$84.6 \%$} \\
\hline$\left[\mathrm{Fe}_{7} \mathrm{O}_{8} \mathrm{H}_{4} \mathrm{St}_{8}\right] \mathrm{St}$ & \multicolumn{4}{|c|}{$82.0 \%$} \\
\hline
\end{tabular}

\section{Investigation of the hydrolysis pathway of iron chlorides}

The structural differences of FeSt 2 and $\mathrm{FeSt}_{3}$ may originate from different reactions occurring during iron (II) \& (III) chloride hydrolysis when dissolved in water, and then during the complexation reaction with stearates.

\section{Hydrolysis of iron}

The behaviour of metallic cations in water has been clearly described by Jolivet ${ }^{17}$ and can be summarized by the following equations when considering iron. First, during the dissolution step in water, the chloride ligand will be replaced by aquo ligand to give hexa-coordinated cations in an octahedric environment for both iron II \& III

$$
\mathrm{FeCl}_{x} \cdot n \mathrm{H}_{2} \mathrm{O} \stackrel{\mathrm{H}_{2} \mathrm{O}}{\longrightarrow}\left[\mathrm{Fe}\left(\mathrm{H}_{2} \mathrm{O}\right)_{6}\right]^{\mathrm{z+}}+\mathrm{zCl}^{-}
$$

However, because of the charge transfer $\mathrm{H}_{2} \mathrm{O} \rightarrow \mathrm{M}$, the $\mathrm{O}-\mathrm{H}$ bound is weakened, and thus the acidity of the aquo ligand is enhanced. This favours the deprotonation of the aquo ligand (more easily than water alone), and several acido-basic equilibria can be observed depending on the solution $\mathrm{pH}$.

$$
\left[\mathrm{Fe}\left(\mathrm{H}_{2} \mathrm{O}\right)\right]_{6}+\mathrm{H}_{2} \mathrm{O} \rightarrow\left[\mathrm{Fe}(\mathrm{OH})_{h}\left(\mathrm{H}_{2} \mathrm{O}\right){ }_{-6-h}\right]^{(\mathrm{z}-h)+}+h \mathrm{H}^{+}
$$

The deprotonation of the aquo ligand will be influenced by the nature of the metallic cation. Especially, the higher $\mathrm{z}$ is, the more deprotonated the ligand because the $\mathrm{M}-\mathrm{OH}_{2}$ bond will be more polarized. Another important parameter is the size of the cation, since a smaller cation would have a smaller 
coordination, so a more polarized $\mathrm{M}-\mathrm{OH}_{2}$ bond. However, since iron II \& III have the same coordination, this would not be relevant in our situation.

A model is proposed in Jolivet's book to determine $h$, which is related to the hydrolysis rate, by using the equation below, where $\mathrm{z}$ is the formal charge $(+2$ or +3$), \mathrm{N}$ is the coordination number ( 6 in both case) and $\chi_{m}{ }^{*}$ is the Muliken electronegativity ( 1.72 for iron). The results of the calculation are given in Table 3. One should note that the concentration is not the same for $\mathrm{FeCl}_{2}$ and $\mathrm{FeCl}_{3}$. This is because the stearate to iron ratio is not the same for $\mathrm{FeSt}_{2}$ and $\mathrm{FeSt}_{3}$ ( 2 and 3 respectively), but the concentration of sodium stearate is kept constant for the synthesis. Therefore, we work at lower iron concentration with $\mathrm{FeSt}_{3}$.

$$
h=\left[\frac{1}{1+0.014 p H}\right] \times\left[1.36 z-N(0.236-0.038 p H)-\frac{\left(2.261-0.02 p H-\chi_{m}^{*}\right)}{\sqrt{\chi_{m}^{*}}}\right]
$$

Those calculations can give an insight about the species that we have in solutions during the dissolution step of iron chlorides. The results give $\mathrm{Fe}(\mathrm{OH})_{1.6}\left(\mathrm{H}_{2} \mathrm{O}\right)_{4.4}$ and $\mathrm{Fe}(\mathrm{OH})_{2.6}\left(\mathrm{H}_{2} \mathrm{O}\right)_{3.4}$ for $\mathrm{FeSt}_{2}$ and $\mathrm{FeSt}_{3}$ respectively. Yet, this indicates that ferric ions are more sensitive to hydrolysis than ferrous ions. However, one should be careful when interpreting these results. First, it is reasonable to suppose that there are several species in solution. Secondly, the aquo and hydroxo ligands are very labile, and there are perpetual exchanges between ligands. Finally, this calculation is made by using a model with limitation, such as the non-consideration of structural isomers during the calculations.

Nevertheless it shows that the complex with Fe"l' is surrounded by "more" hydroxyl groups than Fe". We can also confirm that the difference in hydrolysis is not due to the difference in concentration. Indeed, we calculated $h$ for $\mathrm{FeCl}_{3}$ at $0.1 \mathrm{M}$ and found also $2.6(\mathrm{pH}=1.77)$.

\section{Condensation by olation or oxolation}

After this hydrolysis step, some condensation can occur by either olation $\mathrm{M}-\mathrm{OH}+\mathrm{M}-\mathrm{H}_{2} \mathrm{O} \rightarrow \mathrm{M}-(\mathrm{OH})-$ $\mathrm{M}+\mathrm{H}_{2} \mathrm{O}$, or oxolation $\mathrm{M}-\mathrm{OH}+\mathrm{M}-\mathrm{OH} \rightarrow \mathrm{M}-\mathrm{O}-\mathrm{M}+\mathrm{H}_{2} \mathrm{O}$. It has been reported that condensation would occur for ferric cations for $\mathrm{pH}>1$, while a $\mathrm{pH}>6$ is proposed for ferrous cations ${ }^{17,18}$. However, the case of ferrous species is particular due to the fast oxidation of iron II when in oxidizing environment like in our synthesis conditions at $80^{\circ} \mathrm{C}$ in water and under air. For ferric ions, many oxo-hydroxide based species have been reported in the literature (goethite $\alpha-\mathrm{FeOOH}$, alkagenide $\beta-\mathrm{FeOOH} .$. ) and are very dependent on the $\mathrm{pH}$. Rose et al. ${ }^{19}$ investigated the early stage formation of iron oxyhydroxide from iron III nitrate at $\mathrm{pH} 3$, and observed by SAXS the formation of iron clusters within the first seconds of mixing, and it was reported that the size of these polycations increases with the increase in $\mathrm{pH}^{20}$. Therefore, as we may advance that species such as $\left[\mathrm{Fe}_{a} \mathrm{O}_{b}(\mathrm{OH})_{c}(\mathrm{H} 2 \mathrm{O})_{d}\right]$ are formed/present in the water solutions of iron chlorides before the addition in the sodium stearate solution and considering that in our experimental conditions, the $\mathrm{pH}$ of the ferrous and ferric solution is 3.1 and 1.9 respectively, we may advance that some condensation may occur especially with Felll solution as the $\mathrm{pH}$ of the ferric solution is higher than 1 . The condensation should be very limited within the ferrous solution which $\mathrm{pH}$ is below $\mathrm{pH}=6$.

Furthermore, during the preparation of iron chloride solutions, we observe that the solutions were slightly turbid, but turned translucent if the $\mathrm{pH}$ was lower than 1 . This is characteristic of the presence 
of hydroxide species in suspension. The ferric solution is prepared 20 minutes before addition, while the ferrous solution was prepared just upon addition, in order to prevent the oxidation of iron. This solution was green, indicating that oxidation of iron II has not occurred. Therefore, we can advance that prior to the reaction with sodium stearate, condensation has already begun within the ferric chloride solutions leading to the presence of polycationic complexes, while no evidence of condensation was found for ferrous ions.

\section{Complexation of sodium stearate}

Iron chloride solution is introduced in a RBF containing two or three equivalents of sodium stearate (previously dissolved at $80^{\circ} \mathrm{C}$ ) for iron II and III respectively. The solution is kept under stirring at this temperature for $15 \mathrm{~min}$ (black line on the Figure S11). This duration of 15 minutes was chosen because the reaction was adapted from previous established protocol ${ }^{21}$. The $\mathrm{pH}$ of the starting stearate based solution is 9.5, which drops following the injection of the iron chloride suspension into the stearate based solution, as shown in Figure S11. One may notice that the $\mathrm{pH}$ evolution is different depending on the nature of starting iron chlorides II or III.

Upon this mixing step, several reactions should occur simultaneously. Firstly, stearate ligands will complex iron cations, probably by substitution of aquo ligand. They can also coordinate to iron cations which are already involved in polycations formed during the hydrolysis step. Secondly, since the temperature and $\mathrm{pH}$ are higher than those of the pre-formed iron chloride solutions, condensation should also be favoured. The competition between those two main reactions may drive the final structure of FeSt ${ }_{2}$ and $\mathrm{FeSt}_{3}$. Oxidation of ferrous species is also expected because of the oxidizing environment. This will eventually favor condensation, as we have shown that condensation of ferric ions was easier. Nevertheless, the $\mathrm{pH}$ stabilization of the mixture, below 6 for the FeSt 2 mixture and 3 for the $\mathrm{FeSt}_{3}$ one, occurs quickly within $30 \mathrm{~s}$ and it has already been reported that the presence of complexing agent such as carboxylates could stop the condensation of iron by stabilizing polycations ${ }^{18,22}$.

For $\mathrm{FeSt}_{2}$, according to $\mathrm{pH}$, we do not expect important condensation reaction in the iron chloride solution as it stays always below 6 . Therefore, we probably have species such as $\left[\mathrm{Fe}(\mathrm{OH})\left(\mathrm{H}_{2} \mathrm{O}\right)_{5}\right]^{+}$, $\left[\mathrm{Fe}(\mathrm{OH})_{2}\left(\mathrm{H}_{2} \mathrm{O}\right)_{4}\right]$ or $\left[\mathrm{Fe}_{2}(\mathrm{OH})_{2}\left(\mathrm{H}_{2} \mathrm{O}\right)_{8}\right]^{2+}$ before mixing with the stearate solution. Once in contact with stearate, the complexation should start quickly on those species, to form the species predicted by Doyle: $\left[\mathrm{Fe}(\mathrm{OH})_{2} \mathrm{St}_{2}\right],\left[\mathrm{Fe}_{2}(\mathrm{OH})_{2} \mathrm{St}_{4}\right]$ (Figure 4). Yet, oxidation will occur, favouring hydroxylation and condensation. We followed the evolution of $\mathrm{pH}$ with time in the reaction mixture as shown in Figure S12. Because we introduced the chloride solution into the stearate solution, the initial pH of 9.5 is the $\mathrm{pH}$ of the stearate solution. For FeSt ${ }_{2}$, following the mixing step, the $\mathrm{pH}$ drops to 5.8 and stays constant for 60s, before dropping again at 5.35. It was reported that condensation of ferrous species happens at pH 5-6 which stays constant during the condensation ${ }^{23}$. This would suggest that condensation occurs during this mixing step with $\mathrm{FeSt}_{2}$.

Regarding $\mathrm{FeSt}_{3}$, we have already some polycations in the chloride solution. Therefore, stearate chain should substitute water on these polycations, which stabilize them and prevent their growth. We can also expect to form, as with FeSt ${ }_{2}$, monomeric like $\left[\mathrm{Fe}(\mathrm{OH})_{2} \mathrm{St}_{2}\right]$ or dimeric $\left[\mathrm{Fe}_{2}(\mathrm{OH})_{2} \mathrm{St}_{4}\right]$ structures, 
which would eventually form $\left[\mathrm{Fe}_{3} \mathrm{OSt}_{6}\right]^{+}$by condensation (Figure 4). $\mathrm{pH}$ monitoring with $\mathrm{FeSt}_{3}$ shows a quick drop to $\mathrm{pH} 2.9$, which is high enough to promote condensation of monomeric species. In addition, it has been reported that heating at $80-100^{\circ} \mathrm{C}$ of an acidic solution of iron III leads to the formation of $\mu_{3}$-oxo or $\mu_{3}$-hydroxo units. Finally, we should keep in mind that in the case of $\mathrm{FeSt}_{3}$, we have three stearate chains for one iron. However, in all the reported structures, the ratio St/Fe is often close to 2 . Therefore, it would make sense to consider the presence of more free stearates with $\mathrm{FeSt}_{3}$ than with $\mathrm{FeSt}_{2}$.

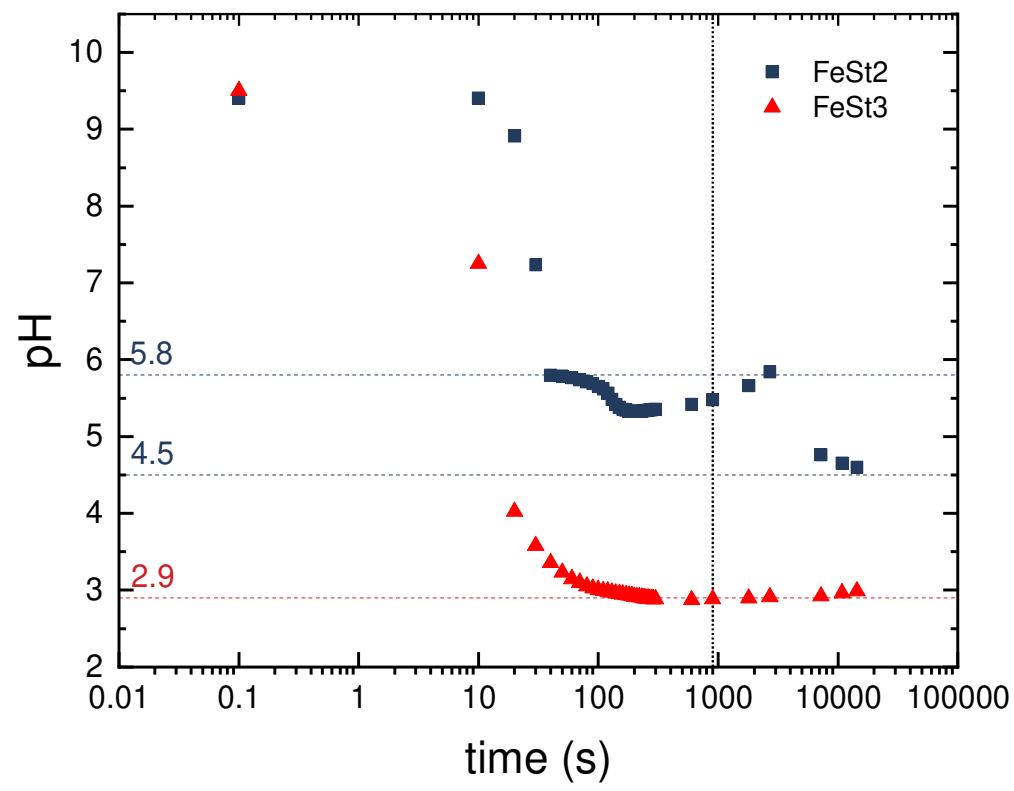

Figure S12. Evolution of $\mathrm{pH}$ with time in the neck after introduction of iron (II) (blue square) or iron (III) chlorides (red triangle). The black line shows the time where the reaction is stopped.

To summarize, this analysis suggests that polycations would be formed during the preparation of iron chloride solutions with iron III chlorides, but not likely with iron II chlorides. Therefore, after mixing with the stearate solution, stearate would form complexes such as monomeric or dimeric species with ferric and ferrous iron, but also bigger polycationic structures with ferric ions.

\section{Influence of the synthesis conditions on $\mathrm{FeSt}_{3}$ structure}

We made the hypothesis earlier that polycations would be present in the iron III chloride solution even before the reaction with sodium stearate, but not in the ferrous chloride solution. Therefore, the complexation of sodium stearate on these polycations would lead to the formation of polynuclear species for $\mathrm{FeSt}_{3}$. The identification of $\left[\mathrm{Fe}_{7}\left(\mu_{3}-\mathrm{O}(\mathrm{H})\right)_{6}\left(\mu_{2}-\mathrm{O}(\mathrm{H})\right)_{x} \mathrm{St}_{12-\mathrm{x}}\right] \mathrm{St}$ complex with $\mathrm{FeSt}_{3}$ and not with $\mathrm{FeSt}_{2}$ supports this conclusion. In order to check further this hypothesis, we synthesized iron III stearate by using a ferric chloride solution at $\mathrm{pH} 1$ by addition of $\mathrm{HCl}$. At this $\mathrm{pH}$, only $\left[\mathrm{Fe}\left(\mathrm{H}_{2} \mathrm{O}\right)_{6}\right]^{3+}$ is expected to be the main hydrolysis species and the solution is below the $\mathrm{pH}$ reported to favor condensation. We effectively observed that the solution becomes limpid after the addition of $\mathrm{HCl}$. We performed then the mixing with the sodium stearate solution as usual, and we did not identify any $\mathrm{Fe}_{7}$ based species in MALDI-TOF, only species below $3000 \mathrm{Da}^{2} \mathrm{Fe}_{3} \mathrm{O}$ based species (Figure S12). However, no differences were seen in IR spectra (Figure S13). This supplementary experiment confirms our hypothesis that the 
condensation in iron chloride solutions leads to the presence of polynuclear complexes in the assynthesized iron stearates. One may further notice that no condensation would favor the formation of $\mathrm{Fe}_{3} \mathrm{O}$ based complexes.
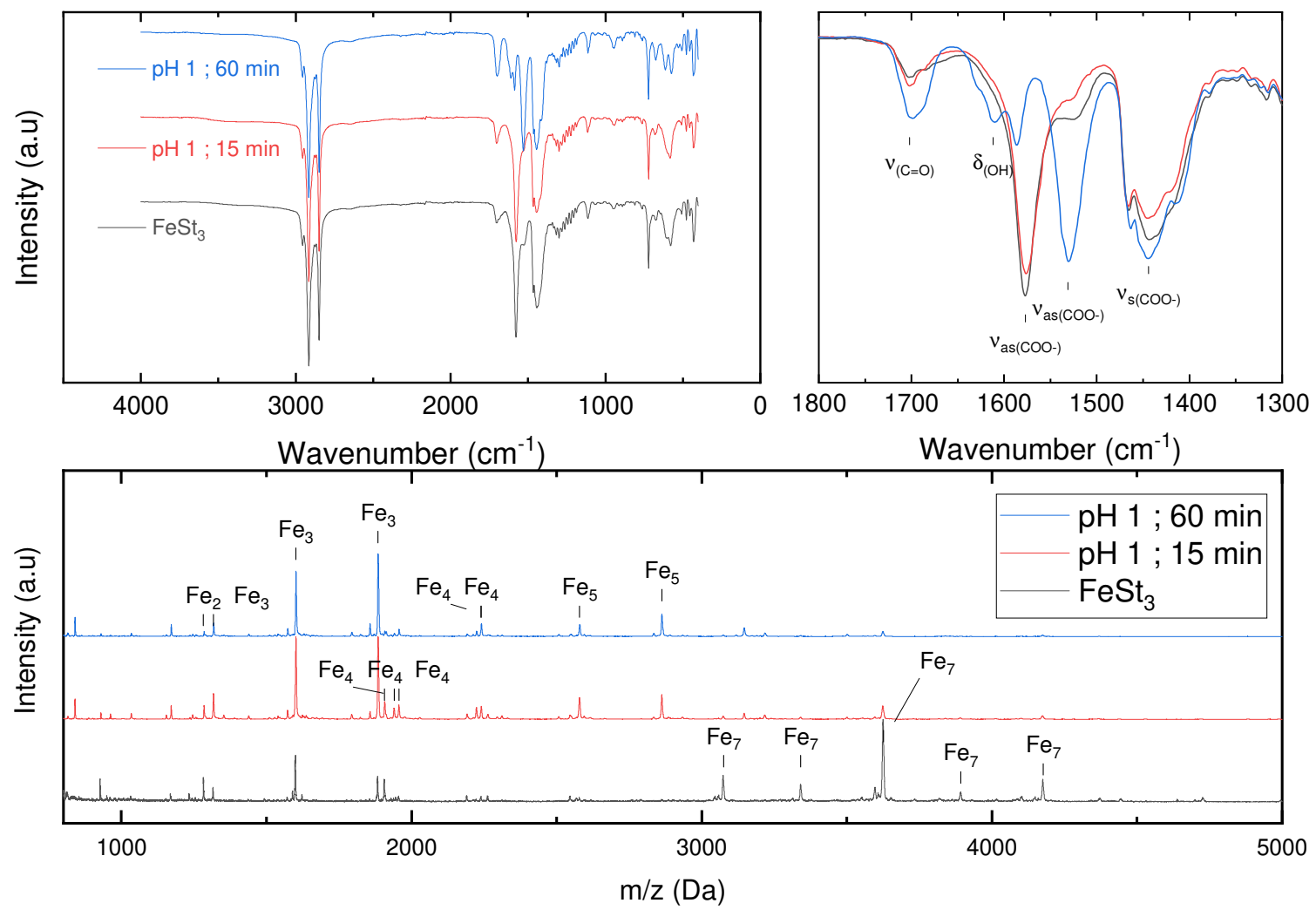

Figure S13. (Top) IR and (bottom) MALDI-TOF spectra of stearates synthesized with an iron chloride solution at pH 1 after mixing with stearate solution for (blue) $60 \mathrm{~min}$ (red) $15 \mathrm{~min}$ and of "classic" FeSt 3 for comparison (pH of $\mathrm{FeCl}_{3}$ solution $=1.88$, mixing time of $15 \mathrm{~min}$ ). The inset in the top right hand corner shows the change of coordination after $1 \mathrm{~h}$.

Secondly, we investigated the effect of the reaction time (after mixing of iron chloride and sodium stearate solutions) on the formation of polynuclear complexes when the iron III chloride solution was at $\mathrm{pH} 1$. We tested a reaction time of $60 \mathrm{~min}$ when it was of $15 \mathrm{~min}$ usually. We noticed no difference between the MALDI-TOF spectra, confirming again that, at our synthesis $\mathrm{pH}$ above 1 , the polycations $\mathrm{Fe}_{7}$ were formed in the chloride solution, and not during the complexation of sodium stearate. However, we did observe a change in the IR spectra of complexes when the reaction time was $1 \mathrm{~h}$ instead of 15 minutes. Indeed, the carboxylate coordination became bidentate chelate instead of bridging after 15 minutes. Moreover, this reaction time effect on the carboxylate coordination was also observed in the standard conditions (without setting the iron chloride solution $\mathrm{pH}$ at 1 ). These results suggest that the "stable" carboxylate coordination would be the chelating bidentate one but also that the carboxylate coordination does not depend on the type of polynuclear iron complexes. The formation of the bridging coordination with $\mathrm{FeSt}_{3}$ may be explained by the following observations: i) water molecules are involved in the bridging coordination (above experiments with $D_{2} O$ ) ii) we are working at $\mathrm{pH} 2.9$, below the $\mathrm{pKa}$ of sodium stearate $(\mathrm{pKa}=4.8)$ during $\mathrm{FeSt}_{3}$ synthesis, while the $\mathrm{pH}$ is at 5.8 for $\mathrm{FeSt}_{2}$ (Figure S12). There would be a competition between the coordination of stearate on iron and the acidification of stearate to form stearic acid, which could form hydrogen bonds with water 
coordinated to iron. That may explain the presence of water in the bridging coordination seen with $\mathrm{FeSt}_{3}$, even if it is not the more stable coordination.

Therefore, we can conclude that without preformed polycations during the iron chloride solution formation, the main species are $\mathrm{Fe}_{3}\left(\mu_{3}-\mathrm{O}(\mathrm{H})\right)$ based species with a bidentate chelate coordination, while the presence of preformed polycations leads to the formation of $\mathrm{Fe}_{7}$ based clusters. The presence also of $\mathrm{Fe}_{3} \mathrm{O}$ based complex in $\mathrm{FeSt}_{3}$ may be explained by an uncompleted condensation.

\section{References}

(1) Abrahamson, H. B.; Lukaski, H. C. Synthesis and Characterization of Iron Stearate Compounds. Journal of Inorganic Biochemistry 1994, 54 (2), 115-130. https://doi.org/10.1016/01620134(94)80025-1.

(2) Nelson, P. N.; Ellis, H. A. Odd-Even Chain Packing, Molecular and Thermal Models for Some Long Chain Sodium(I) n-Alkanoates. Journal of Molecular Structure 2014, 1075, 299-310. https://doi.org/10.1016/j.molstruc.2014.05.069.

(3) Mehrotra, R. C.; Bohra, R. Metal Carboxylates; Academic Press: London; New York, 1983.

(4) Lu, Y.; Miller, J. D. Carboxyl Stretching Vibrations of Spontaneously Adsorbed and LBTransferred Calcium Carboxylates as Determined by FTIR Internal Reflection Spectroscopy. Journal of Colloid and Interface Science 2002, 256 (1), 41-52. https://doi.org/10.1006/jcis.2001.8112.

(5) Palacios, E. G.; Juárez-López, G.; Monhemius, A. J. Infrared Spectroscopy of Metal Carboxylates: II. Analysis of Fe(III), Ni and Zn Carboxylate Solutions. Hydrometallurgy 2004, 72 (1), 139-148. https://doi.org/10.1016/S0304-386X(03)00137-3.

(6) Deacon, G. B.; Huber, F.; Phillips, R. J. Diagnosis of the Nature of Carboxylate Coordination from the Direction of Shifts of Carbon?oxygen Stretching Frequencies. Inorganica Chimica Acta 1985, 104 (1), 41-45. https://doi.org/10.1016/S0020-1693(00)83783-4.

(7) Manhas, B. S.; Trikha, A. K. J. Indian Chem. Soc. 1982, No. 59, 315.

(8) Edwards, H. G. M.; Lewis, I. R. Vibrational Spectroscopic Studies of Iron(II) Acetate. Journal of Molecular Structure 1993, 296 (1), 15-20. https://doi.org/10.1016/0022-2860(93)80113-A.

(9) Nakamoto, T.; Katada, M.; Sano, H. Synthesis and Mössbauer Spectroscopic Studies of OxoCentered Mixed-Valence Trinuclear Iron Carboxylates with Long Chain Fatty Acid Anions. Chem. Lett. 1990, 19 (2), 225-228. https://doi.org/10.1246/cl.1990.225.

(10) Hendrickson, D. N. Valence-Detrapping Modes for Electron Transfer in the Solid State of MixedValence, Oxo-Centered, Trinuclear Iron Acetate Complexes: X-Ray Structure and Physical Data for [Fe30(02CCH3)6(4-Et-Py)3](4-Et-Py). 10.

(11) Baran, P.; Boča, R.; Chakraborty, I.; Giapintzakis, J.; Herchel, R.; Huang, Q.; McGrady, J. E.; Raptis, R. G.; Sanakis, Y.; Simopoulos, A. Synthesis, Characterization, and Study of Octanuclear Iron-Oxo Clusters Containing a Redox-Active $\mathrm{Fe}_{4} \mathrm{O}_{4}$-Cubane Core. Inorg. Chem. 2008, 47 (2), 645-655. https://doi.org/10.1021/ic7020337.

(12) Chang, H.; Kim, B. H.; Jeong, H. Y.; Moon, J. H.; Park, M.; Shin, K.; Chae, S. I.; Lee, J.; Kang, T.; Choi, B. K.; Yang, J.; Bootharaju, M. S.; Song, H.; An, S. H.; Park, K. M.; Oh, J. Y.; Lee, H.; Kim, M. S.; Park, J.; Hyeon, T. Molecular-Level Understanding of Continuous Growth from Iron-Oxo Clusters to Iron Oxide Nanoparticles. J. Am. Chem. Soc. 2019, 141 (17), 7037-7045. https://doi.org/10.1021/jacs.9b01670.

(13) Feld, A.; Weimer, A.; Kornowski, A.; Winckelmans, N.; Merkl, J.-P.; Kloust, H.; Zierold, R.; Schmidtke, C.; Schotten, T.; Riedner, M.; Bals, S.; Weller, H. Chemistry of Shape-Controlled Iron Oxide Nanocrystal Formation. ACS Nano 2019, 13 (1), 152-162. https://doi.org/10.1021/acsnano.8b05032.

(14) Cotin, G.; Kiefer, C.; Perton, F.; Boero, M.; Özdamar, B.; Bouzid, A.; Ori, G.; Massobrio, C.; Begin, D.; Pichon, B.; Mertz, D.; Begin-Colin, S. Evaluating the Critical Roles of Precursor Nature and 
Water Content When Tailoring Magnetic Nanoparticles for Specific Applications. ACS Appl. Nano Mater. 2018, 1 (8), 4306-4316. https://doi.org/10.1021/acsanm.8b01123.

(15) Cotin, G.; Perton, F.; Petit, C.; Sall, S.; Kiefer, C.; Begin, V.; Pichon, B.; Lefevre, C.; Mertz, D.; Greneche, J.-M.; Begin-Colin, S. Harnessing Composition of Iron Oxide Nanoparticle: Impact of Solvent-Mediated Ligand-Ligand Interaction and Competition between Oxidation and Growth Kinetics. Chem. Mater. 2020, 32 (21), 9245-9259. https://doi.org/10.1021/acs.chemmater.0c03041.

(16) Jaw, K.-S.; Hsu, C.-K.; Lee, J.-S. The Thermal Decomposition Behaviors of Stearic Acid, Paraffin Wax and Polyvinyl Butyral. Thermochimica Acta 2001, 367-368, 165-168. https://doi.org/10.1016/S0040-6031(00)00680-8.

(17) Jolivet, J.-P.; Henry, M.; Livage, J. De la Solution à l'oxyde: condensation des cations en solution aqueuse, chimie de surface des oxydes; InterEditions : CNRS Editions: Paris, 1994.

(18) Jolivet, J.-P.; Chanéac, C.; Tronc, E. Iron Oxide Chemistry. From Molecular Clusters to Extended Solid Networks. Chem. Commun. 2004, No. 5, 477-483. https://doi.org/10.1039/B304532N.

(19) Rose, A. L.; Bligh, M. W.; Collins, R. N.; Waite, T. D. Resolving Early Stages of Homogeneous Iron(III) Oxyhydroxide Formation from Iron(III) Nitrate Solutions at PH 3 Using Time-Resolved SAXS. Langmuir 2014, 30 (12), 3548-3556. https://doi.org/10.1021/la404712r.

(20) Bottero, J. Yves.; Tchoubar, D.; Arnaud, M.; Quienne, P. Partial Hydrolysis of Ferric Nitrate Salt. Structural Investigation by Dynamic Light Scattering and Small-Angle x-Ray Scattering. Langmuir 1991, 7 (7), 1365-1369. https://doi.org/10.1021/la00055a013.

(21) Cotin, G. Nouvelles stratégies vers la synthèse de nanoparticules magnétiques multifonctionnelles innovantes combinant imagerie par IRM et/ou thérapie par hyperthermie magnétique. 344.

(22) Jolivet, J.-P.; Tronc, E.; Chanéac, C. Iron Oxides: From Molecular Clusters to Solid. A Nice Example of Chemical Versatility. Comptes Rendus Geoscience 2006, 338 (6), 488-497. https://doi.org/10.1016/j.crte.2006.04.014.

(23) Santoyo Salazar, J.; Perez, L.; de Abril, O.; Truong Phuoc, L.; Ihiawakrim, D.; Vazquez, M.; Greneche, J.-M.; Begin-Colin, S.; Pourroy, G. Magnetic Iron Oxide Nanoparticles in 10-40 Nm Range: Composition in Terms of Magnetite/Maghemite Ratio and Effect on the Magnetic Properties. Chem. Mater. 2011, 23 (6), 1379-1386. https://doi.org/10.1021/cm103188a. 